University of Rhode Island

DigitalCommons@URI

Open Access Master's Theses

1984

\title{
The Relationship of Sample Size to the Stability of Component Patterns: A Simulation Study
}

Edward Guadagnoli

University of Rhode Island

Follow this and additional works at: https://digitalcommons.uri.edu/theses

\section{Recommended Citation}

Guadagnoli, Edward, "The Relationship of Sample Size to the Stability of Component Patterns: A Simulation Study" (1984). Open Access Master's Theses. Paper 1575.

https://digitalcommons.uri.edu/theses/1575

This Thesis is brought to you for free and open access by DigitalCommons@URI. It has been accepted for inclusion in Open Access Master's Theses by an authorized administrator of DigitalCommons@URI. For more information, please contact digitalcommons-group@uri.edu. 
THE RELATIONSHIP OF SAMPLE SIZE TO THE STABILIT OF COAPONENT PATTERNS: A SIUULATION STUDI

BI

EDTARD GOADAGMOLI

A THESIS SUBHTTED IN PABTIAL FOLFILLUEHT OF THE REQUIREHENTS FOR THE DEGREE OF

MASTER OF ARTS

IN

PSTCHOLOGY

DNIVERSITY OF RHODE ISLAND

1984 
A variety of rules have been suggested for determining the number of observations required to produce a stable solution when performing a factcr or component analysis. The most popular rules suggest that sample size be determined as a function of the number of variables. These rules, however, lack empirical or theoretical rationale. In order to more precisely examine the conditions under which a sample component pattern becomes stable relative to its population pattern, the effect of number of variables (p), number of components (m), and component saturation $\left(a_{i j}\right)$ were examined in addition to the effect of sample size (N). Computer simulated sample component patterns were compared to population component patterns by means of a single summary statistic. g. and by direct comparison of the patterns in terms of salient and non-salient component loading identification. Results indicate that the number of variables is not an important factor in determining an acceptable level of comparability between patterns. component saturation and to a lesser degree, sample size and the number of variables per component, surfaced as important factors. A good match to the population pattern was attained across all conditions when the sample component pattern was well defined $\left(a_{i j}=\right.$ -80). Sample component patterns possessing moderate component saturation (.60) provided a good fit to the population pattern across conditions when sample size was 
greater than or equal to 150 observations. Weakly defined sample component patterns ( $a_{i j}=.40$, 1ou $p / m$ Iatio) provided a good match when sample size was in the range of 300 to 400 observations. 
I wish to thank wayne $F$. Velicer for introducing me to Pactor Analysis methodology and for allowing me to become involved in the continuing research program he has established in order to assess and further refine various issues associated with this technique.

To my committee members I wish to express gratitude for their support and arailability.

Finally, but perhaps most importantly, I wish to thank ay wife and daughter for allowing me the time necessary to see this project through to completion. 
ABSTR ACT

ACK NONL EDGEHENT

iv

IIST OF TABIES

$\mathbf{\nabla} \mathbf{i}$

IIST OF FIGURES

$\nabla i i$

INTRODUCTION

SETHOD

Factors Hanipulated

13

Data Generation

pattern comparison

BESULTS

9 statistic comparisons

23

Decision Table Comparisions

DISCUSSION

REFERENCES

43

APPENDIX A

APPENDIX B

APPENDIX C

APPENDIX D

82

A PPENDIX E 
1 Rules to Determine Sample size

2 Decision Table comparing Sample Decisions on Salience with the population state of Affairs

3 Conditions Under which tore Than 5 Sample Correlation tatrices Were Generated

4 Average 9. TYpe I Error. TYpe II Error, and kappa for 69 Patterns with .40 Loadings

5 Average 9. Type I Error, TY pe II Error, and kappa for 69 Patterns with .60 Loadings

6 Average 9 , TYpe I Error. TYpe II Error, and kappa for 69 patterns with -80 loadings 


\section{Iist of Figures}

FIGURE

B- 1 Average $g$ as a Function of Sample Size for .40 Component Saturation and 3 components

B-2 Average $g$ as a Function of Sample Size for .40 Component Saturation and 6 components

B-3 Average $g$ as a Function of Sample size for . 40 Component Saturation and 9 Components

B-4 Average $g$ as a Function of Sample Size for .40 Component Saturation and 18 Components

B-5 Average $g$ as a Function of Sample size for .60 Component Saturation and 3 components

B-6 Average $g$ as a Function of Sample size for -60 Component Saturation and 6 Components

B-7 Average $g$ as a Function of Sample size for .60 Component saturation and 9 components

B-8 Average $g$ as a Function of Sample Size for .60 Component Saturation and 18 Components

B-9 Average $g$ as a Function of Sample size for .80 Component Saturation and 3 Components

B-10 Average $g$ as a Function of Sample Size for .80 Component Saturation and 6 Components

B-11 Average $g$ as a Function of Sample size for . 80 Component Saturation and 9 Components

B-12 Average $g$ as a Function of Sample Size for .80 Component Saturation and 18 Components

C-1 Average kappa as a Function of Sample Size for . 40 Component Saturation and 3 components 
C-2 Average kappa as a Function of Sample Size for . 40 Component Saturation and 6 components

C-3 Average kappa as a Function of Sample Size for .40 Component Saturation and 9 components

C-4 Average kappa as a Function of Sample Size for .40 Component Saturation and 18 components 71

C-5 Average kappa as a Function of Sample Size for . 60 Component Saturation and 3 Components

C-6 Average kappa as a Function of Sample Size for .60 Component Saturation and 6 Components 74

C-7 Average kappa as a Function of Sample Size for .60 Component Saturation and 9 Components

C-8 Average kappa as a Function of Sample Size for .60 Component Saturation and 18 Components 76

C-9 Average kappa as a Function of Sample size for .80 Component Saturation and 3 Components

C-10 Average kappa as a Function of Sample Size for .80 Component Saturation and 6 components 79

C-11 Average kappa as a Function of Sample Size for .80 Component Saturation and 9 components

C-12 Average kappa as a Function of Sample Size for .81 Component Saturation and 18 components

D-1 Average Type I Error as a Function of Sample Size for -40 Component Saturation and 3 components

D-2 Average Type I Error as a Function of Sample Size for .40 component Saturation and 6 components 
D-3 Average Type I Error as a Function of Sample Size for .40 component Saturation and 9 Components

D-4 Average Type I Error as a Function of Sample Size for .40 Component Saturation and 18 Components

D-5 Average Type I Error as a Function of Sample Size for .60 Component Saturation and 3 Components

D-6 Average Type I Error as a Function of Sample Size for .60 component Saturation and 6 components

D-7 Average Type I Error as a Function of Sample Size for .60 Component Saturation and 9 components

D-8 Average $T y p e$ I Error as a Function of Sample Size for .60 Component Saturation and 18 Components

D-9 A verage Type I Error as a Function of Sample Size for .80 Component Saturation and 3 components

D-10 Average Type I Error as a Function of Sample size for .80 component Saturation and 6 components

D-11 A verage Type I Error as a Function of Sample Size for .80 Component Saturation and 9 components

D-12 Average Type I Error as a Function of Sample Size for . 80 Component Saturation and 18 components

E-1 Average Type II Error as a Function of Sample Size for .40 Component Saturation and 3 components 
E-2 Average Type II Error as a Function of Sample Size for .40 Component Saturation and 6 components

E-3 Average Type II Error as a Function of Sample Size for .40 Component Saturation and 9 components

E-4 Average Type II Error as a Function of Sample Size for .40 Component Saturation and 18 Components

E-5 Average Type II Error as a Function of Sample Size for . 60 Component Saturation and 3 components

E-6 Average Type II Error as a Punction of Sample Size for . 60 Component Saturation and 6 components

E-7 Average Type II Error as a Function of Sample Size for .60 Component Saturation and 9 components

E-8 Average Type II Error as a Function of Sample Size for .60 Component Saturation and 18 Components

E-9 Average Type II Error as a Function of Sample Size for .80 Component Saturation and 3 components

E-10 Average Type II Error as a Function of Sample Size for .80 Component Saturation and 6 components

E-11 A verage Type II Error as a Function of Sample Size for .80 Component Saturation and 9 components

E-12 Average Type II Error as a Punction of Sample Size for .80 Component Saturation and 18 Components 
Introduction

Factor analysis or component analysis is typically employed by the researcher who wishes to reduce a set of observed variables, p, to a new, smaller set of variables, m. This smaller set of variables, labeled factors or components, depending upon the specific method employed, both preserves most of the information present in the original set of variables and has the advantage of being more parsimonious. The purpose of an analysis may be the replacement of $\mathrm{p}$ scores with m factor or component scores or the interpretation of the ( $\mathrm{p} \times \mathrm{m}$ ) pattern of "loadings", i.e.. correlations between the p observed variables and the $m$ factors or components. The latter purpose is intended to facilitate the interpretation of the relationships existing between the observed variables. A major issue with respect to these procedures involves determining the number of independent observations (N) required in order to obtain a sample pattern that is stable and approximates its population pattern. Researchers and textbook authors typically recommend that the necessary sample size be determined in relation to the number of variables involved in the research problem. 
Additionally, a minimum sample size of 100 to 200 observations is of ten recommended. These recommendations are typically provided with little rationale, either theoretical or empirical. The rules relating $\mathrm{N}$ as a function of $p$. seem to be based on "shrinkage" concepts in multiple regression. The recommendation for a minimum sample size of 100 to 200 observations seems to be based on the argument that a correlation coefficient becomes an "adequate" estimator of the population correlation coefficient when sample sizes reach this level. The effect of sample size has been examined empirically within the design of past studies (Brown, 1968; Cliff, 1970; Manners $\&$ Brush, 1979; Pennell, 1968; Velicer, Peacock, $E$ Jackson, 1982: Zwick \& Velicer, 1982) which focused on various other factor analytic issues. The issue of sample size was not addressed directly, however, resulting in information of limited generalizability and utility.

On a theoretical basis, a number of researchers have suggested various types of rules to determine sample size. These rules, however, are not empirically based but seem to be based on the experience of the author, an unstated set of beliefs, or a communication from some uncited expert source. The generation of a particular rule, then, appears to have evolved essentially through an informal process rather than as a consequence of any direct experimental evidence or rigorous theoretical development. A necessary lower limit for all rules is that the sample 
size should be greater than the number of variables. The case in which the number of observations is less than the number of variables results in a matrix which is not of full rank. Aleamoni (1976) discusses instances when an analysis is possible if the number of observations is less than the number of variables. He has found, however, the solution obtained was not as accurate.

Rules suggesting $N$ as a function of $p$ are the most popular. A great variety of these rules have been advocated. Gorsuch (1974) suggests an "absolute minimum ratio" of five observations to every variable. Nunnally (1978) and Kunce, Cook, and Miller (1975) recommend a ten to one ratio. Lindeman, Merenda, and Gold (1980) argue that a ratio of 20 observations to every variable is required. Baggaley (1982) derived a formula to calculate the necessary $N$ which depends upon the number of variables and the mean absolute value of the correlations present in the correlation matrix. The mean absolute value of the correlations is obtained from the following expression:

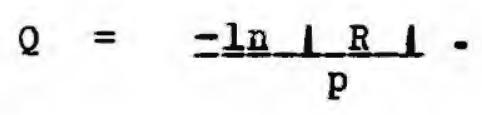

Where:

I $R$ I is the determinant of the correlation matrix and $p$ is the number of variables.

The sample size suggested with respect to a specific 
number of variables is obtained from:

$$
N=\left[\frac{\left[1.645+\left(p^{2}-p-1\right)\right]^{2}}{2 p^{2} Q}+\frac{1}{3}+\frac{11}{6 p}\right] p
$$

From an examination of a range of $p$ and $Q$ values, Baggaley (1982) suggests the following: "For variables expected to intercorrelate about .30 , use at least twice as many subjects as variables. With an expected intercorrelation level of . 20 use at least three times as many subjects as variables and with intercorrelations averaging about . 15 the ratio should be at least four to one." (p. 83). Employment of a technique discussed by Tinkelman (1971) is suggested by Baggaley (1982) in order to obtain an idea as to what degree variables will intercorrelate. Brislin, Sonner, and Thorndike (1973). interested in cross-cultural research, emphasize the need for a large sample size especially since "liberal amounts of unavoidable measurement error" (p. 279) usually occur in cross-cultural data collection. The square of the number of variables plus $50\left(N=p^{2}+50\right)$ is suggested as a guide to decide upon the necessary sample size. The implausibility of this rule with respect to data sets common today is obvious (ex. if $p=200, N=40,050$ ). As a "bare minimum". Brislin, et al. (1973) suggest ten observations to every variable.

A different type of rule recommends that the number 
of observations be determined as a function of the number of expected factors. Cattell (1978) bases his recommendation on the following expression, $N=2^{k}$, where $k$ equals the number of expected factors. This rule. however, can provide problems if the number of expected factors is moderate or large in number. For example, if 15 factors are expected from a given data set, this rule recommends 215 or 32,768 observations. Realizing that the number of observations may quickly become exorbitant. Cattell (1978) suggested a lower limit of three to six observations per variable.

another set of rules recommends a minimum (or specific) sample size. The most familiar advice one receives with respect to these rules is to obtain a sample which is as large as possible (Press, 1972: Guertin \& Bailey, 1970: Humphreys, Ilgen, MC Grath, E Montanelli. 1969). Rummel (1970), while not willing to suggest an absolute rule, states that the number of observations relative to the number of variables should be as large as practical. Gorsuch (1974) and Lindeman, et al. (1980) warn that an analysis should not be performed with fewer than 100 observations. Comrey (1973) rates the adequacy of various sample sizes on the following scale: "50 very poor: 100 poor: 200 fair; 300 good; 500 very good; and 1000 excellent." (p. 200) - Comrey (1973) concludes that a sample of 500 is preferred with the minimum being 200 observations (Comrey, 1978). Loo (1983) agrees with 
the minimum sample size suggested by comrey (1978) and argues that the number of variables should not be a concern in establishing a necessary sample size value. Loo (1983) further states that the primary concern should involve obtaining stable correlation coefficients, the result of which is not a function of the number of variables. Guertin and Bailey (1970), in an effort to observe the relationship sample size had on factor structure reliabilty, generated samples of $N=25$ and $N=100$ from a total sample of 200 subjects who possessed scores on the 11 WaIs subtests. Comparing the varimax rotated patterns obtained for the smaller samples to the varimax rotated solution provided by the total sample led Guertin and Bailey (1970) to conclude that basing "product moment I's on an $n$ of 100 is a questionable procedure and is suitable for only a very tentative pilot study-" (p. 217). These results led to the recommendation to employ as many subjects as possible. Guilford (1954), also concerned with the consistency of factor loadings, reports that samples of 200 subjects provide loadings which agree fairly well with factor loadings obtained from samples of over 1000 subjects. For this reason, Guilford (1954) suggests a minimum sample size of 200 subjects. Additionally: Guertin and Bailey (1970) suggest that if factor structure reliability is an issue of prime importance, the researcher should split the available $N$ into validation and cross validation groups and then 
compare the resulting factor structures. Table 1 provides a summary of the various rules offered by researchers in order to obtain the sample size necessary to generate a stable factor or component solution.

only a limited number of studies have empirically tested the relation between sample size and the stability of the sample solution. Sampling from a population of 2,322 freshmen attending a large midwestern University, Aleamoni (1973) generated samples consisting of 17, 25. 100. 400, and 1600 individuals. Fifteen measures, the majority of which were aptitude and achievement scores. were obtained for each individual comprising the population. Employing a principal component analysis, Aleamoni (1973) found that factor variance accounted for increased as sample size decreased, indicating that smaller samples may be accounting for more error variance. component similarity was also found to decrease with a reduction in sample size. Quartimax, varimax, and unrotated patterns were compared to the population pattern. Aleamoni (1973) concluded "if we want to use sample factor structures as a basis for generalizing to their corresponding population factor structures, drawing random samples of $N=400$ is adequate for generalizing to a population of $N=2.322 . "$ (p. 269). Future studies employing samples between $N=100$ and $N=400$ vere suggested "in order to specify the exact minimum sample 
Table 1

Rules to Determine Sample size

$\begin{array}{lll}\text { Source Type Bule } & \end{array}$

Part I. $N=f(p)$

Baggaley (1982)

See Equation (2)

Brislin, Sonner, Thorndike (1973) $N=p^{2}+50 ; N=10 p$

Cattell (1978)

$\mathrm{N}=3 \mathrm{p}$ to $\mathrm{N}=6 \mathrm{p}$

Gorsuch (1974)

$N=5 p$ (minimus)

Kunce, Cook, Hiller (1975)

$\mathrm{N}=10 \mathrm{p}$

Lindeman, Merenda, Gold (1980)

$N=20 \mathrm{p}$

Nungally (1978)

$N=10 p$

Part II. $N=f(m)$

Cattell (1978)

$N=2^{m}$

Part III. $N$ = minimum, maximum, or specific value Comrey (1973; 1978)

$N=500$ (preferred): $\mathrm{N}=200$ minimum

Gorsuch (1974)

$N=100$ minimum

Guertin Baliey (1970)

Haximum $\mathrm{N}$ possible; cross validation

Guilford (1954)

$N=200$ (minimum)

Humphreys, Ilgen, BcGrath, Hontanelii (1969)

Maximum $\mathbf{y}$ possible

Lindeman, Merenda, Gold (1980)

$N=100$ (minimum)

Press (1972)

laximum possible

Bummell (1970)

Maximum possible 
size required to reflect the population factor structure" (Aleamoni, 1973, p. 269).

velicer, et al. (1982) compared the solutions obtained from three types of Factor Analysis procedures, principal component analysis, image analysis, and maximum likelihood factor analysis, in order to determine under what conditions the methods produce different patterns. A comparison of sample factor and component patterns to their respective population factor and component patterns suggested that "with only moderate sample sizes $(N=144)$. the fit of the pattern to the population target was quite good." (p. 386). Both Aleamoni (1973) and velicer et al. (1982), however, employed only one level of p.

This review illustrates the diversity of the rules existing and the varied recommendations they provide. The rationale for these rules is limited and often unstated. Previous empirical investigations are also very limited in scope, typically limited to one data set or one value of p. Choosing a sample size on the basis of the rules previously discussed may quickly exceed one's ability to provide the recommended sample size. That is, in pre-computer days a data set of 10 to 20 variables was typical, primarily because numbers beyond this range were quite unwieldy to analyze by hand. Employing a rule which suggested, for example, ten subjects to every variable resulted in a reasonable recommendation for the number of subjects (100 to 200). Today, however, data sets 
containing 100 to 200 variables are not uncommon in Factor Analytic studies. The same rule under these conditions would suggest 1000 to 2000 subjects to produce a stable solution. Sample sizes in this range most often exceed the resources available to the researcher. The limited empirical results presented (Aleamoni, 1983; Velicer, et al. 1980) suggest a more workable value and provide a framework for future research.

The purpose of the present study was to determine empirically the conditions necessary to produce a stable sample solution with respect to a population pattern. A principal component procedure (Hotelling. 1933) was employed to produce population and sample component patterns. While component analysis is less developed theoretically, Velicer (1974, 1976, 1977) and Velicer, et al. (1982) have demonstrated, through empirical and Monte Carlo approaches, that principal component solutions differ little from the solutions generated from factor analysis methods. Although factor analysis procedures are commonly the recommended procedures in this area of research, serious theoretical problems do exist (Steiger and Schonemann. 1978). Further, Glass and Taylor (1966) following a survey of educational research journals. report that component analysis is the most frequently performed analysis. Pruzek and Rabinowitz (1981). over a decade later, report that this trend not only has continued but has increased. In addition, component 
analysis does not suffer from some of the convergence problems and computational limitations that factor analysis does (Jackson and Chan, 1980; Velicer and Jackson, 1984), permitting the assessment of a vider range of situations.

In order to evaluate the conditions under which stable component patterns are produced, several variables vere manipulated. The number of variables, number of components, and sample size were implicated as potentially inportant factors with respect to the rules discussed above. In addition to these variables, component saturation, the magnitude of component loadings, was also varied. Correlation matrices vere computer generated so that direct control over the variables manipulated was possible. Principal component patterns were obtained from both population and sample correlation matrices. 
Method

In order to detect more precisely deviations in sample component patterns relative to population components patterns, several factors were varied. These factors included sample size, number of variables, number of components, and component saturation. An attempt was made to sample conditions wich are often encountered by applied researchers. The situations generated, however, did not fully reflect those conditions. Population component patterns possessed variables which loaded on only one component. Each component was defined by the same number of variables and all nonzero loadings were equal. While these conditions may be percieved as representing relatively "clean" or idealized conditions, their examination represents an important first step in the evaluation of this problem. The direct manipulation of these variables can only be accomplished through the use of simulated data. Correlation matrices, therefore. were computer generated. The computer generation of these matrices allowed manipulation and comparison of known conditions. While this adrantage does exist, these 
conditions do not fully reflect actual research conditions. Tucker, Koopman, and Linn (1969) discuss problems associated with this type of procedure.

Following a principal component analysis, the resulting sample component patterns were compared to their respective population component patterns. Comparison methods involved a least squares difference approach and a direct pattern comparison approach. A summary statistic, g. was calculated which measured the average squared difference between comparable loadings of the sample and population component patterns. Sample and population component patterns were also compared directly by examining agreement between the two patterns with respect to salient and non-salient component loading identification.

\section{Factors Manipulated}

The similarity of sample component patterns to population patterns was examined across seven levels of sample size (N), four levels of the number of variables (p). three levels of component saturation $\left(a_{i j}\right)$ and three levels of the number of components (m).

Sample size levels of $\mathrm{N}=50,100,150,200$. 300, 500, 1000 were chosen not only to represent a range of small to large samples but also to examine precisely the sample size range suggested by previous research. 
The number of variables present varied from $p=36$ to $\mathrm{p}=$ 144. Intermediate levels included $\mathrm{p}=72$ and $p=108$. Again, levels of this variable were chosen to reflect those situations often encountered by investigators in the field.

The levels m $=3,6,9$ were implemented for the number of components factor. Values of m much larger than 9 are not desired by applied researchers since interpretation may become a problem at this point. In the interest of practicality, however, the cells in which $m=3$ and $p=108$ and $p=144$ vere not examined since the number of variables per component (48 and 36 respectively) represent situations wich are unusual. For cases in wich $p=108$ and $p=144$ the value $m=18$ was employed.

Three levels of component saturation were utilized. With respect to principal component analysis, component loadings of .30 or .40 are usually regarded as salient to that particular component while loadings below the cutoff are ignored. Loadings employed in this design represented the range from close to the lower limit, $a_{i j}=-40$, to $a$ moderate level $a_{i j}=.60$, to a very vell defined value, $a_{i j}=-80$, above which loadings are not usually found.

\section{Data Generation}

The conditions described represent 252 possible cells in this design $\left(\begin{array}{l}7 \times 4 \\ 4\end{array}\right.$ 
207 combinations were examined given the $N \geq$ p condition necessary to perform a principal component analysis. Appendix a provides a description of the overall design.

A population matrix was constructed for each possible condition. Population correlation matrices vere generated following a procedure employed by $\mathrm{Zwick}$ and Velicer (1982) and Velicer, et al. (1982). A ( $\mathrm{p} \times \mathrm{m})$ population pattern matrix (A) was generated with respect to every possible p. m. and $a_{i j}$ combination defined in the design. Post multiplying $A$ by its transpose (A') generated a ( $P$ P ) matrix, $R^{*}\left(A^{\prime}=R^{*}\right)$. The population correlation matrix was obtained by replacing the elements in the diagonal of the $R^{*}$ matrix with unities. A computer program developed by Montanelli (1975) was used to generate five sample correlation matrices from each population correlation matrix for every level of sample size employed in the study. A principal component analysis was employed to produce population and sample component patterns from the respective correlation matrices.

\section{Pattern Comparison}

In order to compare sample component patterns to population patterns, a summary statistic. g, was employed. This statistic is based on the usual least squares criterion. First, a difference matrix (E) is calculated from the sample component pattern $\left(A^{*}\right)$ and the population 
pattern (A), where:

$$
\mathbf{E}=\mathbf{A} * \mathbf{A} \text {. }
$$

The summary statistic, $g$, is then defined as:

(4) $\mathrm{g}=\operatorname{trace}(\mathrm{E} \cdot \mathrm{E}) / \mathrm{pm}$

which can be interpreted as the average (squared) difference between comparable loadings of the sample and population patterns (Velicer, 1977; Velicer et al., 1982). Comparisons were made following varimax rotation (Kaiser, 1958) of the population and sample component patterns. In order to facilitate comparison between patterns, a permutation matrix (Velicer, 1974, 1976, 1977) was generated. This permutation matrix allowed a one to one component match to be made with the population pattern by permuting the columns of the sample component pattern. In order to simplify interpretation, the value, $g=-01$, was selected as the maximum value for describing the fit between sample and population component patterns as good. Values below this cutoff imply that on the average, the difference between comparable loadings of the population and sample component pattern $\left(g^{\frac{1}{2}}\right)$ occur only in the second decimal place. The average $g$ was calculated over the five samples generated for each condition.

Since $g$ is a single scalar value, all configural 
information regarding pattern comparability is lost. That is, comparability relative to the structure (pattern of component loadings) of the patterns is lost. For this reason a comparison of population and sample component. patterns was also obtained using a method employed previously by Velicer et al. (1982). This method involves first determining those variables which are considered salient to a component. A variable is usually determined to be salient if the component loading is greater than .40. "The justification of this arbitrary cutoff, usually .30 or .40 , is based on the interpretation of the loading as a correlation coefficient and the common judgement that correlations below, 30 are not 'psychologically significant' even if the sample size is such that they are statistically significant" (Velicer et al.. 1982, p. 375). Salient loadings present in the sample pattern vere compared to salient loadings in the population pattern. Decision tables were generated which described the results of the comparison with respect to hits and misses (see Table 2). Two types of error (misses) are possible: Type I error. where a variable is judged salient when it is not salient and Type II error, where a variable is not judged to be salient when it actually is salient. Decision tables vere constructed following comparisions of the varimax rotated sample pattern to the rotated population solution. 
Table 2

Decision Table comparing Sample Decisions on Salience with the population state of Affairs

$$
\text { Population state of Affairs }
$$

YES

Sample Y ES

Decision No
No Error: $\mathbf{A}$

Type II ErIor
No

Type I Error

No Error: B 
A great variety of agreement statistics (Fleiss, 1981) exist which may be calculated from the type of decision table described in Table 2. The kappa statistic, a measure of agreement, was employed in the present study. In addition to providing a correction for chance expected agreement, kappa is the appropriate agreement measure to employ under conditions which involve comparison to a standard or "correct set" of responses (Light, 1971). The population component pattern state of affairs (salient/not salient component loading) represents the standard to which the sample component pattern is compared. Complete agreement between the two patterns is defined by a kappa value of 1.00 . Kappa $\geq 0.00$ signifies agreement greater than or equal to chance level, values belov 0.00 represent agreement below chance level. Landis and Koch (1977) provide guidelines for interpreting kappa. Kappa values greater than .75 represent excellent agreement beyond the chance level, values between .40 and .75 are indicators of fair to good agreement beyond the chance level and values below .40 represent poor agreement.

Three summary statistics, kappa, Type I error, and Type II error were calculated from the pooled decision tables resulting from the five samples generated for each combination of the variables manipulated. Average Type I error was scaled by the number of non salient loadings which should have occurred in a particular pattern. Divison by the number of non salient loadings, $p(m-1)$, was 
employed in order to alloy comparison across levels of $p$ employed in the study. The resulting value multiplied by 100 represents the average percentage of possible Type I error classifications. Similarly, average TYpe II error was scaled by the number of actual salient loadings (p) vich should have been present in the pattern and is presented as the average percentage of possible Type II error classifications. 
Results

Five sample correlation matrices, generated for each level of sample size, vere derived from each of the 36 population correlation matrices (defined by a combination of $a_{i j}, m$, and $p$ levels). It was observed that, in several instances, a subset (or all) of the resulting sample component patterns did not possess a structure well enough defined so that a one to one component match with the population component structure could be attained. That is, a permutation matrix employed to match the sample pattern vith the population pattern could not be generated. In cases in wich five clear matches were not accomplished, the number of matrices generated was increased until five matches were attained. The conditions under which more matrices vere generated and the number of samples generated are presented in Table 3. Note that one condition $\left(P=108, a_{i j}=.40, \quad I I=18\right.$, $N=150$ ) was dropped from the study because of the inability to achieve five successful alignments within a reasonable number of generations. 
Table 3

Conditions under which hore Than 5 Sample

Correlation Matrices Uere Generated

\begin{tabular}{|c|c|c|c|c|c|c|}
\hline$p$ & $a_{i j}$ & III & N & Number of & Samples & Required \\
\hline 36 & .40 & 6 & 50 & & 12 & \\
\hline 36 & .40 & 6 & 100 & . & 7 & . \\
\hline 36 & .40 & 6 & 150 & & 6 & \\
\hline 36 & .40 & 9 & 50 & & 26 & \\
\hline 36 & .40 & 9 & 100 & & 18 & \\
\hline 36 & .40 & 9 & 150 & & 8 & \\
\hline 36 & .40 & 9 & 300 & & 6 & \\
\hline 72 & .40 & 9 & 100 & & 12 & \\
\hline 72 & .40 & 9 & 150 & & 7 & \\
\hline 108 & .40 & 9 & 150 & & 6 & \\
\hline 108 & .40 & 18 & 150 & & $* *$ & \\
\hline 108 & .40 & 18 & 200 & & 11 & \\
\hline 108 & .40 & 18 & 300 & & 8 & \\
\hline 108 & .40 & 18 & 500 & & 6 & \\
\hline 144 & .40 & 18 & 150 & & 19 & \\
\hline 144 & .40 & 18 & 200 & & 16 & \\
\hline
\end{tabular}

* 1 match attained in sample of 30 . condition eliminated from study 
Tables 4 through 6 present the average g, kappa, Type I error and Type II error which resulted from comparisons made at all levels of $p, m$, and $N$. Each table displays these comparison statistics for a specific level of component saturation.

\section{g Statistic Comparisong}

Values of $g$, the average squared difference between comparable loadings in sample and population component patterns, increased as component saturation decreased. At $a_{i j}=.60$ and $a_{i j}=.80$ saturation levels, $g$ values occurred below the $g=.01\left(g^{\frac{1}{2}}=.10\right)$ maximum difference value employed to describe a good fit for all but the smallest sample size levels $\left(N=50\right.$ for $a_{i j}=.80 ; N \leq 150$ for $\left.a_{i j}=.60\right)$. At these saturation levels, performance generally did not vary as a result of the number of variables or the number of components present. Where differences did occur in the level of $\mathrm{g}$ with respect to these variables, differences were in the third decimal place. Appendix $B$ provides plots of the g statistic as a function of $N, m, a_{i j}$, and $p$. Performance at the $a_{i j}=.40$ saturation level was not as consistent as performance at higher saturation levels. That is, the effects of $p, m$, and $N$ on $g$ performance were observed.

At higher saturation levels $\left(a_{i j}=.60, a_{i j}=.80\right)$ the effect of $p$ on resulting $g$ levels was minimal. While 
Table 4

Average $g_{e}$ Type I Errore Type II Errore and kappa

for 69 Patterns vith .40 loadings

Rattern $p$ m $N \quad g$ Eype I Type II Error kappa

$\begin{array}{rrrrrrrr}1 & 36 & 3 & 50 & .0555 & 9 & 40 & 0.54 \\ 2 & 36 & 3 & 100 & .0153 & 1 & 23 & 0.81 \\ 3 & 36 & 3 & 150 & .0110 & 0 & 25 & 0.80 \\ 4 & 36 & 3 & 200 & .0079 & 0 & 17 & 0.87 \\ 5 & 36 & 3 & 300 & .0049 & 0 & 8 & 0.94 \\ 6 & 36 & 3 & 500 & .0029 & 0 & 4 & 0.97 \\ 7 & 36 & 3 & 1000 & .0015 & 0 & 2 & 0.99 \\ 8 & 72 & 3 & 100 & .0124 & 0 & 32 & 0.74 \\ 9 & 72 & 3 & 150 & .0075 & 0 & 27 & 0.79 \\ 10 & 72 & 3 & 200 & .0053 & 0 & 28 & 0.78 \\ 11 & 72 & 3 & 300 & .0037 & 0 & 27 & 0.79 \\ 12 & 72 & 3 & 500 & .0022 & 0 & 16 & 0.87 \\ 13 & 72 & 3 & 1000 & .0012 & 0 & 9 & 0.93 \\ 14 & 36 & 6 & 50 & .0499 & 8 & 42 & 0.52 \\ 15 & 36 & 6 & 100 & .0284 & 3 & 30 & 0.72 \\ 16 & 36 & 6 & 150 & .0226 & 1 & 26 & 0.79 \\ 17 & 36 & 6 & 200 & .0117 & 0 & 11 & 0.93 \\ 18 & 36 & 6 & 300 & .0087 & 0 & 6 & 0.96 \\ 19 & 36 & 6 & 500 & .0043 & 0 & 0 & 1.00 \\ 20 & 36 & 6 & 1000 & .0024 & 0 & 0 & 1.00 \\ 21 & 72 & 6 & 100 & .0153 & 0 & 29 & 0.79 \\ 22 & 72 & 6 & 150 & .0106 & 0 & 25 & 0.83 \\ 23 & 72 & 6 & 200 & .0079 & 0 & 18 & 0.88 \\ 24 & 72 & 6 & 300 & .0051 & 0 & 17 & 0.89 \\ 25 & 72 & 6 & 500 & .0032 & 0 & 6 & 0.96 \\ 26 & 72 & 6 & 1000 & .0015 & 0 & 1 & 0.99 \\ 27 & 108 & 6 & 150 & .0089 & 0 & 26 & 0.82 \\ 28 & 108 & 6 & 200 & .0068 & 0 & 25 & 0.83 \\ 29 & 108 & 6 & 300 & .0042 & 0 & 20 & 0.87 \\ 30 & 108 & 6 & 500 & .0025 & 0 & 12 & 0.93 \\ 31 & 108 & 6 & 1000 & .0013 & 0 & 4 & 0.97 \\ 32 & 144 & 6 & 150 & .0080 & 0 & 33 & 0.77 \\ 33 & 144 & 6 & 200 & .0062 & 0 & 32 & 0.78 \\ 34 & 144 & 6 & 300 & .0040 & 0 & 25 & 0.83 \\ 35 & 144 & 6 & 500 & .0024 & 0 & 22 & 0.85 \\ 36 & 144 & 6 & 1000 & .0012 & 0 & 12 & 0.93 \\ 37 & 36 & 9 & 50 & .0483 & 6 & 42 & 0.49 \\ 38 & 36 & 9 & 100 & .0364 & 4 & 0.61 \\ 39 & 36 & 9 & 150 & .0253 & 3 & 0.73 \\ 40 & 36 & 9 & 200 & .0204 & 1 & 0.82\end{array}$


Table 4 (cont.)

Pattern $\quad \mathrm{p} \quad \mathrm{l} \quad \mathrm{N} \quad \mathrm{g} \operatorname{liror}_{\text {ErI }}^{\text {Typor }}$ kappa

\begin{tabular}{rrrrrrrr}
\hline 41 & 36 & 9 & 300 & .0138 & 0 & 11 & 0.91 \\
42 & 36 & 9 & 500 & .0077 & 0 & 4 & 0.97 \\
43 & 36 & 9 & 1000 & .0032 & 0 & 0 & 1.00 \\
44 & 72 & 9 & 100 & .0248 & 2 & 41 & 0.65 \\
45 & 72 & 9 & 150 & .0159 & 0 & 32 & 0.77 \\
46 & 72 & 9 & 200 & .0114 & 0 & 24 & 0.85 \\
47 & 72 & 9 & 300 & .0066 & 0 & 9 & 0.94 \\
48 & 72 & 9 & 500 & -0039 & 0 & 3 & 0.99 \\
49 & 72 & 9 & 1000 & .0021 & 0 & 1 & 0.99 \\
50 & 108 & 9 & 150 & .0110 & 0 & 28 & 0.82 \\
51 & 108 & 9 & 200 & .0096 & 0 & 25 & 0.84 \\
52 & 108 & 9 & 300 & .0058 & 0 & 19 & 0.88 \\
53 & 108 & 9 & 500 & .0031 & 0 & 7 & 0.96 \\
54 & 108 & 9 & 1000 & -0016 & 0 & 1 & 0.99 \\
55 & 144 & 9 & 150 & .0101 & 0 & 35 & 0.77 \\
56 & 144 & 9 & 200 & -0072 & 0 & 26 & 0.84 \\
57 & 144 & 9 & 300 & .0048 & 0 & 19 & 0.88 \\
58 & 144 & 9 & 500 & .0027 & 0 & 13 & 0.92 \\
59 & 144 & 9 & 1000 & .0015 & 0 & 4 & 0.98 \\
60 & 108 & 18 & 150 & $\$ 7$ & $*$ & 7 & .7 \\
61 & 108 & 18 & 200 & .0131 & 0 & 32 & 0.78 \\
62 & 108 & 18 & 300 & -0097 & 0 & 24 & 0.85 \\
63 & 108 & 18 & 500 & .0059 & 0 & 9 & 0.95 \\
64 & 108 & 18 & 1000 & -0026 & 0 & 0 & 0.99 \\
65 & 144 & 18 & 150 & .0139 & 0 & 42 & 0.70 \\
66 & 144 & 18 & 200 & .0119 & 0 & 43 & 0.71 \\
67 & 144 & 18 & 300 & .0078 & 0 & 25 & 0.85 \\
68 & 144 & 18 & 500 & .0045 & 0 & 11 & 0.94 \\
69 & 144 & 18 & 1000 & .0020 & 0 & 1 & 0.99 \\
& & & & & & & \\
\hline
\end{tabular}

* Condition eliminated from the design 
Table 5

Average ge Type I Error, Type II Error, and kappa

for 69 patterns with .60 Loadings

Pattern $p$ m $N \quad g$ Error Error kappa

\begin{tabular}{|c|c|c|c|c|c|c|c|}
\hline $\begin{array}{r}1 \\
2 \\
3 \\
4 \\
5 \\
6 \\
7 \\
8 \\
9 \\
10 \\
11 \\
12 \\
13 \\
14 \\
15 \\
16 \\
17 \\
18 \\
19 \\
20 \\
21 \\
22 \\
23 \\
24 \\
25 \\
26 \\
27 \\
28 \\
29 \\
30 \\
31 \\
32 \\
33 \\
34 \\
35 \\
36 \\
37 \\
38 \\
39 \\
40\end{array}$ & $\begin{array}{r}36 \\
36 \\
36 \\
36 \\
36 \\
36 \\
36 \\
72 \\
72 \\
72 \\
72 \\
72 \\
72 \\
36 \\
36 \\
36 \\
36 \\
36 \\
36 \\
36 \\
72 \\
72 \\
72 \\
72 \\
72 \\
72 \\
108 \\
108 \\
108 \\
108 \\
108 \\
144 \\
144 \\
144 \\
144 \\
144 \\
36 \\
36 \\
36 \\
36\end{array}$ & $\begin{array}{l}3 \\
3 \\
3 \\
3 \\
3 \\
3 \\
3 \\
3 \\
3 \\
3 \\
3 \\
3 \\
3 \\
6 \\
6 \\
6 \\
6 \\
6 \\
6 \\
6 \\
6 \\
6 \\
6 \\
6 \\
6 \\
6 \\
6 \\
6 \\
6 \\
6 \\
6 \\
6 \\
6 \\
6 \\
6 \\
6 \\
9 \\
9 \\
9 \\
9\end{array}$ & $\begin{array}{r}50 \\
100 \\
150 \\
200 \\
300 \\
500 \\
1000 \\
100 \\
150 \\
200 \\
300 \\
500 \\
1000 \\
50 \\
100 \\
150 \\
200 \\
300 \\
500 \\
1000 \\
100 \\
150 \\
200 \\
300 \\
500 \\
1000 \\
150 \\
200 \\
300 \\
500 \\
1000 \\
150 \\
200 \\
300 \\
500 \\
1000 \\
50 \\
100 \\
150 \\
200\end{array}$ & $\begin{array}{l}.0176 \\
.0078 \\
.0049 \\
.0037 \\
.0024 \\
.0014 \\
.0007 \\
.0069 \\
.0015 \\
.0034 \\
.0023 \\
.0013 \\
.0007 \\
.0236 \\
.0089 \\
.0061 \\
.0044 \\
.0032 \\
.0018 \\
.0009 \\
.0084 \\
.0055 \\
.0041 \\
.0024 \\
.0016 \\
.0008 \\
.0050 \\
.0038 \\
.0025 \\
.0015 \\
.0008 \\
.0052 \\
.0037 \\
.0025 \\
.0015 \\
.0008 \\
.0277 \\
.0117 \\
.0077\end{array}$ & $\begin{array}{l}0 \\
0 \\
0 \\
0 \\
0 \\
0 \\
0 \\
0 \\
0 \\
0 \\
0 \\
0 \\
0 \\
1 \\
0 \\
0 \\
0 \\
0 \\
0 \\
0 \\
0 \\
0 \\
0 \\
0 \\
0 \\
0 \\
0 \\
0 \\
0 \\
0 \\
0 \\
0 \\
0 \\
0 \\
0 \\
0 \\
2 \\
0 \\
0 \\
0\end{array}$ & $\begin{array}{r}4 \\
1 \\
0 \\
0 \\
0 \\
0 \\
0 \\
0 \\
0 \\
0 \\
0 \\
0 \\
0 \\
0 \\
0 \\
0 \\
0 \\
0 \\
7 \\
7 \\
0 \\
0 \\
0 \\
0 \\
0 \\
0\end{array}$ & $\begin{array}{l}0.96 \\
0.99 \\
1.00 \\
1.00 \\
1.00 \\
1.00 \\
1.00 \\
1.00 \\
1.00 \\
1.00 \\
1.00 \\
1.00 \\
1.00 \\
0.92 \\
1.00 \\
1.00 \\
1.00 \\
1.00 \\
1.00 \\
1.00 \\
1.00 \\
1.00 \\
1.00 \\
1.00 \\
1.00 \\
1.00 \\
1.00 \\
1.00 \\
1.00 \\
1.00 \\
1.00 \\
1.00 \\
1.00 \\
1.00 \\
1.000 \\
1.00 \\
0.84 \\
0.99 \\
1.00 \\
1.00\end{array}$ \\
\hline
\end{tabular}


Table 5 (cont.)

\begin{tabular}{|c|c|c|c|c|c|c|c|}
\hline Pattern & $\mathbf{p}$ & m & N & g & $\begin{array}{l}\text { Type I } \\
\text { Error }\end{array}$ & $\begin{array}{l}\text { Type II } \\
\text { Error }\end{array}$ & kappa \\
\hline 41 & 36 & 9 & 300 & .0034 & 0 & 0 & 1.00 \\
\hline 42 & 36 & 9 & 500 & .0021 & 0 & 0 & 1.00 \\
\hline 43 & 36 & 9 & 1000 & .0010 & 0 & 0 & 1.00 \\
\hline 44 & 72 & 9 & 100 & .0096 & 0 & 1 & 0.99 \\
\hline 45 & 72 & 9 & 150 & .0061 & 0 & 0 & 1.00 \\
\hline 46 & 72 & 9 & 200 & .0047 & 0 & 0 & 0.99 \\
\hline 47 & 72 & 9 & 300 & .0030 & 0 & 0 & 1.00 \\
\hline 48 & 72 & 9 & 500 & .0018 & 0 & 0 & 1.00 \\
\hline 49 & 72 & 9 & 1000 & .0009 & 0 & 0 & 1.00 \\
\hline 50 & 108 & 9 & 150 & .0056 & 0 & 0 & 0.99 \\
\hline 51 & 108 & 9 & 200 & .0042 & 0 & 0 & 1.00 \\
\hline 52 & 108 & 9 & 300 & .0028 & 0 & 0 & 1.00 \\
\hline 53 & 108 & 9 & 500 & .0016 & 0 & 0 & 1.00 \\
\hline 54 & 108 & 9 & 1000 & .0008 & 0 & 0 & 1.00 \\
\hline 55 & 144 & 9 & 150 & .0056 & 0 & 0 & 0.99 \\
\hline 56 & 144 & 9 & 200 & .0040 & 0 & 0 & 1.00 \\
\hline 57 & 144 & 9 & 300 & .0026 & 0 & 0 & 1.00 \\
\hline 58 & 144 & 9 & 500 & .0016 & 0 & 0 & 1.00 \\
\hline 59 & 144 & 9 & 1000 & .0008 & 0 & 0 & 1.00 \\
\hline 60 & 108 & 18 & 150 & -0077 & 0 & 1 & 0.99 \\
\hline 61 & 108 & 18 & 200 & .0052 & 0 & 0 & 1.00 \\
\hline 62 & 108 & 18 & 300 & .0035 & 0 & 0 & 1.00 \\
\hline 63 & 108 & 18 & 500 & .0020 & 0 & 0 & 1.00 \\
\hline 64 & 108 & 18 & 1000 & .0010 & 0 & 0 & 1.00 \\
\hline 65 & 144 & 18 & 150 & .0064 & 0 & 0 & 0.99 \\
\hline 66 & 144 & 18 & 200 & .0049 & 0 & 0 & 1.00 \\
\hline 67 & 144 & 18 & 300 & .0031 & 0 & 0 & 1.00 \\
\hline 68 & 144 & 18 & 500 & .0018 & 0 & 0 & 1.00 \\
\hline 69 & 144 & 18 & 1000 & .0009 & 0 & 0 & 1.00 \\
\hline
\end{tabular}


Table 6

Ayerage $q$. Type I EIror. Type II EIrore and kappa

for 69 Patterns with. 80 Loadings

Pattern $p$ m $N \quad g$ Type I Type II kappa

-

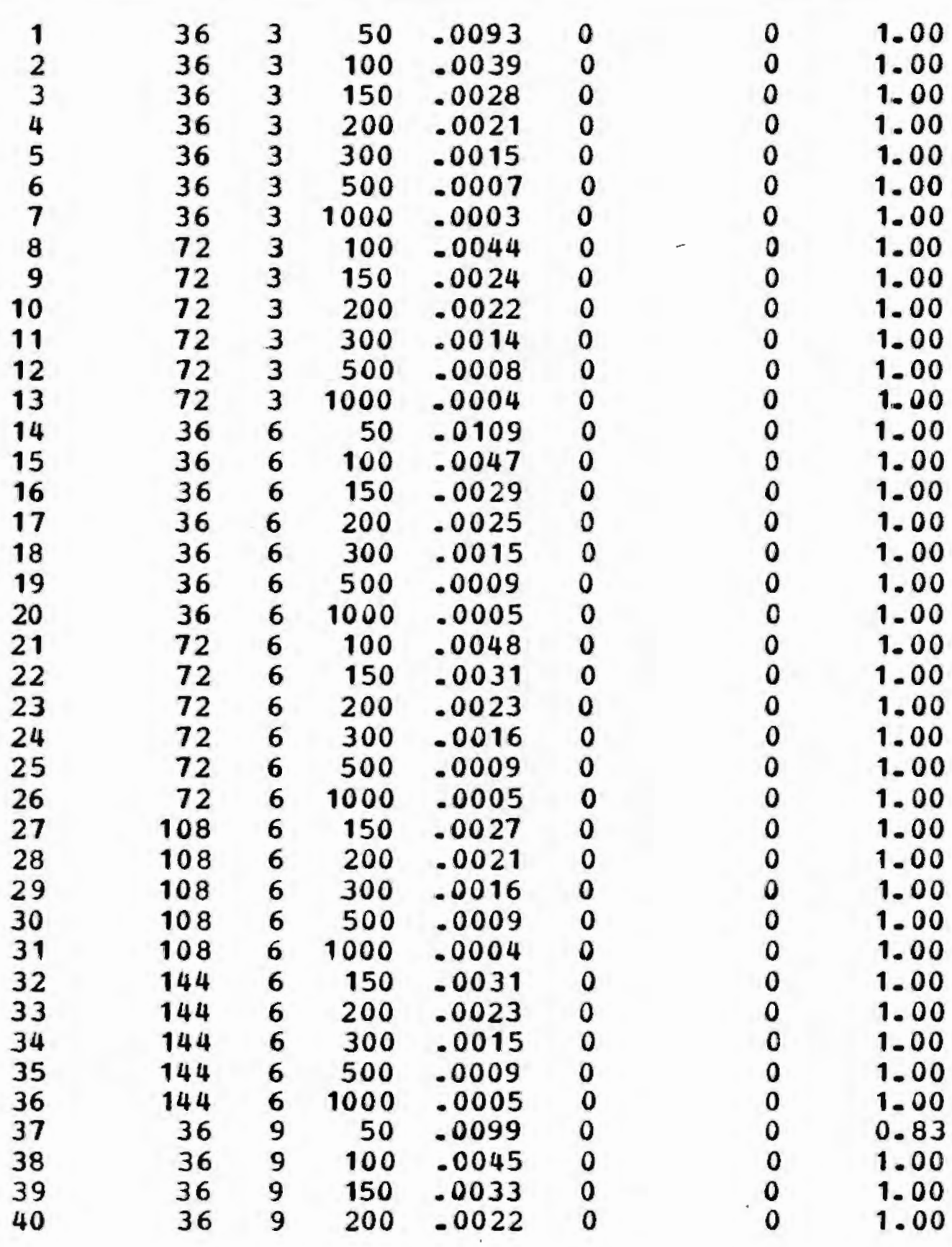


Table 6 (cont.)

\begin{tabular}{|c|c|c|c|c|c|c|c|}
\hline Pattern & p & II & $\mathbf{N}$ & $q$ & $\begin{array}{l}\text { Type I } \\
\text { Error }\end{array}$ & $\begin{array}{l}\text { Type II } \\
\text { Error }\end{array}$ & kappa \\
\hline 41 & 36 & 9 & 300 & .0016 & 0 & 0 & 1.00 \\
\hline 42 & 36 & 9 & 500 & .0010 & 0 & 0 & 1.00 \\
\hline 43 & 36 & 9 & 1000 & .0005 & 0 & 0 & 1.00 \\
\hline 44 & 72 & 9 & 100 & .0047 & 0 & 0 & 1.00 \\
\hline 45 & 72 & 9 & 150 & .0031 & 0 & 0 & 1.00 \\
\hline 46 & 72 & 9 & 200 & .0024 & 0 & 0 & 1.00 \\
\hline 47 & 72 & 9 & 300 & .0016 & 0 & 0 & 1.00 \\
\hline 48 & 72 & 9 & 500 & .0010 & 0 & 0 & 1.00 \\
\hline 49 & 72 & 9 & 1000 & .0005 & 0 & 0 & 1.00 \\
\hline 50 & 108 & 9 & 150 & .0031 & 0 & 0 & 1.00 \\
\hline 51 & 108 & 9 & 200 & .0022 & 0 & 0 & 1.00 \\
\hline 52 & 108 & 9 & 300 & .0016 & 0 & 0 & 1.00 \\
\hline 53 & 108 & 9 & 500 & .0009 & 0 & 0 & 1.00 \\
\hline 54 & 108 & 9 & 1000 & .0050 & 0 & 0 & 1.00 \\
\hline 55 & 144 & 9 & 150 & .0034 & 0 & 0 & 1.00 \\
\hline 56 & 144 & 9 & 200 & .0025 & 0 & 0 & 1.00 \\
\hline 57 & 144 & 9 & 300 & .0016 & 0 & 0 & 1.00 \\
\hline 58 & 144 & 9 & 500 & .0009 & 0 & 0 & 1.00 \\
\hline 59 & 144 & 9 & 1000 & .0005 & 0 & 0 & 1.00 \\
\hline 60 & 108 & 18 & 150 & .0034 & 0 & 0 & 1.00 \\
\hline 61 & 108 & 18 & 200 & .0026 & 0 & 0 & 1.00 \\
\hline 62 & 108 & 18 & 300 & .0017 & 0 & 0 & 1.00 \\
\hline 63 & 108 & 18 & 500 & .0010 & 0 & 0 & 1.00 \\
\hline 64 & 108 & 18 & 1000 & .0005 & 0 & 0 & 1.00 \\
\hline 65 & 144 & 18 & 150 & .0035 & 0 & 0 & 1.00 \\
\hline 66 & 144 & 18 & 200 & .0026 & 0 & 0 & 1.00 \\
\hline 67 & 144 & 18 & 300 & .0017 & 0 & 0 & 1.00 \\
\hline 68 & 144 & 18 & 500 & .0010 & 0 & 0 & 1.00 \\
\hline 69 & 144 & 18 & 1000 & .0005 & 0 & 0 & 1.00 \\
\hline
\end{tabular}


larger variable sets did result in lower values of $g$, the difference in performance (when a difference did exist) at any level of $m$ occurred in the third decimal place. The criterion level of .01, for all levels of $p$, was met at small sample sizes $(N=50$ to $N=150)$. Greater differences in resulting $g$ values between levels of $p$ were observed at the $a_{i j}=.40$ saturation level. Larger variable sets reached the cutoff value of $g=.01$ at smaller sample sizes. At low sample size levels, the difference in $g$ performance relative to the smallest level of $p$ (36) and the largest level (144) was larger than under similar conditions at higher saturation levels (e.g. $g=.015$ for $p=36$ and $p=144$ at $N=150 ; m=6$ vs. $g=.001$ for the same conditions at $\left.a_{i j}=.60\right)$. G performance, however, became more similar across levels of $p$ as sample size increased. Larger variable sets $(p=72$. 108. 144) displayed more similar (homogeneous) values across all conditions.

The effect of $m$ on $g$ performance was also evident at the $a_{i j}=-40$ level. Greater values of Il land correspondingly the less well a component is defined in terms of $\mathrm{p} / \mathrm{m})$ resulted in increased $g$ values for any combination of $\mathrm{p}$ and $\mathrm{N}$. For all levels of $\mathrm{p}$. the rate of decrease in $g$ as sample size increased was slower as $m$ increased. That is, attaining the cutoff level of $g=.01$ required larger sample sizes as m increased for any level of $\mathrm{p}$. 
While differences in performance among levels of $p$ and m were observed at this saturation level, the cutoff value was ultimately attained and surpassed under all conditions when a sufficient sample size level was reached. As discussed above, the sample size required to reach the cutoff level was higher the smaller the variable set and the greater the number of components (see Appendix B). The largest sample size required to meet the .01 criterion was $N=450$ for $\mathrm{p}=36$ and $m=9$. Across all levels of $m$, the sample size required to meet the cutoff for the remaining $p$ levels was smaller $(N=150$ to $N=300)$.

\section{Decision Table Comparisons}

Three comparison statistics were calculated from the information contained in the decision tables (see Table 2) constructed. Decision tables vere constructed in order to observe comparability between patterns relative to the correct identification of salient and non-salient component loadings. A salience cutoff level of .40 was defined. A measure of agreement, kappa, was calculated in addition to the calculation of the percentage of possible Type I and Type II errors occurring. Decision tables were pooled over the five samples generated per condition and an average was obtained.

Relative to the results obtained with respect to the 
$g$ statistic, kappa, Type I error, and Type II error performance was similar. For kappa, perfect performance (kappa $=1.00)$ resulted across all levels of $p_{0} m$, and $N$ at the $a_{i j}=.80$ saturation level. This performance level was attained beyond $N=100$ for all conditions when component saturation level equaled.60. For the case in which $p=36$ and $N=50$, performance decreased as $m$ increased. At any level of $m$, however, kappa was higher than the .75 level defining excellent fit between the patterns. Appendix $c$ provides plots of kappa as a function of $N_{0} m_{*} a_{i j}$, and $p_{-}$As occurred with $g$ performance, the effects of $m, p$, and $N$ became most evident at the $a_{i j}=.40$ saturation level. An increase in sample size, with respect to any level of $p$ or $m$, resulted in higher kappa values. The criterion value of .75 was attained at sample size levels beyond 200 for any combination of $p$ and $m$. Lower levels of $p(36,72)$ displayed poorer performance than larger levels (108. 144) at lower sample sizes $(N=50$ to $N=250)$. At sample sizes greater than these, however, smaller variable sets possessed greater kappa values. An increase in m resulted in more homogeneous performance among levels of $p$. With an increase in $\mathbb{m}$, however, a decrease in kappa values occurred.

Type I error, the incorrect identification of a non-salient component loading, was a relatively rare event under any condition. At the $a_{i j}=.80$ saturation level. 
Type I error was non-existent. Type $I$ error at the $a_{i j}=.60$ level did not occur beyond $N=100$ for any combination of $p$ and $m$. For $p=36$ and $N=50$, Type $I$ error increased as II increased. The percentage of Type I error occurring at this saturation level did not surpass 3. Appendix $D$ provides plots of Type $I$ error as a function of $N, p_{0} a_{i j}$, and $m$. While Type I error did become more frequent at the $a_{i j}=.40$ saturation level, a percentage of greater than $9 \%$ did not occur. An increase in $N$ resulted in lower Type I error percentages. At $N \geq$ 100, the percentage of errors occurring never exceeded $5 \%$. Smaller variable sets resulted in higher percentages. The difference in percent error among levels of $p$ was enhanced with an increase in $m$. Note, however, that Type I error was a relatively rare event and that when differences occured among levels of $p$, the percentage difference never exceeded $3 \%$.

Relative to Type I error, Type II error was a more frequent event. As occurred with the other comparison statistics discussed. Type II error did not become evident until the $a_{i j}=.40$ saturation level was examined. At $a_{i j}=.80,0.0$ percent errors occurred. At sample sizes of 100 and beyond. Type II error did not occurr at the $a_{i j}=-60$ saturation level (execption: $p=108,144$; II = 18; $N=150 ;$ Type II error $=1 \%$ ). For the case in which $p=36$ and $N=50$, Type II error increased as m increased. This error value, however, never exceeded 11\% 
(m = 9). Appendix E provides plots of Type II error as a function of $N, P, a_{i j}$, and $m$. The $a_{i j}=.40$ level of component saturation provided the best opportunity to observe the effects of $p$, $I$, and $N$ on this statistic. An increase in $\mathbb{N}$ vithin any $p$ and m combination resulted in decreased Type II error percentages. Smaller variable sets possessed lower Type II error percentages. Errors increased as the number of components increased. The error Iate between levels of $p$ decreased as $m$ increased, particularly at larger sample sizes (beyond $N=200$ ). At low sample sizes $(N=50$ to $N=200)$, for any level of $p$. nearly one third of all component loadings which should have been identified as salient vere mis-identified. 


\section{Discussion}

The purpose of this study was to examine the conditions under which sample component patterns become stable with respect to their population patterns. The effect of four factors (sample size, number of variables, number of components, and component saturation) vere examined. Based upon the popularity of the rules discussed earlier, one might have expected that (1) sample size and (2) number of variables would be of primary importance in determining comparability. These factors, however, vere not of major importance. Component saturation (the magnitude of component loadings) was the factor which had the greatest impact. Only at the lowest saturation level $\left(a_{i j}=.40\right)$, were the effects of the other factors most observable. At this low saturation level sample size was important in determining comparability.

The results obtained in this study do little to support the types of rules discussed earlier. The most popular rules, those wich determine $\$$ as a function of $p$, are clearly not substantiated. The various rules differ 
in the recommended ratio of observations to variables, but all rules require more observations as the number of variables increase. The results from this empirical investigation imply the opposite relationship. Larger variable sets always possessed the smaller difference ( $g$ value) at any sample size level (when a difference among $p$ values did exist). The cutoff value of $g=.01$ was always attained at lower sample sizes for larger variable sets. The idea that more observations are needed as the number of variables increase is clearly not supported.

One rule (Cattell, 1978) suggested sample size be determined as a function of the number of expected factors. While increasing the number of components for a given number of variables had an effect on comparability at the .40 component saturation level, the relationship between $m$ and the $N$ required to attain acceptable comparability was not exponential as Cattell's (1978) rule suggests. Under the least well defined (lov p/ll ratio, low component saturation) conditions, a sample size of $N=300$ to 450 would be required to observe acceptable comparability between patterns.

Researchers recommending rules which suggest obtaining a maximum, minimum, or specific number of observations may find support for their suggestions in these results. The results obtained, hovever, show that the sample size reguired to reach an acceptable level of comparability between patterns varies under the 
experimental conditions employed. That is, the specification of one sample size level as aniversal value will over-estimate the number of observations required under some conditions and under-estimate the number under other conditions.

An examination of the results associated with each of the four comparison statistics ( $g$, kappa, Type I error, and Type II error) employed in this study reveals a consistent pattern. If a pattern is well defined with respect to component saturation $\left(a_{i j}=.60\right.$ and $\left.a_{i j}=.80\right)$ neither the number of variables, the number of components, nor sample size is strongly related to the comparability of population and sample component patterns. Implicit within this finding is the fact that a component does not necessarily have to be well defined in terms of the number of variables defining it. The lowest level $(\mathrm{p} / \mathrm{m}=4)$ employed in this study proved adequate. With respect to sample size, at these saturation levels, performance on comparison statistics was perfect or near perfect at all but the lowest sample size $(\mathrm{N}=50)$ level.

When the saturation of a component is low $\left(a_{i j}=.40\right)$ the number of variables defining the component $(p / m)$ had an effect on comparability. The better a component pattern is defined (high $\mathrm{p} / \mathrm{m}$ ratio), the more accurately it will reproduce the population component pattern. A second important factor is sample size. At the low component saturation level, larger sample sizes are 
required to produce sample patterns which accuartely reproduce the population pattern. With respect to the $g$ and kappa criteria, a sample size in the range of 150 to 300 will generally result in acceptable comparability for all values of the $\mathrm{p} / \mathrm{m}$ ratio above 4 .

The pattern of Type I and Type II errors occurring at the low saturation level $\left(a_{i j}=.40\right)$ reveal a tendency for a component to become under-defined rather than over-defined. That is, more component loadings wich should be judged salient are not (Type II error) rather than the reverse occurring.

Further evidence supporting the importance of saturation level is presented in Table 3. This table displays the conditions under which successful matching between the sample and population varimax rotated patterns was a problem. Problems occurred only at the $a_{i j}=.40$ component saturation level. At this level, the effect of sample size and the number of variables per component $(\mathrm{P} / \mathrm{m})$ was also evident. Generally, problems in matching occured when the sample sizes were small (N=50 to 300) and/or wen few variables per component $(\mathrm{p} / \mathrm{m}=4$ to 8$)$ prevailed.

Under the relatively "clean" conditions employed in this design - equal number of variables per component, all non zero loadings equal - the conditions which effect comparability between sample and component patterns are clear. Those component patterns which are comprised of 
variables possessing loadings of .60 and greater will represent the population structure well at sample size levels greater than 100 observations regardless of the number of variables employed and the number of components existing. Patterns possessing lower component loadings $\left(a_{i j}=.40\right)$ rely upon sample size and the number of variables per component to provide good representation. Generally, sample sizes of 150 to 300 observations were required at this saturation level to produce acceptable comparability (relative to criterion values) between patterns whatever the $\mathrm{p} / \mathrm{m}$ ratio. Those patterns containing larger $\mathrm{p} / \mathrm{m}$ ratios require smaller sample sizes within this range.

The sample size recommendations provided here, regardless of the experimental conditions llevel of component saturation, $p / m$ ratio) considered, are generally lower than those recommendations yielded by the various rules discussed earlier. It should be noted, however. that in obtaining the required sample size good sampling techniques should not be disregarded. Most importantly, the collection of smaller samples should require greater attention paid to sampling appropriately from the population of interest (LOO, 1983).

While these results have been derived from an examination of principal component patterns. evidence exists which suggests a similar pattern would surface had a factor analytic procedure been employed. Velicer et al. 
(1982). in addition to finding that the solutions obtained from the two procedures differ minimally, also reported that the match of a sample factor pattern to its population pattern was quite good at the $N=144$ level. A related finding from Boomsma (1980) working with structural analysis type models suggests that such analyses not be performed with less than 100 observations and that a sample size of 200 should provide more than adequate results. The sample size values suggested by Velicer et al. (1982) and Boomsma (1980) fall vithin the range recommended here.

The applied researcher can employ the results obtained here to maximize his/her chances of obtaining and interpreting a solution which best represents its population pattern. Given the importance of component saturation in determining comparability, the researcher, prior to an analysis, should select variables which will be good markers for a component. That is, variables which clearly should define a particular component and will therefore load highly. If an idea of saturation level is unclear, many variables $(>12)$ thought to represent a particular construct (component) should te selected. If these conditions can be accurately stipulated by the researcher beforehand, a sample size of 200 observations should be sufficient to obtain an accurate solution. Following an analysis, the component pattern itself should be investigated with respect to the number of variables 
defining a component and yith respect to the magnitude of component loadings. If components possess four or more variables with $a_{i j} \geq .60$, the pattern may be interpreted whatever the sample size employed. Similarly, a pattern comprised of many variables per component $(>12)$ but low $\left(a_{i j}=.40\right)$ loadings should be an accurate solution at all but the lowest $(N \leq 100)$ sample sizes. If a solution possesses components with only a few variables per component $(<10)$ and low component loadings, the pattern should not be interpreted unless a sample size of 300 or more observations has been employed. Replication would be suggested if these conditions occur with a sample size smaller than 300 observations.

In summary, component saturation has been observed as a major factor in determining comparability between sample and population component patterns. At the lovest component saturation level employed (.40) the effects of sample size and the number of variables per component became most evident. It was observed that a good match to the population pattern is attained across all conditions when the sample component pattern is vell defined $\mathrm{la}_{i j}=$ .80). Sample component patterns possessing moderate component saturation (.60) provided a good fit to the population pattern across conditions when sample size was greater than or equal to 150 observations. Weakly defined sample component patterns $\left(a_{i j}=.40\right.$. low $p / m$ ratio) provided a good match when sample size was in the range of 
300 to 400 observations. 
References

Aleamoni, L. M. (1973). Effects of sample size on eigenvalues, observed communalities, and factor loadings. Journal of Applied Psychologye 58, 266-269. Aleamoni. I. H. (1976). The relation of sample size to number of variables in using factor analysis techniques. Educational and Psychological Measurement. 36. 879-883.

Baggaley, A. R. (1982). Deciding on the ratio of the number of subjects to number of variables in factor analysis. Multivariate Experimental clinical Research. $\underline{6} \cdot 81-85$.

Boomsma, A. (1982). The robustnesS of IISREL against small sample sizes in factor analysis models. In $K$. $G$. Joreskorg and H. Wold (Eds.), Systems under indirect observation (Part I) (Pp 149 - 173). Amsterdam: North Holland.

Brislin, R. W., Sonner, W. J., E Thorndike, R. H. (1973) . Cross - cultural research Methods. New York: John Wiley $\varepsilon$ Sons.

Browne, M. W. (1968). A comparison of factor analysis techniques. Psychometrika, 33, 267-333.

Cattell. B. B. (1978) - The scientific use of factor analysis in behavioral and life sciences. New York: Plenum Press.

Cliff, N. (1970). The relation between sample size and 
population characteristic vectors. Psychometrika, 35. 163-178.

Comrey. A. I. (1973) - A first course in factor analysis.

New York: Academic Press.

Comrey. A. L. (1978) - Common methodological problems in factor analytic studies. Journal of Consulting and clinical Psychologye 46, 648-659.

Fleiss, J. I. (1981). Statistical methods for rates and p드으으tions (2nd ed.). New York: John wiley and Sons. Glass, G.. E Taylor, P. A. (1966). Factor analytic methodology - Review of Educational Researche 36. $566-587$.

Gorsuch, R. I. (1974) - Factor analysis. Philadelphia: B. Saunders Co..

Guertin, W. H., \& Bailey. J. P. (1970). Introduction to modern factor anglysise Ann Arbor: Edwards Brothers, Inc.

Guilford, J. P. (1954). Psychometric methods- New York: Mc Graw - Hill.

Hotelling, H. (1933). Analysis of a complex of statistical variables into principal components. Journal of Educational Psychologye 24, 417-441, 498-520. Humphreys, I. G.. Ilgen, D.. MC Grath, D., E Montanelli, R. (1969) - Capitalization on chance in rotation of factors. Educational and psychological beasurement. 29. 259-271.

Jackson, D. N., E Chan, D. W. (1980). Maximum - Iikelihood 
estimation in common factor analysis: a cautionary note. Psychological Bulletin. 88, 502-508.

Kaiser, H. F. (1958). The varimax criterion for analytic rotation in factor analysis. psychometrika. 23. 187-200.

Kunce, J. T., Cook, W. D.e E Miller, D. E. (1975) . Random variables and correlationàl overkill. Educational and Psychological Measuremente 35, 529-534.

Landis, J. R., E Koch, G. G. (1977). The measurement of observer agreement for categorical data. Biometrics. 33. 159-174.

Light, R. J. (1971). Measures of response agreement for qualitative data: some generalizations and

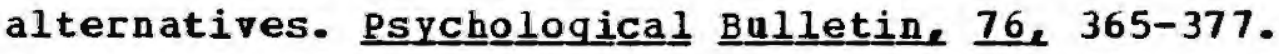
Lindeman, R. H.. Merenda, P. F., E Gold, R. Z. (1980).

Introduction to bivariate and multivariate analysis. Glenview: Scott Foresman and Co. Loo, R. (1983) - Caveat on sample sizes in factor analysis. Perceptual and Motor skillse 56, 371-374. Manners, G. E., E Brush, D. H. (1979). A simulation of factor analytic reliability varying sample size and number of variables. psychological geportse 45. 471-478.

Montanelli, R. G.. Jr. (1975). A computer program to generate sample correlation and covariance matrices. Educa tional and Psychological ㅂeasurement, 35e 195-197. Nunnally, J. C. (1978) - Psychometric theory- New York: Mc 
Graw - Hill.

Pennel1, R. (1968). The influence of communality and $N$ on the sampling distribution of factor loadings. Psychometrika, 33, 423-439.

Press, S. J. (1972) - Applied multivariate analysis. New York: Holt, Rinehart and Winston.

Pruzek, R. M. E Rabinowitz, S. N. (1981). A simple method for exploratory structural analysis. American

Educationa1 Research Journale 18, 173-189.

Rummel. R. J. (1970) - Applied factor analysis. Evanston: Northwestern Oniversity Press.

Steiger, J. H., E Schonemann. P. H. (1978) - A history of factor indeterminacy. In S. Shye (Ed.). Theory construction and data analysis in the behavioral sciences (pp. 136 - 178). San Francisco: Jossey - Bass. Tinkelman, S. N. (1971). Planning the objective test. In R. I. Thorndike (Ed.). Educational measurement (2nd ed.). Washington, DC: American Council on Education. Tucker, L. R., Koopman, R. F.. E Linn, R. L. (1969). Evaluation of factor analytic research procedures by means of simulated correlation matrices. Psychometrika. 34. 421-459.

Velicer, W. F. (1974). A comparison of the stability of factor analysis, principal component analysis, and rescaled image analysis. Educational and Psychological Measurement. $34,563-572$.

Velicer, W. F. (1976). The relation between factor score 
estimates, image scores, and principal component scores. Educational and Psychological ㅂeasurement. 36 . 149-159.

Velicer, H. F. (1977) - An empirical comparison of the similarity of principal component, image, and factor patterns. uㅣtivariate Behavioral eㅗearch, 12, 3-22. Velicer, W. F., \& Jackson, D. N. (1984). Component analysis versus common factor analysis: some issues in selecting an appropriate procedure. unpublished manuscript.

Velicer, W. F., Peacock, A. C. E Jackson, D. H. (1982). A comparison of component and factor patterns: a monte carlo approach. uㅣtivariate Behavioral Research. 17. 371-388.

Zwick, W. R. E Yelicer, W. F. (1982)-Factors influencing four rales for determining the number of components to retain. Multivariate Behavioral Research. 17, 253-269. 
Appendix A 
Table A-1

overa11 Design

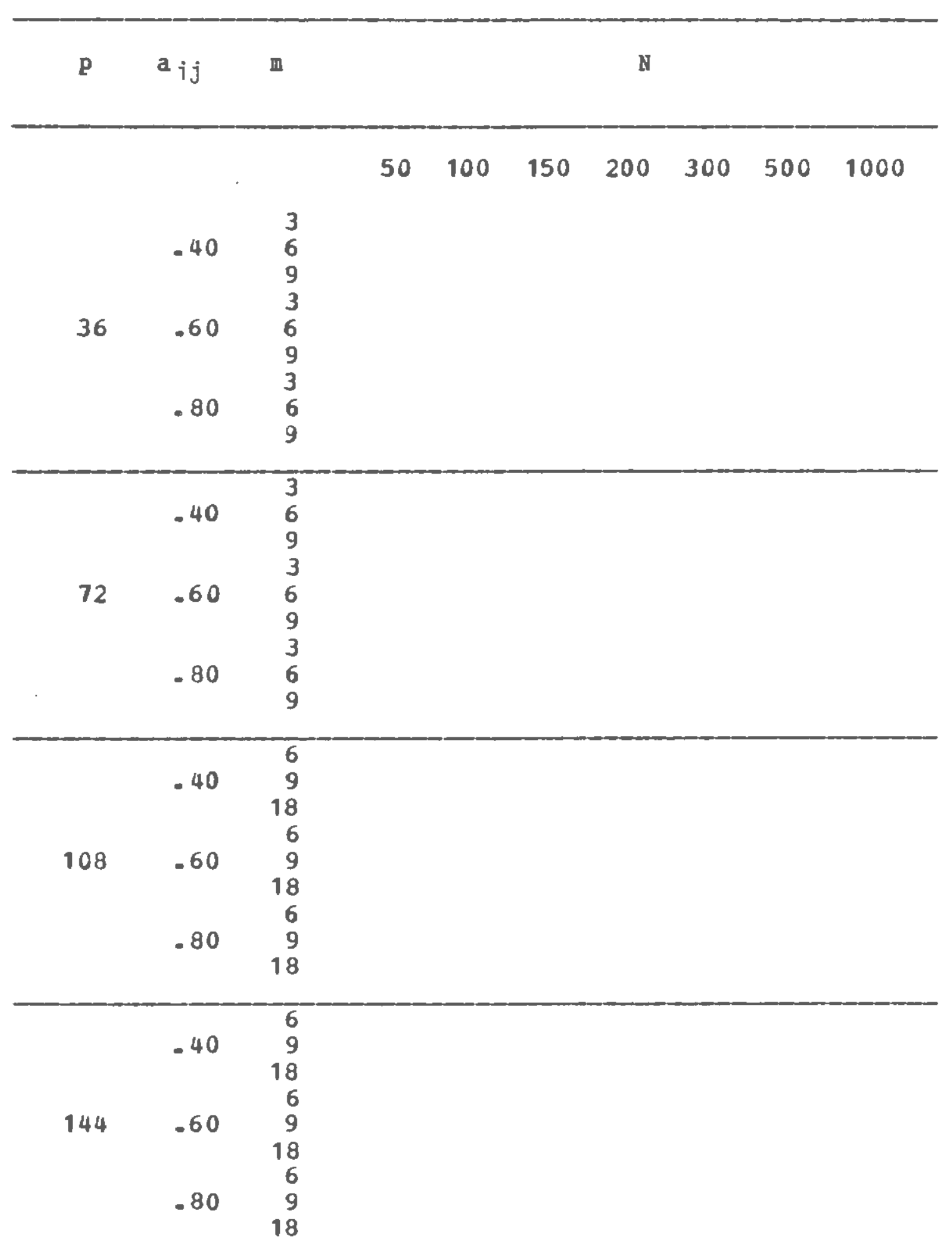


Appendix B 
Figure B-1 Agerage $g$ as a Function of Sample Size for . 40 Component Saturation and 3 components

Figure $B-2$ Average $g$ as a Function of sample Size for .40 component Saturation and 6 Components

Figure B-3 Average $g$ as a Punction of Sample size for .40 Component Saturation and 9 components

Figure $B-4$ Average $g$ as a Function of sample size for .40 Component Saturation and 18 components 


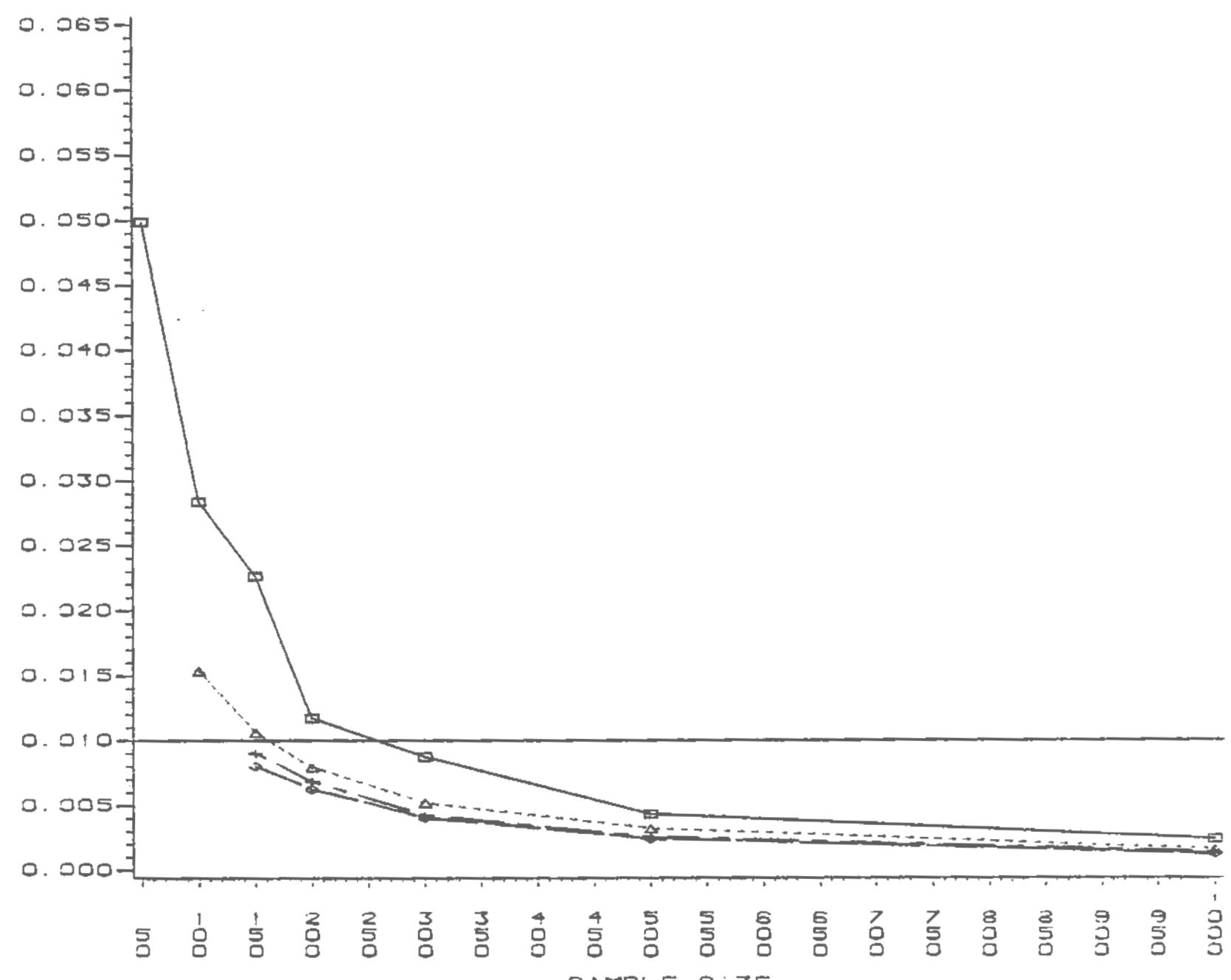

LECEND:

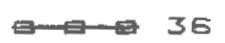
SAMPLE SiZE $\rightarrow-\Delta-->2+100$ 


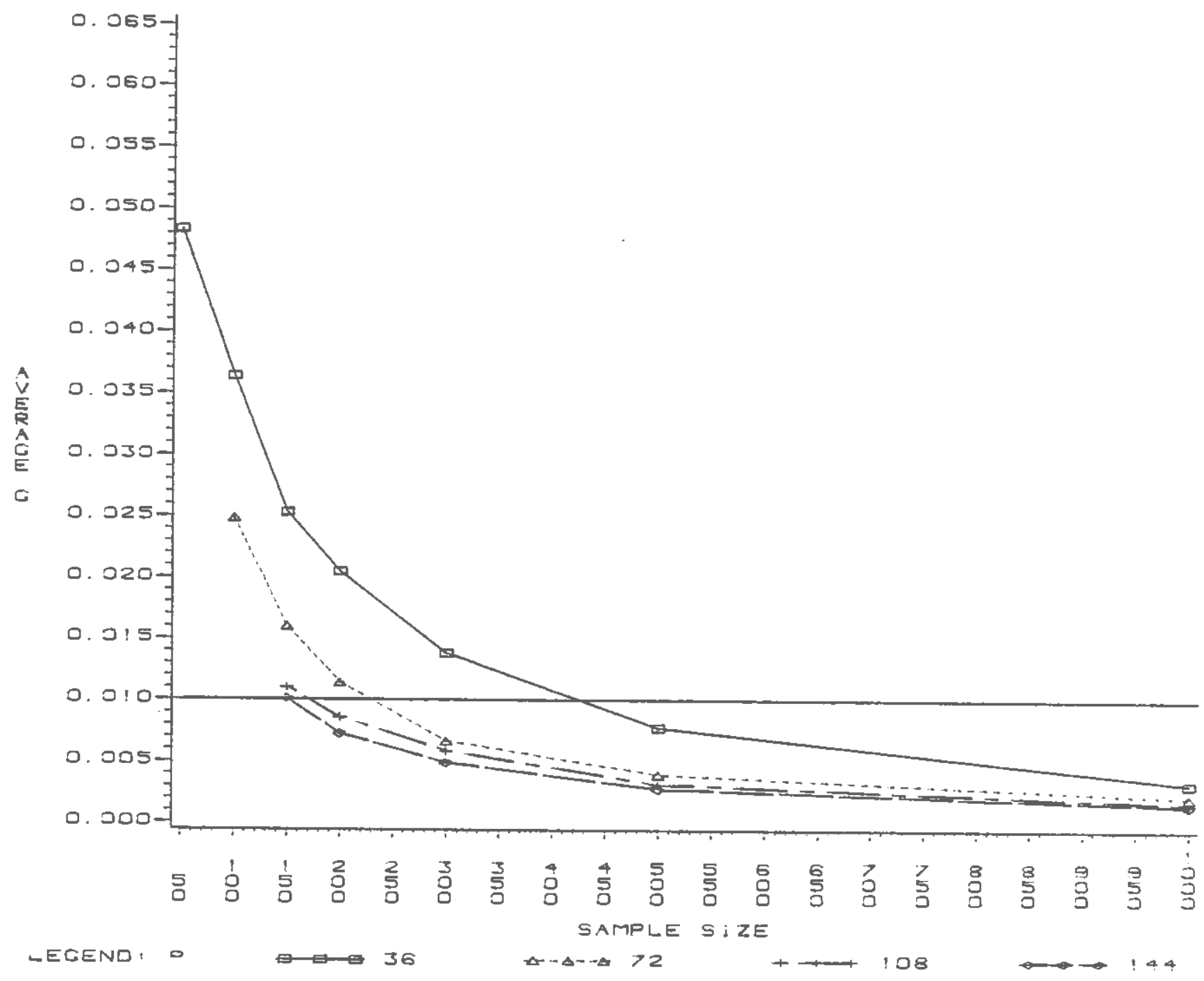




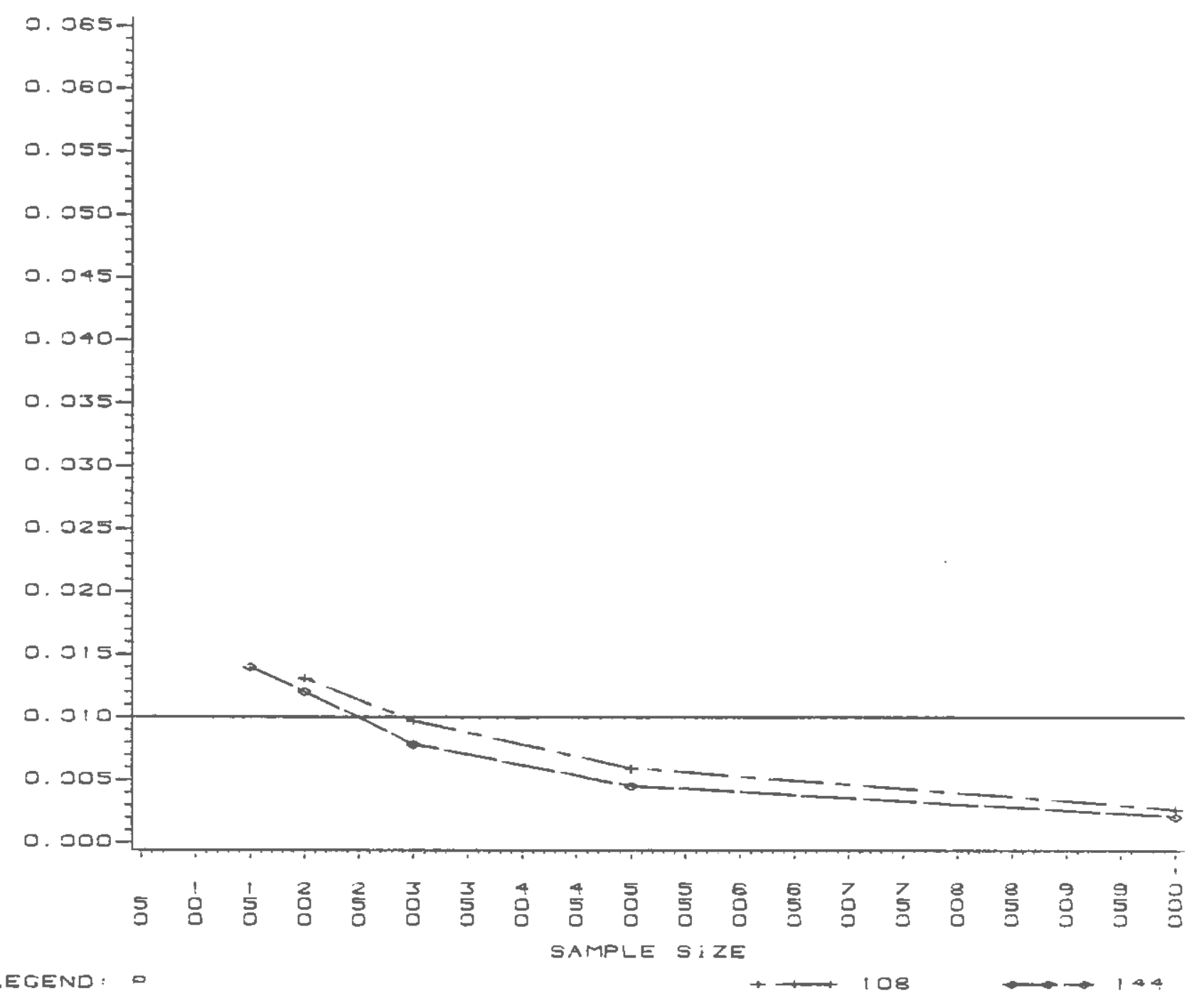


Figure B-5 Average $g$ as a Function of Sample size for . 60 component Saturation and 3 components

Figure $B-6$ Average $g$ as a Function of sample size for 60 Component Saturation and 6 components

Pigure B-7 Average $g$ as a Punction of Sample size for -60 Component Saturation and 9 Components

Pigure $B-8$ average $g$ as a Punction of sample size for .60 Component Saturation and 18 components 


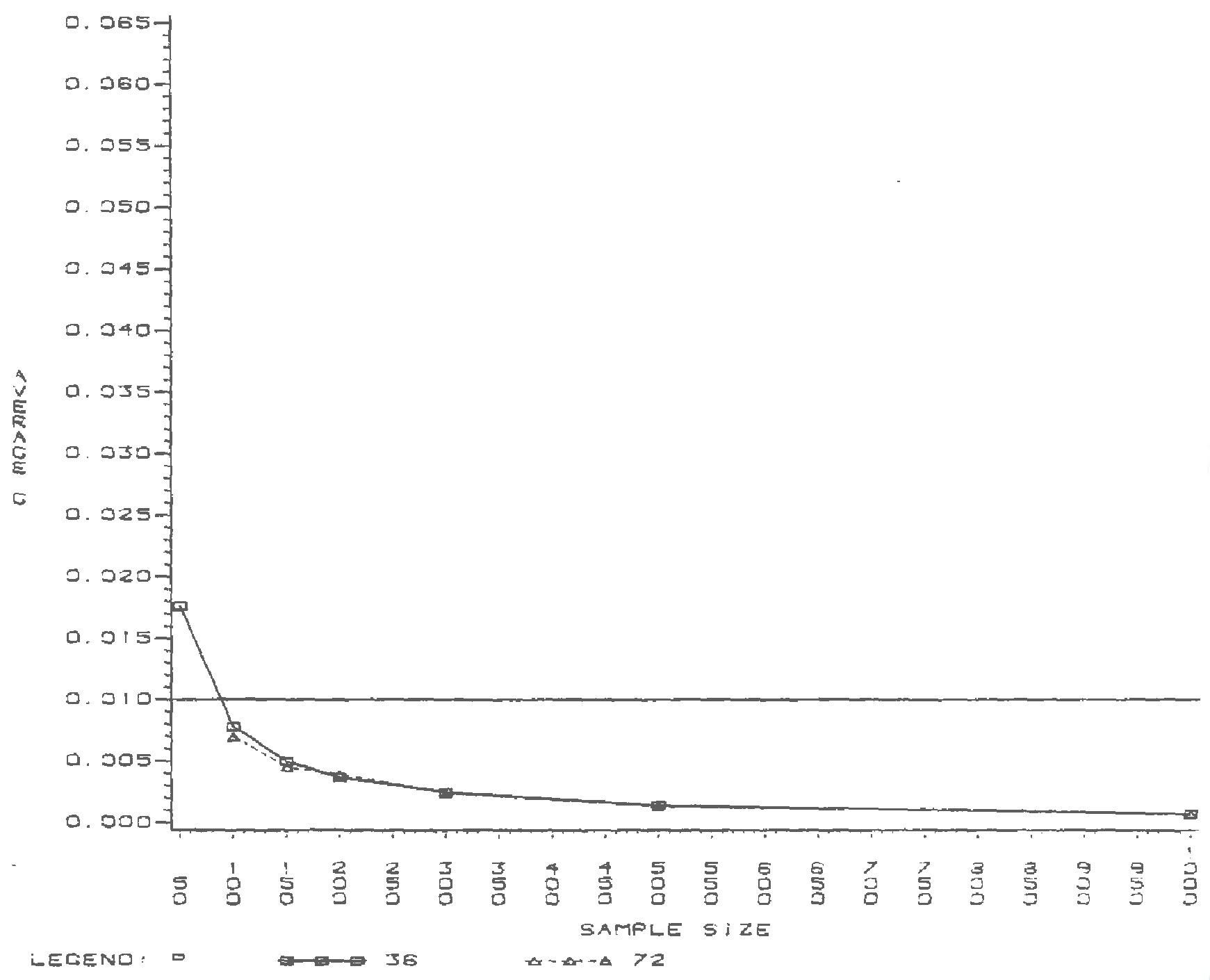




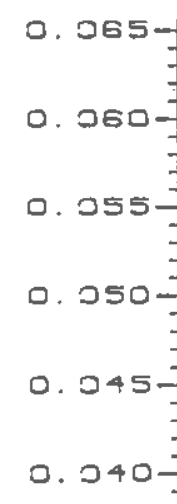

๑. 0357

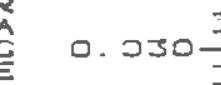

$G$

๑.

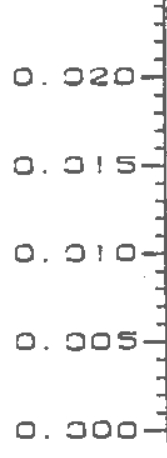

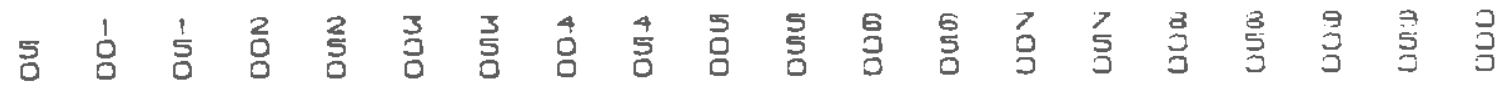
SAMPLE SIZE 


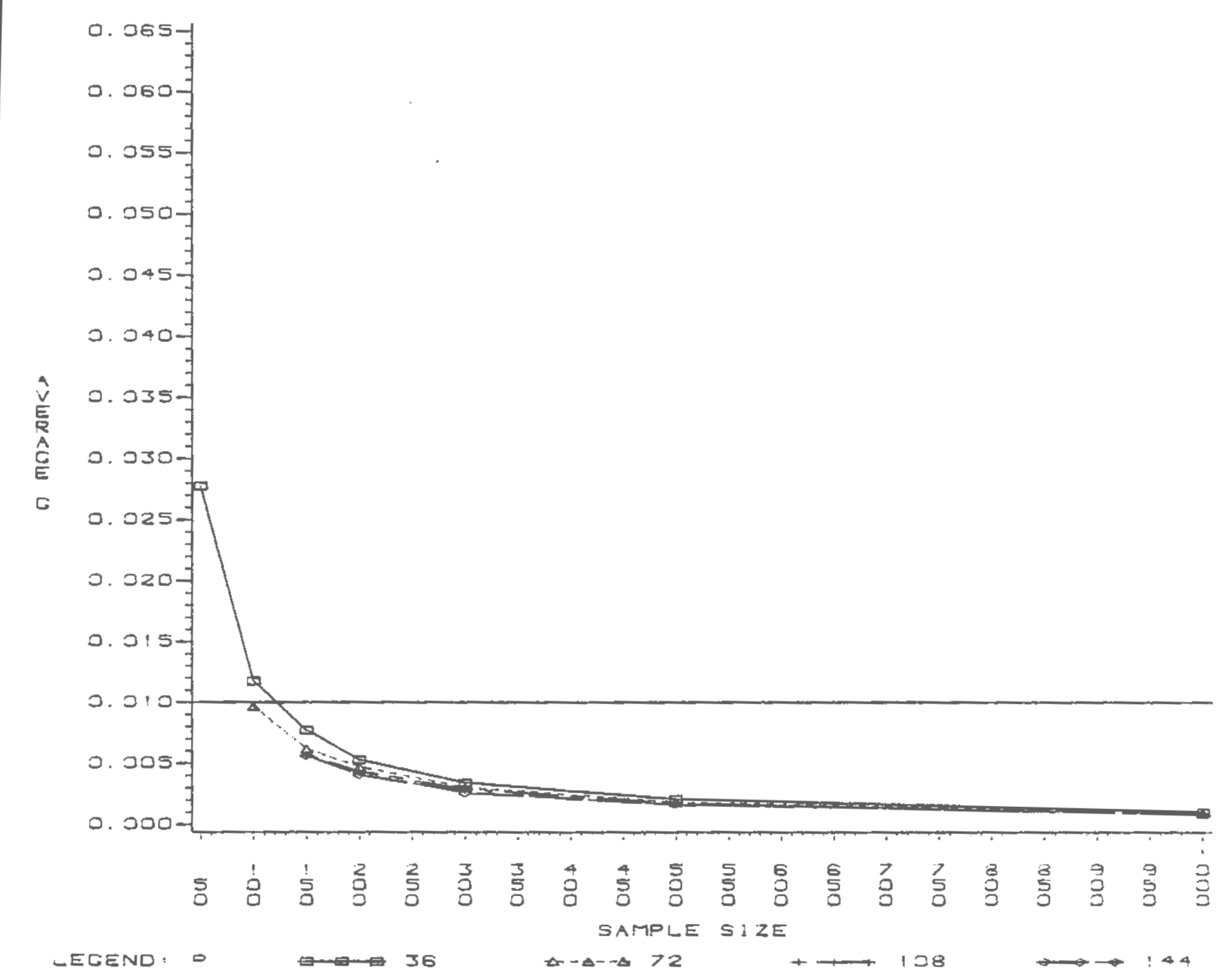




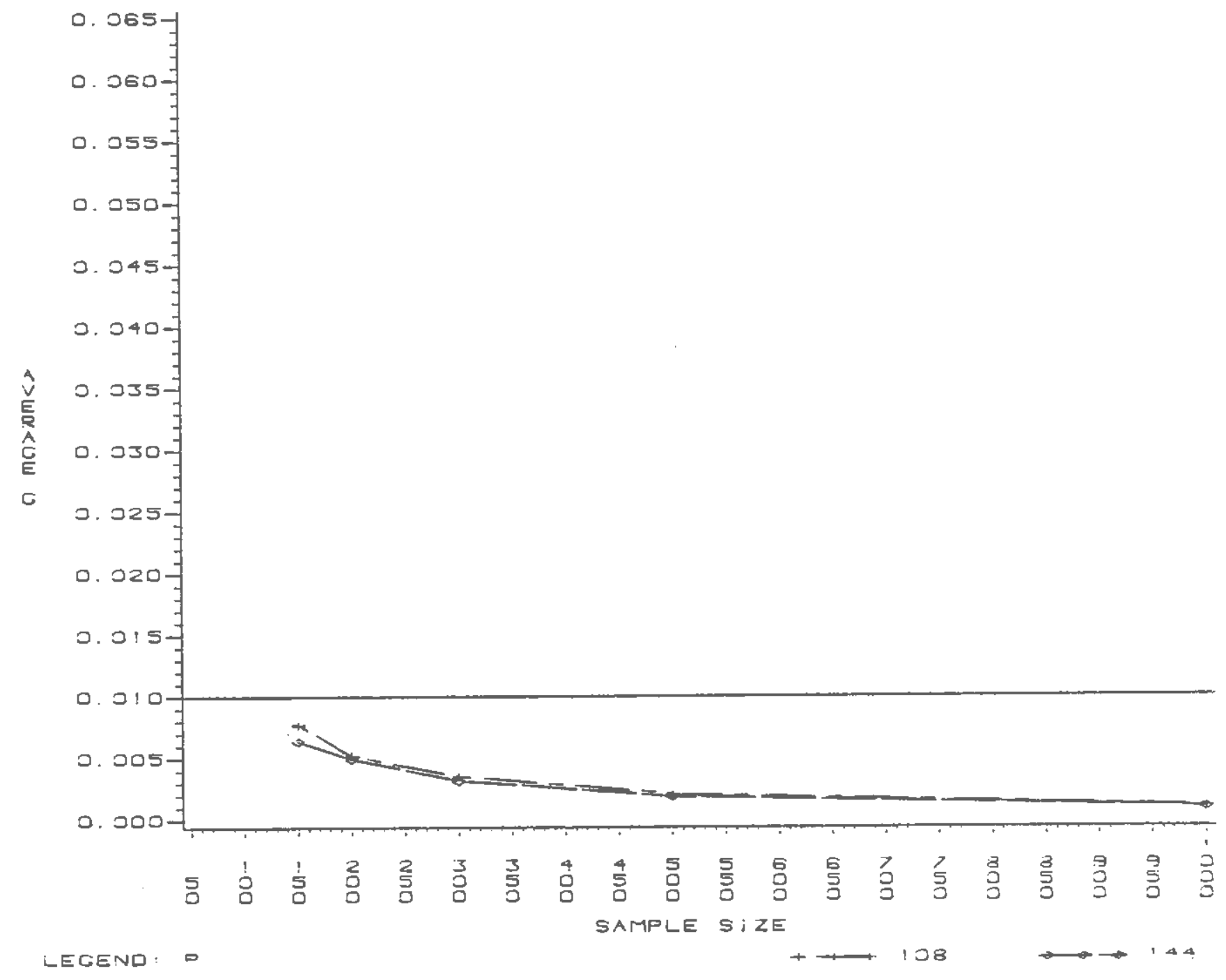


Figure B-9 Arerage $g$ as a Punction of Sample Size for -80 Component Saturation and 3 components

Figure $B-10$ Average $g$ as a Function of sample size for . 80 Component Saturation and 6 Components

Figure B-11 Average $g$ as a Function of Sample size for -80 Component Saturation and 9 components

Figure B-12 Average $g$ as a Function of Sample Size for . 80 Component Saturation and 18 Components 


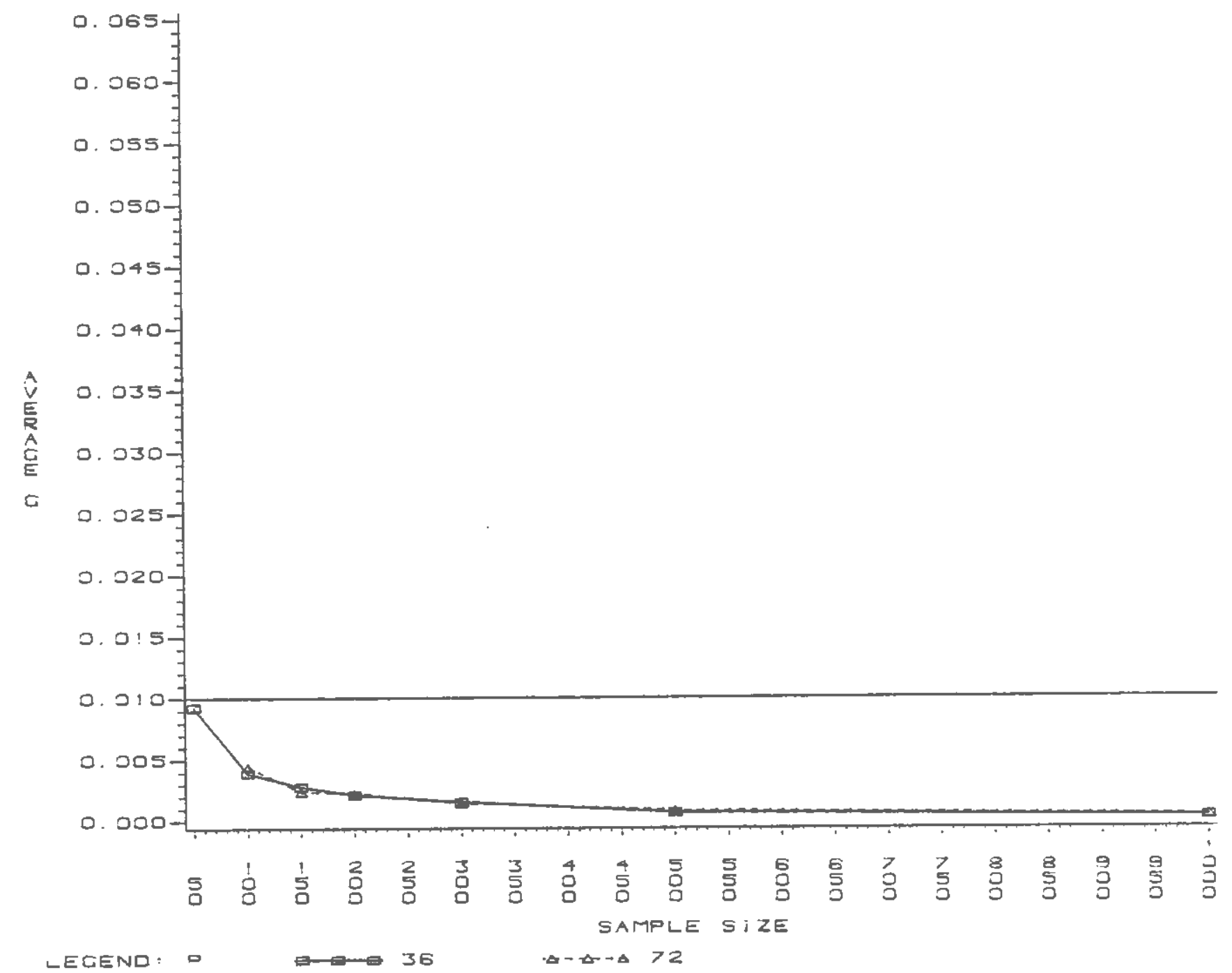




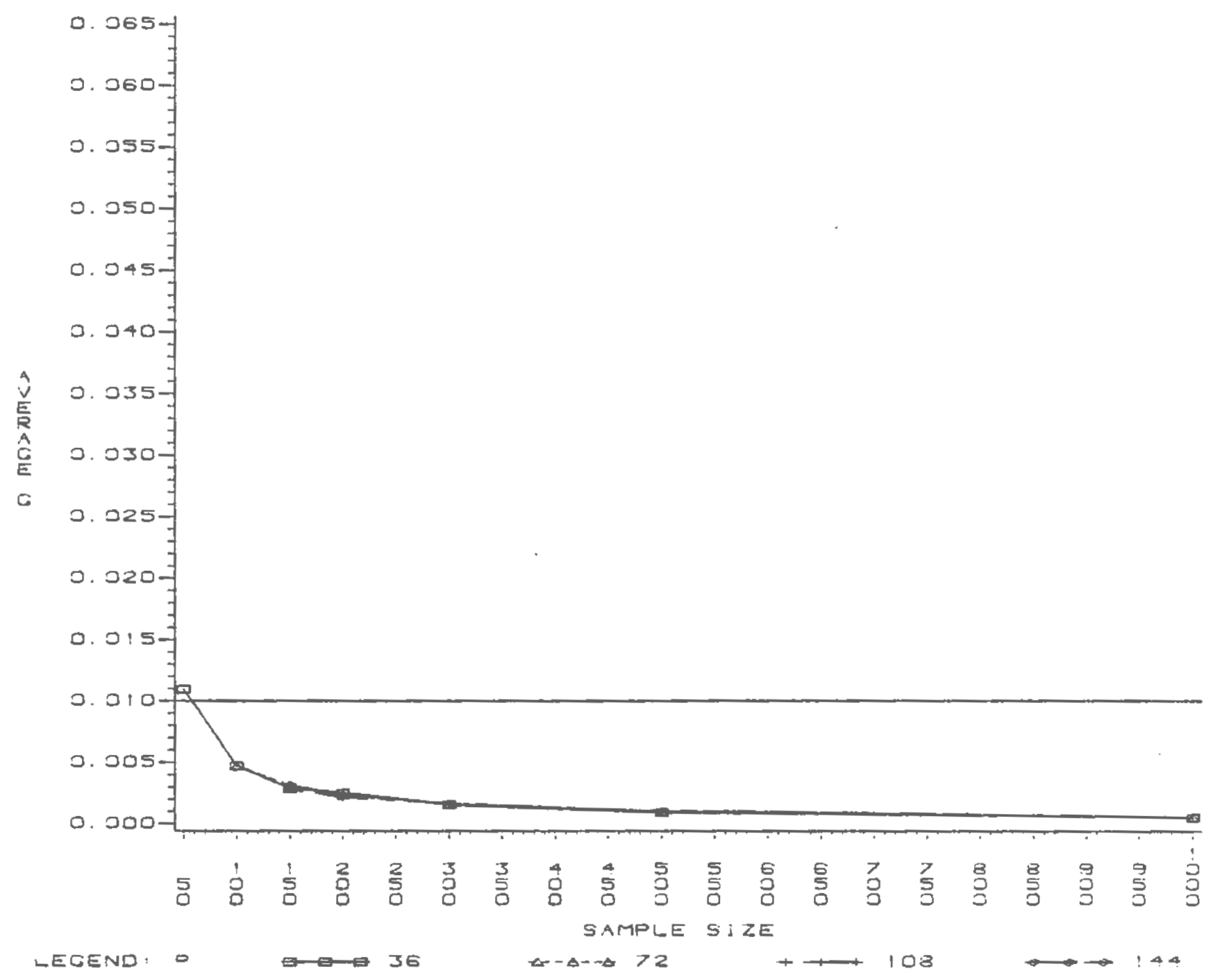




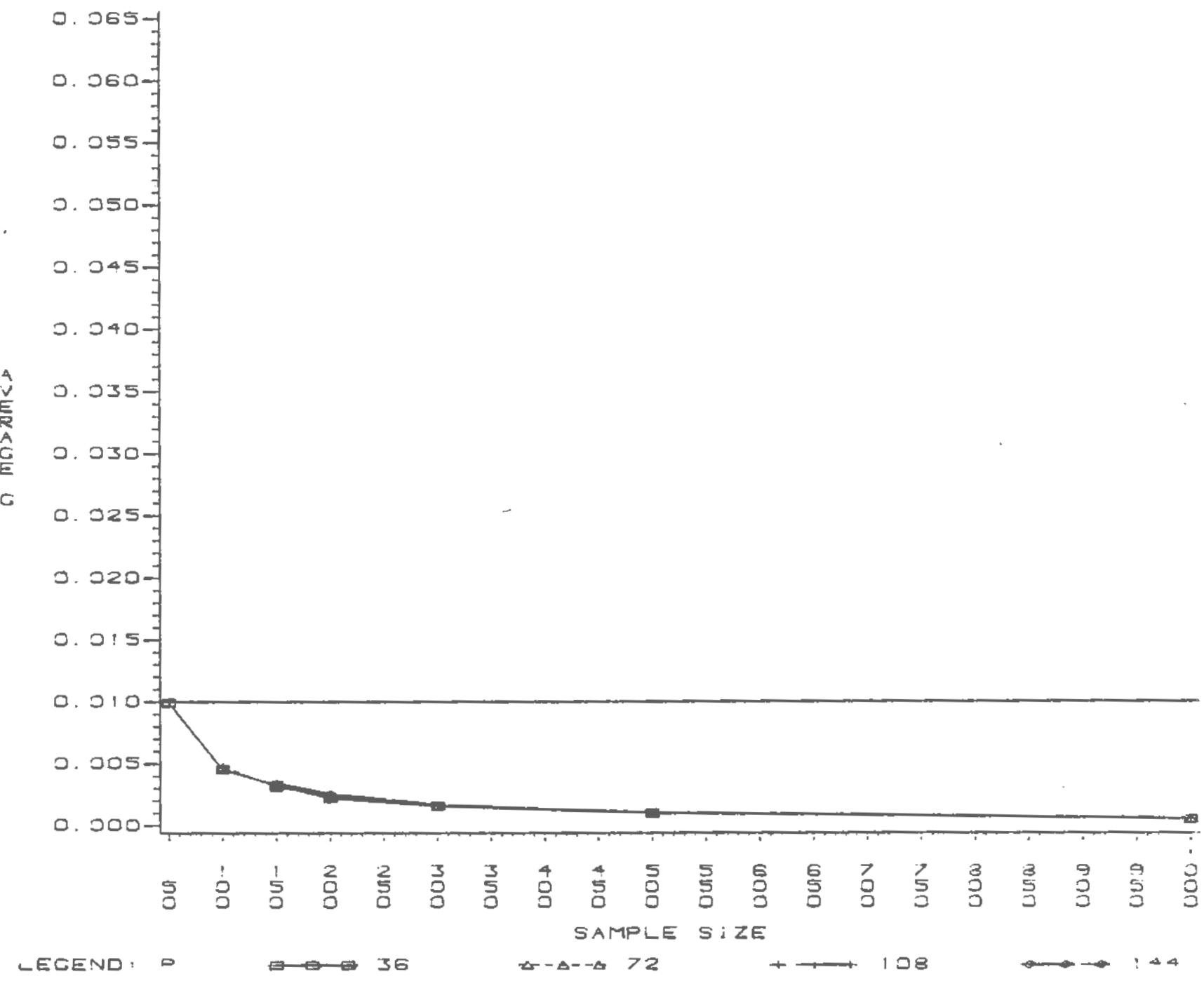




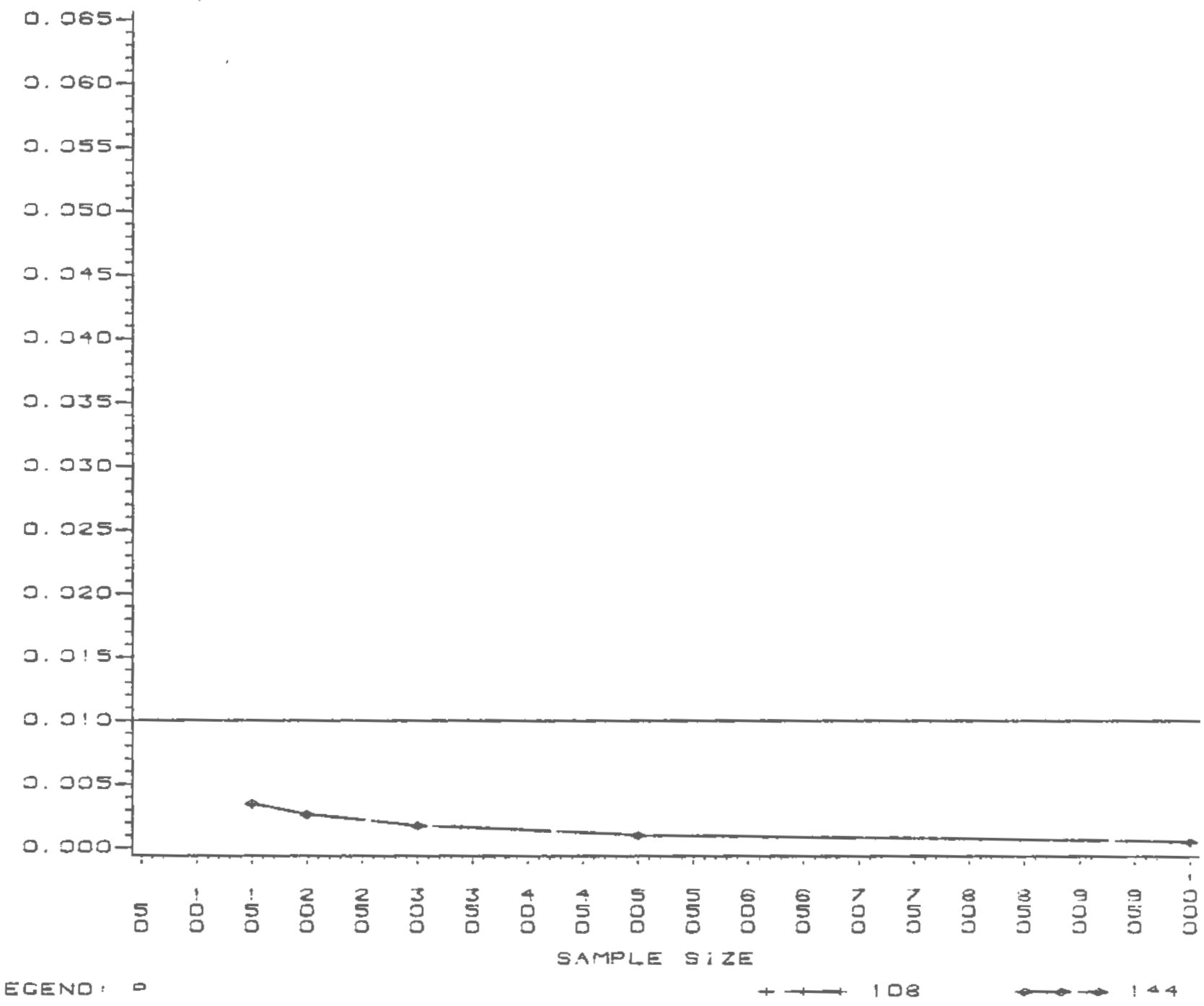


Appendix c 
Figure C-1 Average kappa as a Function of Sample size for .40 Component Saturation and 3 components

Figure C-2 Average kappa as a Function of Sample size for .40 component Saturation and 6 components

Figure C-3 average kappa as a Function of sample size for . 40 Component Saturation and 9 Components

Figure C-4 Average kappa as a Function of Sample Size for .40 component Saturation and 18 components 


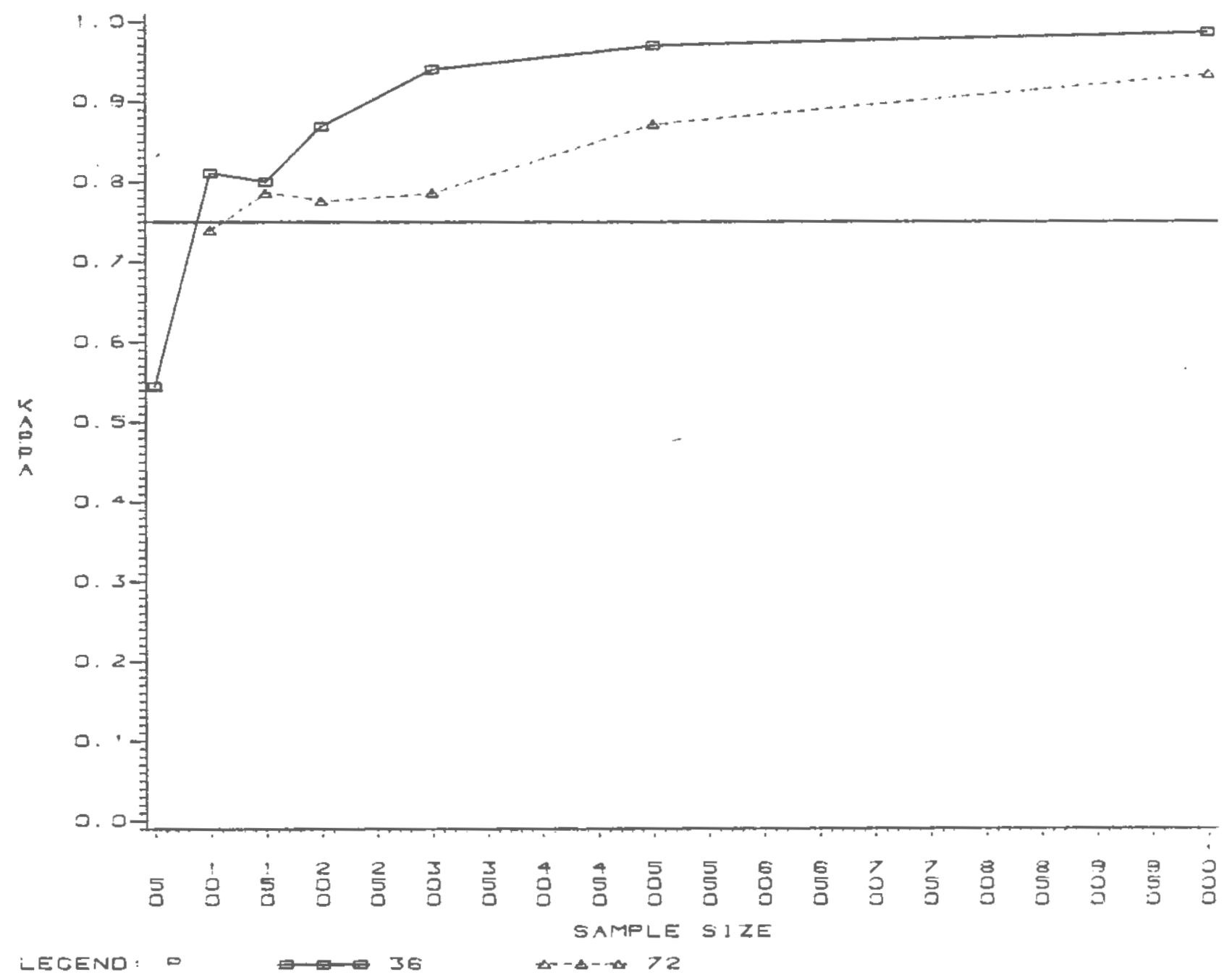




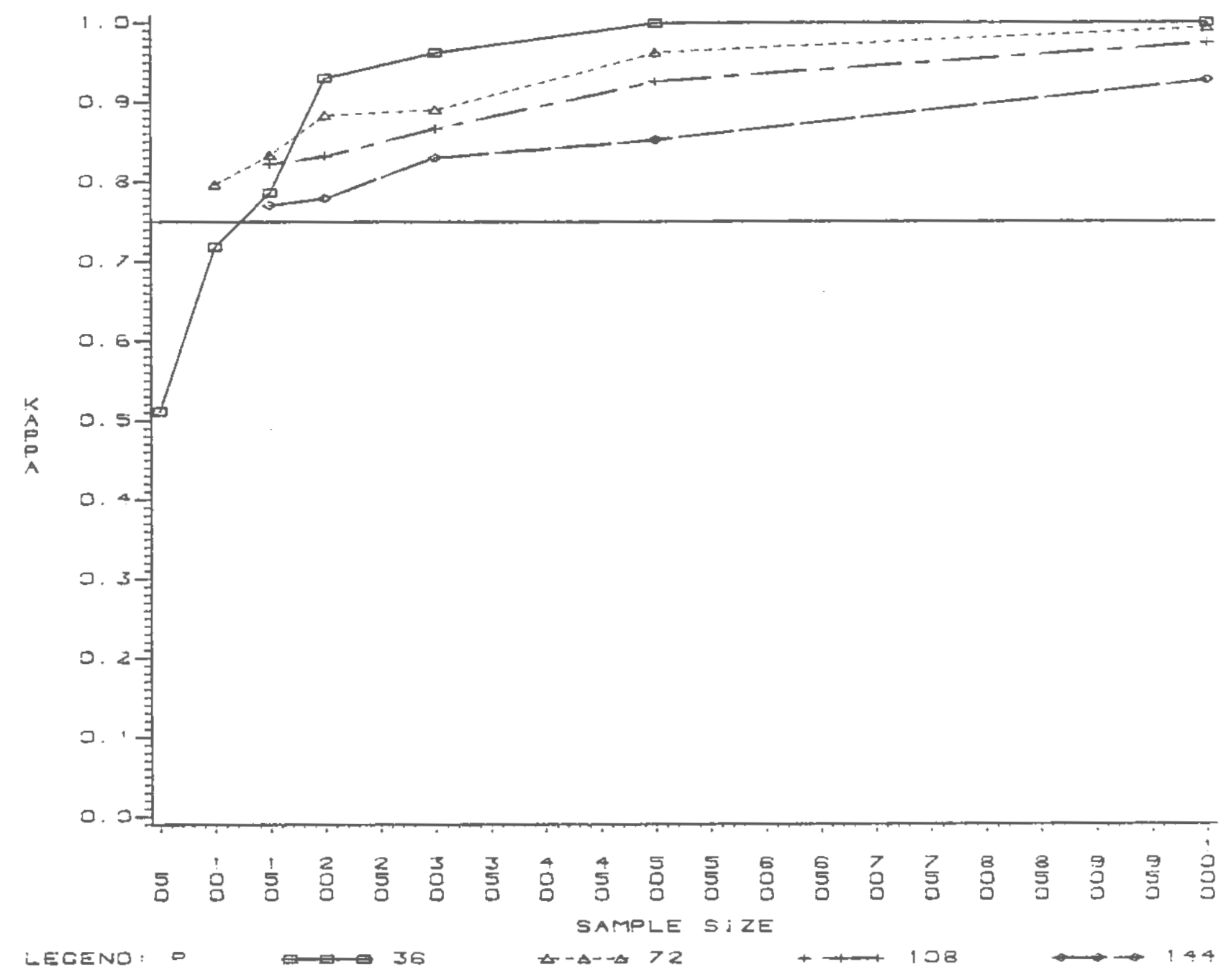




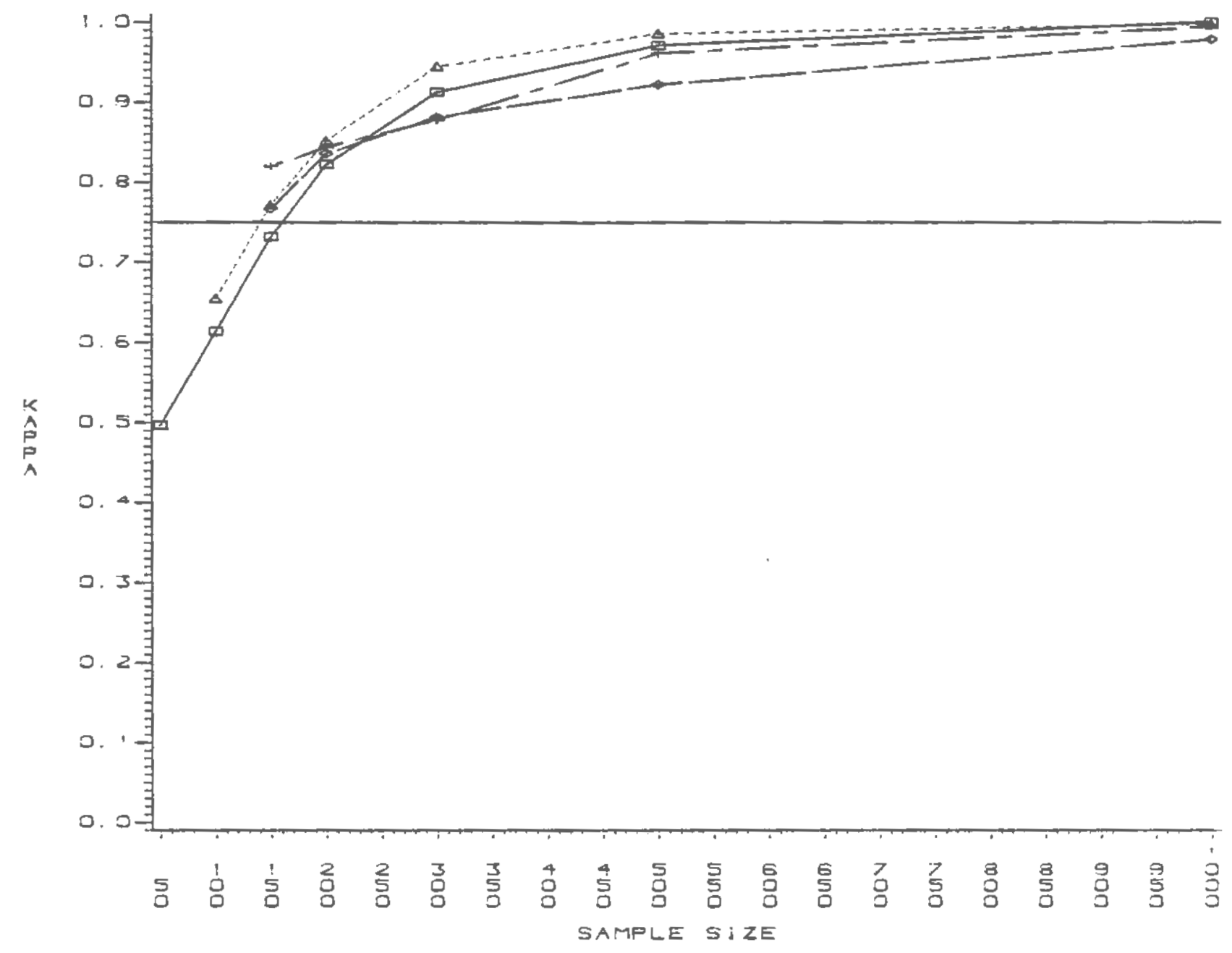

LECEND: D

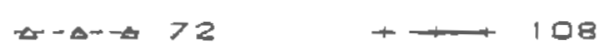




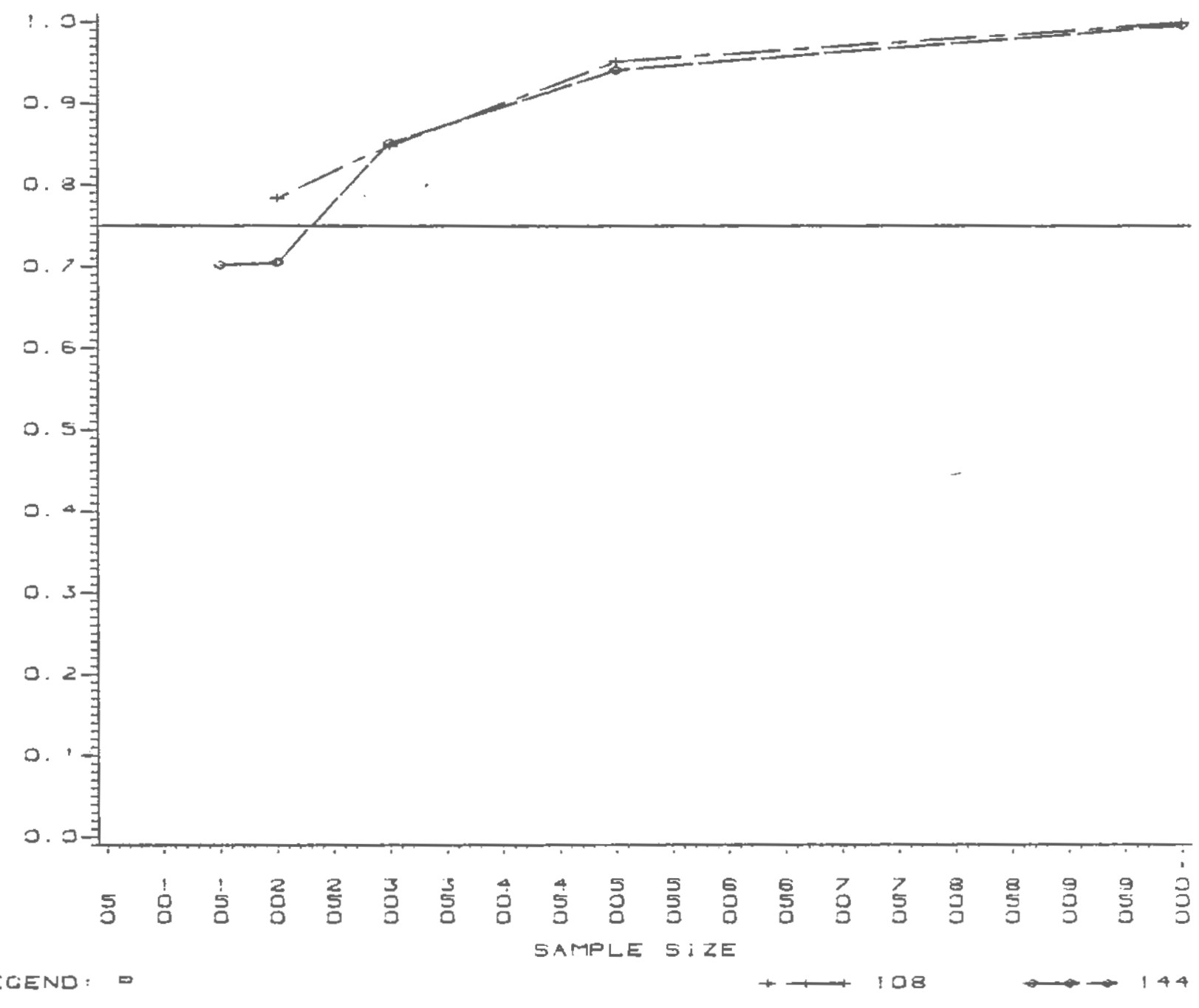


Figure C-5 Average kappa as a Function of Sample size for .60 Component Saturation and 3 components

Figure C-6 Average kappa as a Function of Sample size for .60 Component Saturation and 6 components

Figure C-7 Average kappa as a Function of Sample size for -60 Component saturation and 9 Components

Figure c-8 average kappa as a punction of sample size for -60 component Saturation and 18 components 


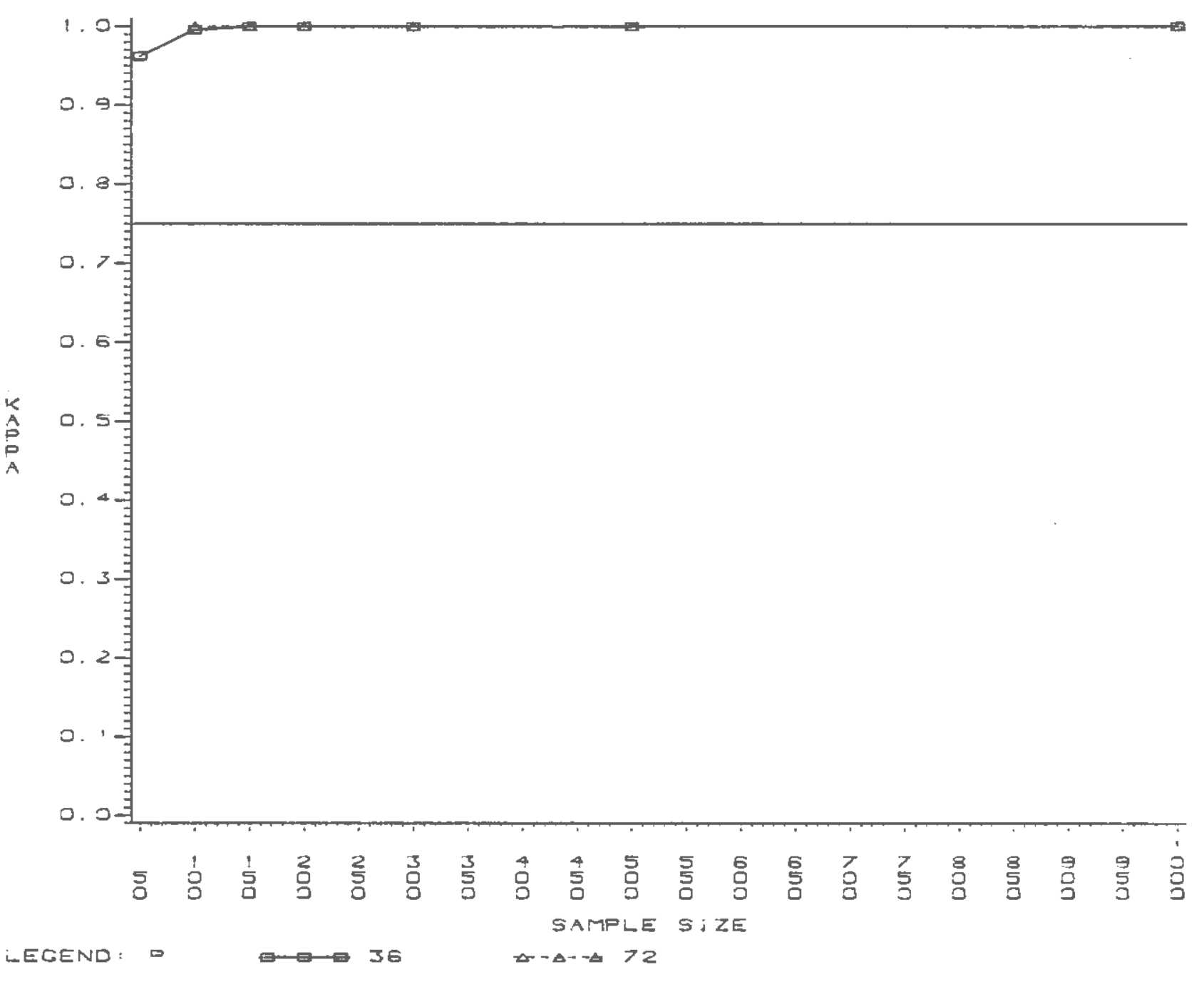




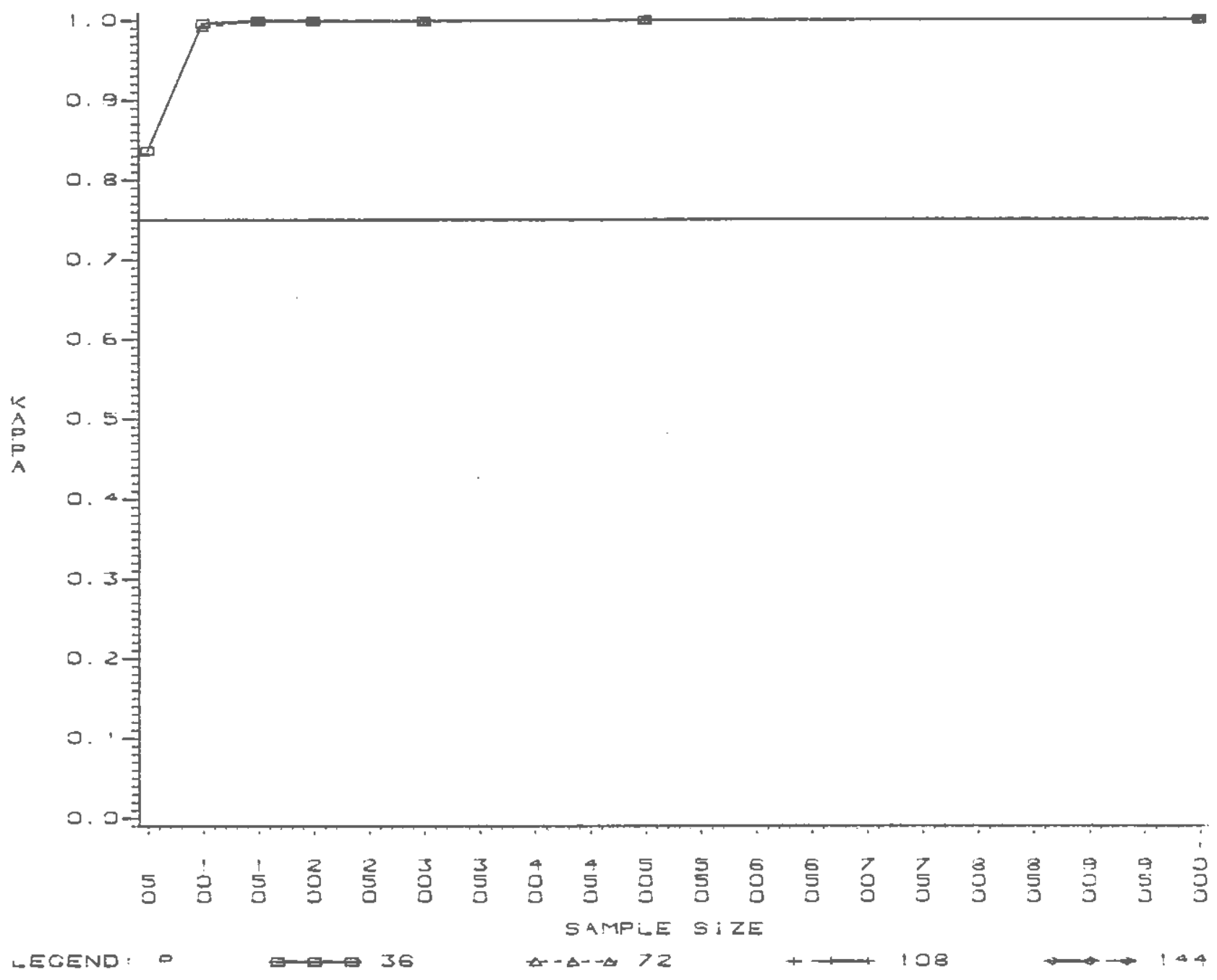




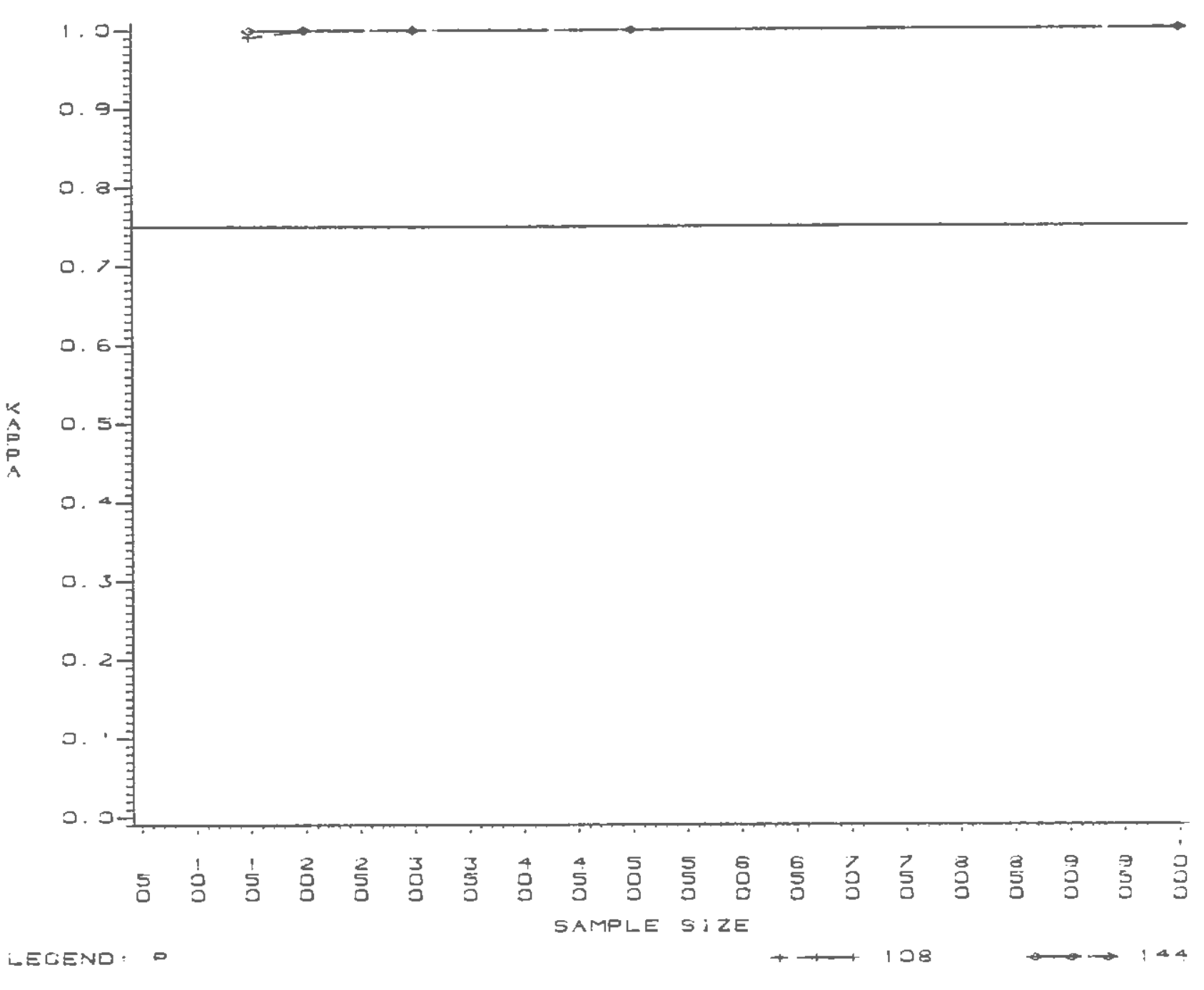


Figure C-9 Average kappa as a Function of Sample size for .80 component saturation and 3 components

Figure C-10 Average kappa as a Function of Sample Size for .80 Component Saturation and 6 components

Figure C-11 Average kappa as a Function of Sample Size for -80 Component Saturation and 9 Components

Figure C-12 Average kappa as a Function of Sample Size for .80 Component Saturation and 18 components 


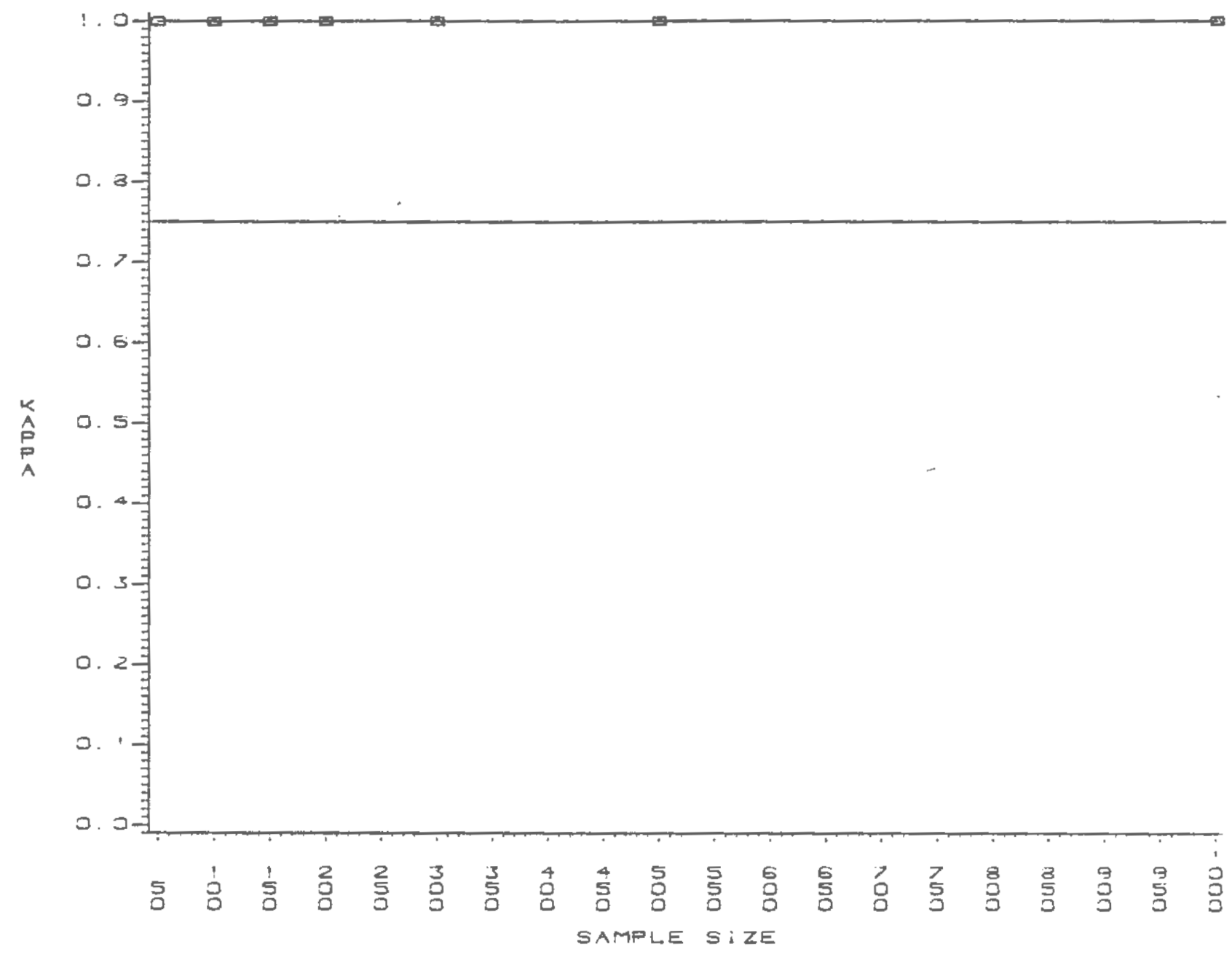




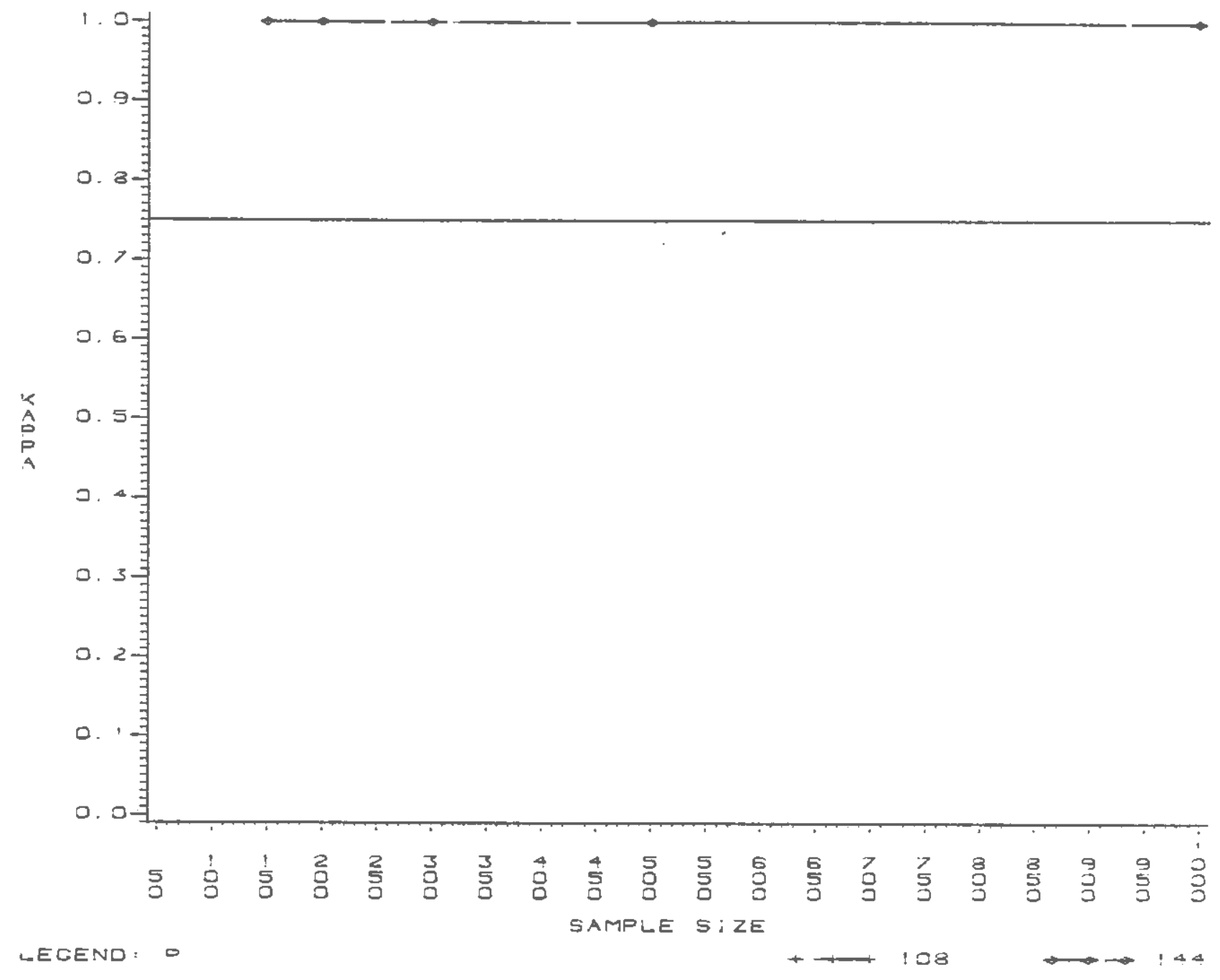


Appendix D 
Figure D-1 Average Type I Error as a Function of Sample Size for 40 Component Saturation and 3 Components

Figure D-2 Average Type I Error as a Function of Sample Size for -40 Corponent Saturation and 6 components

Figure D-3 Average Type I Error as a Function of Sample size for 40 Component Saturation and 9 Components

Figure D-4 Average Type I Error as a Function of Sample Size for 40 Component Saturation and 18 components 


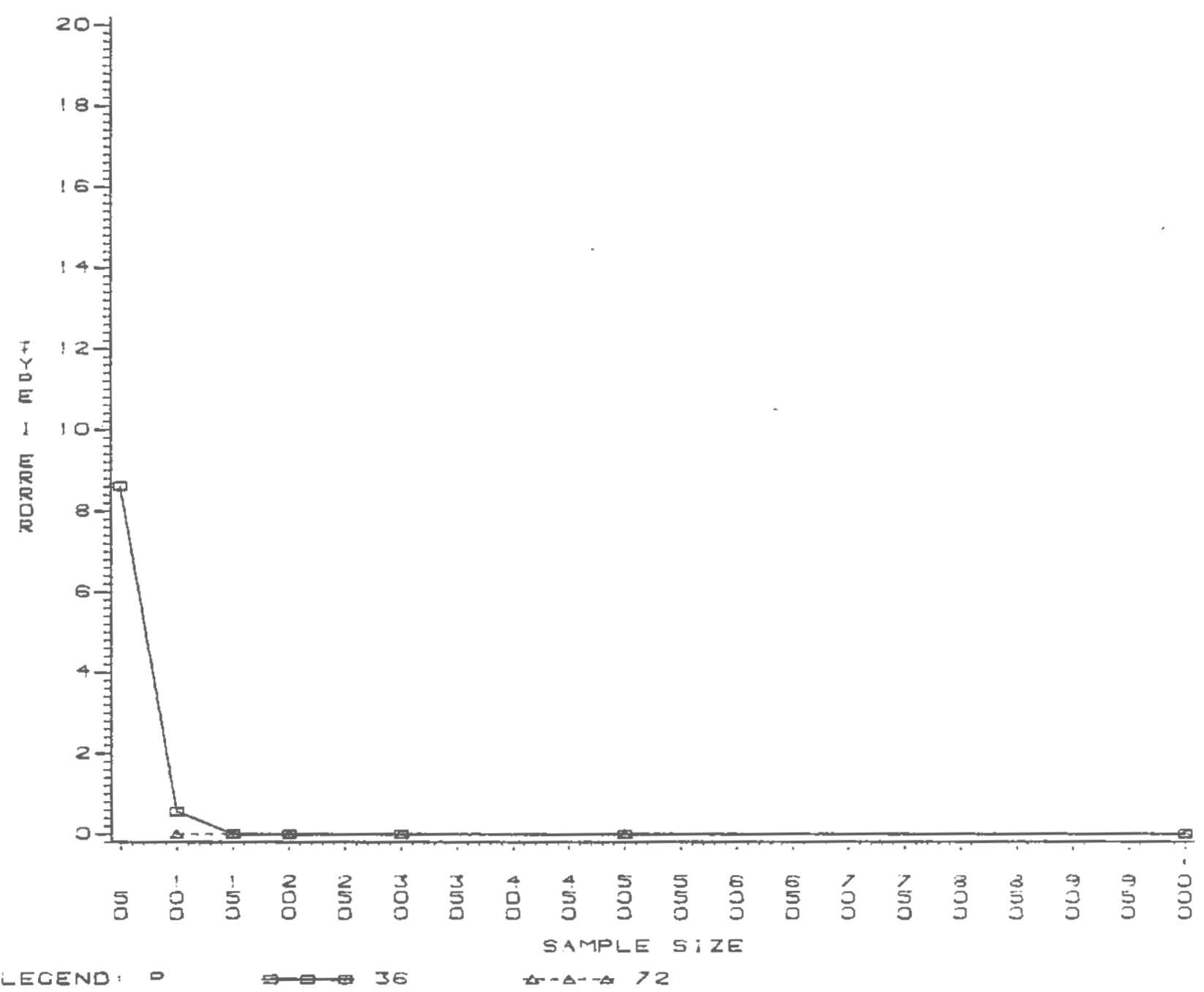




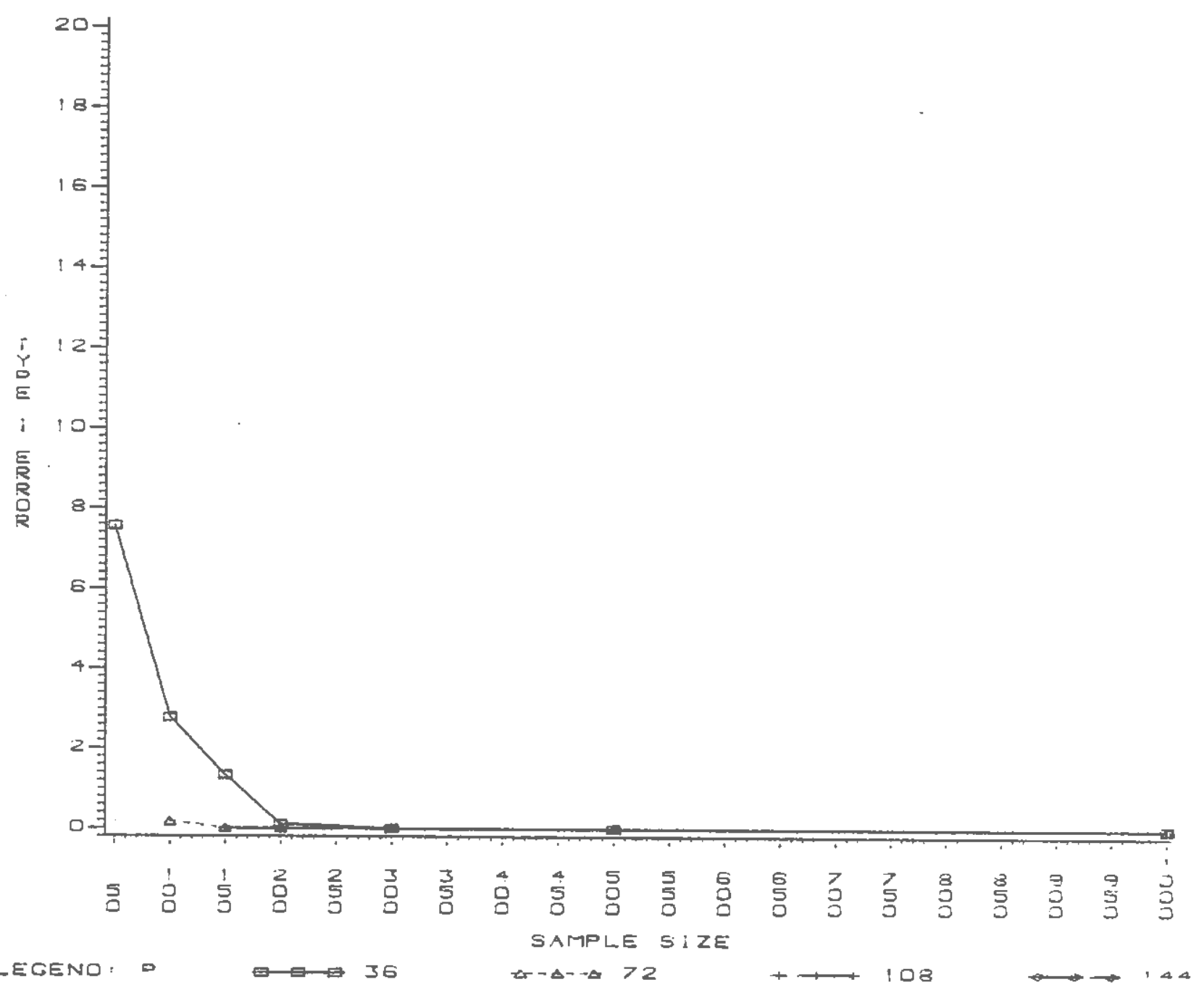




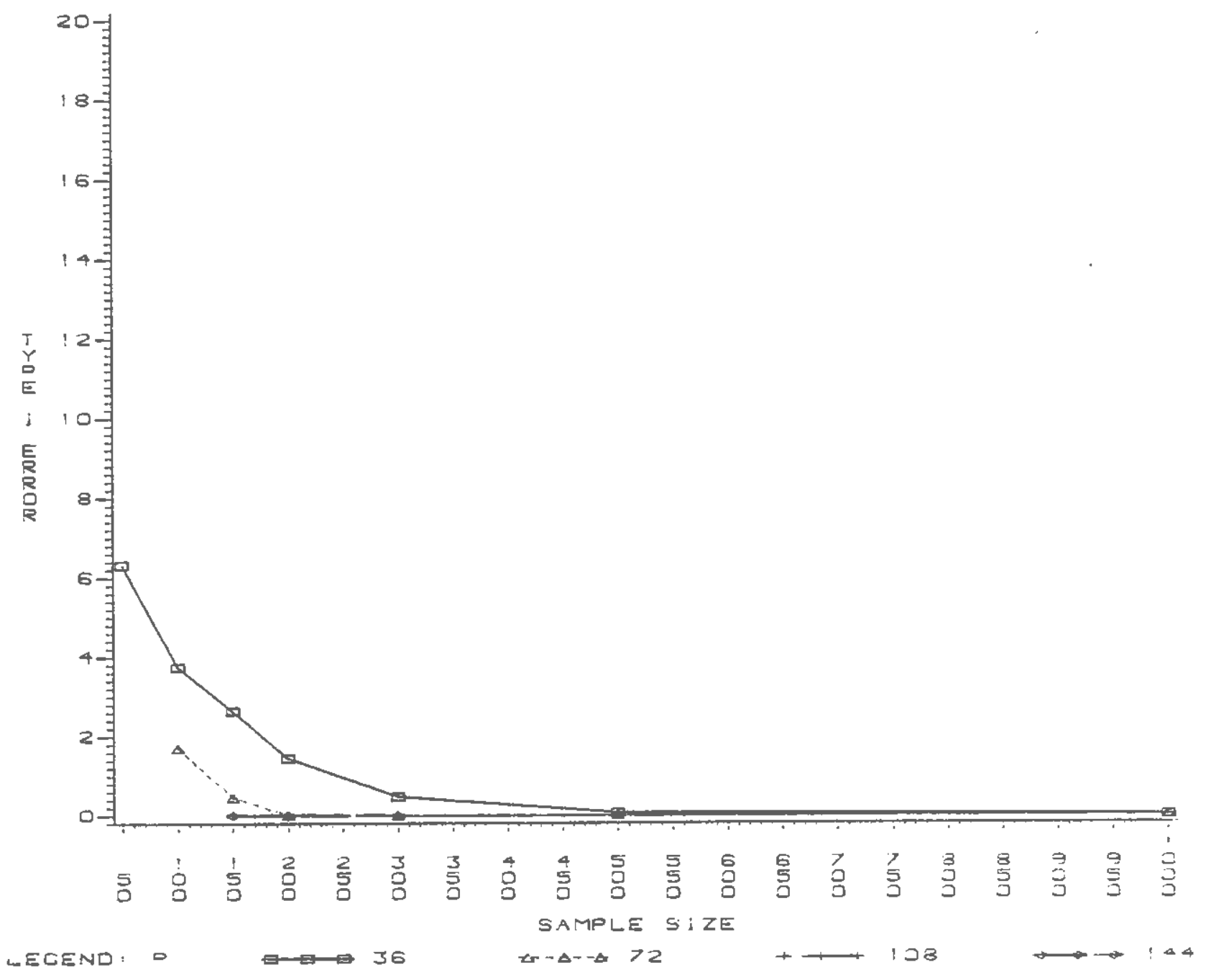




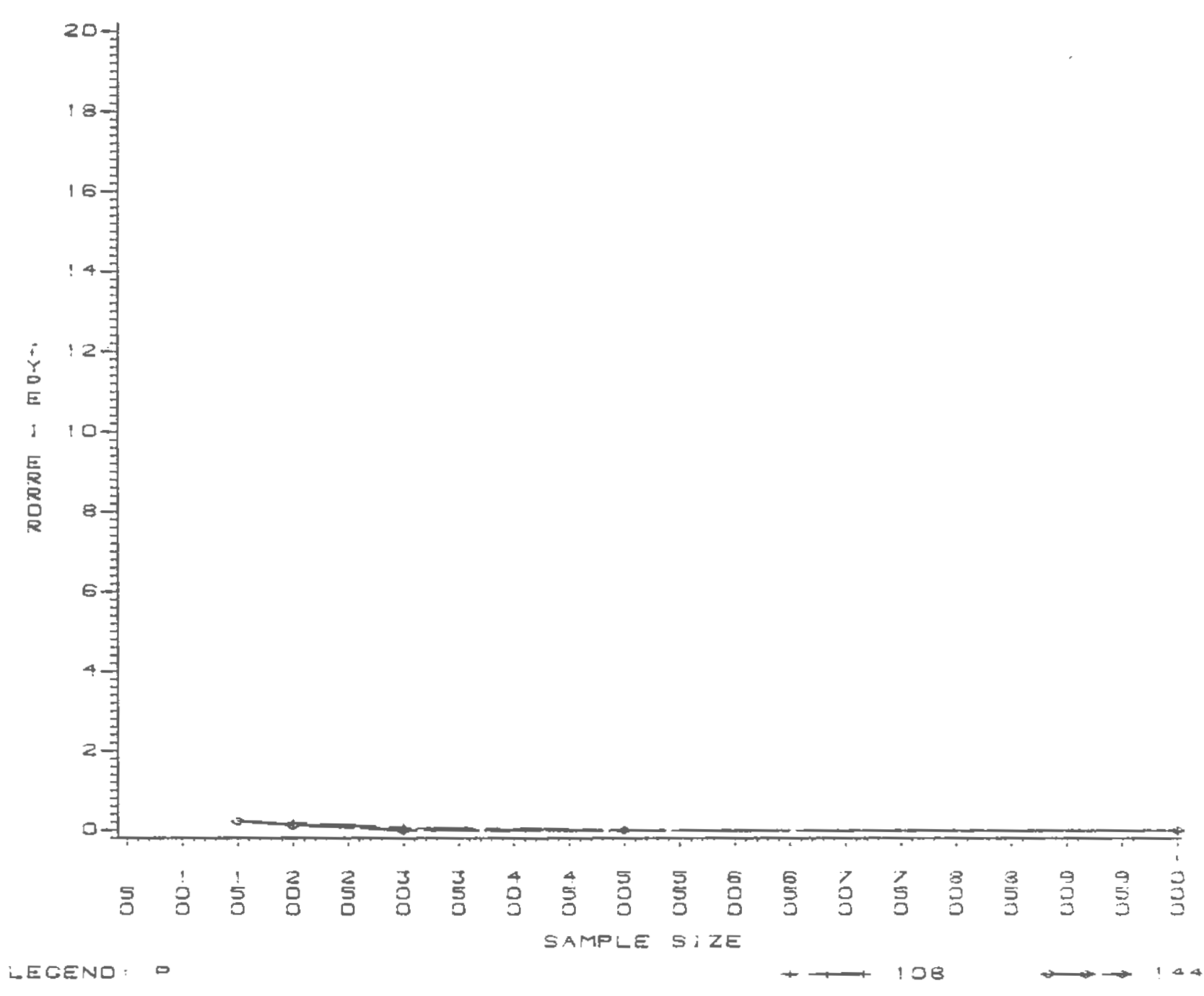


Figure D-5 Average Type I Error as a Function of Sample Size for . 60 component Saturation and 3 Components

Figure D-6 Average Type I Error as a Function of Sample Size for . 60 Component Saturation and 6 components

Figure D-7 Average Type I Error as a Function of Sample Size for . 60 Component Saturation and 9 components

Figure D- 8 Average Type I Error as a Function of Sample Size for . 60 Component Saturation and 18 Components 


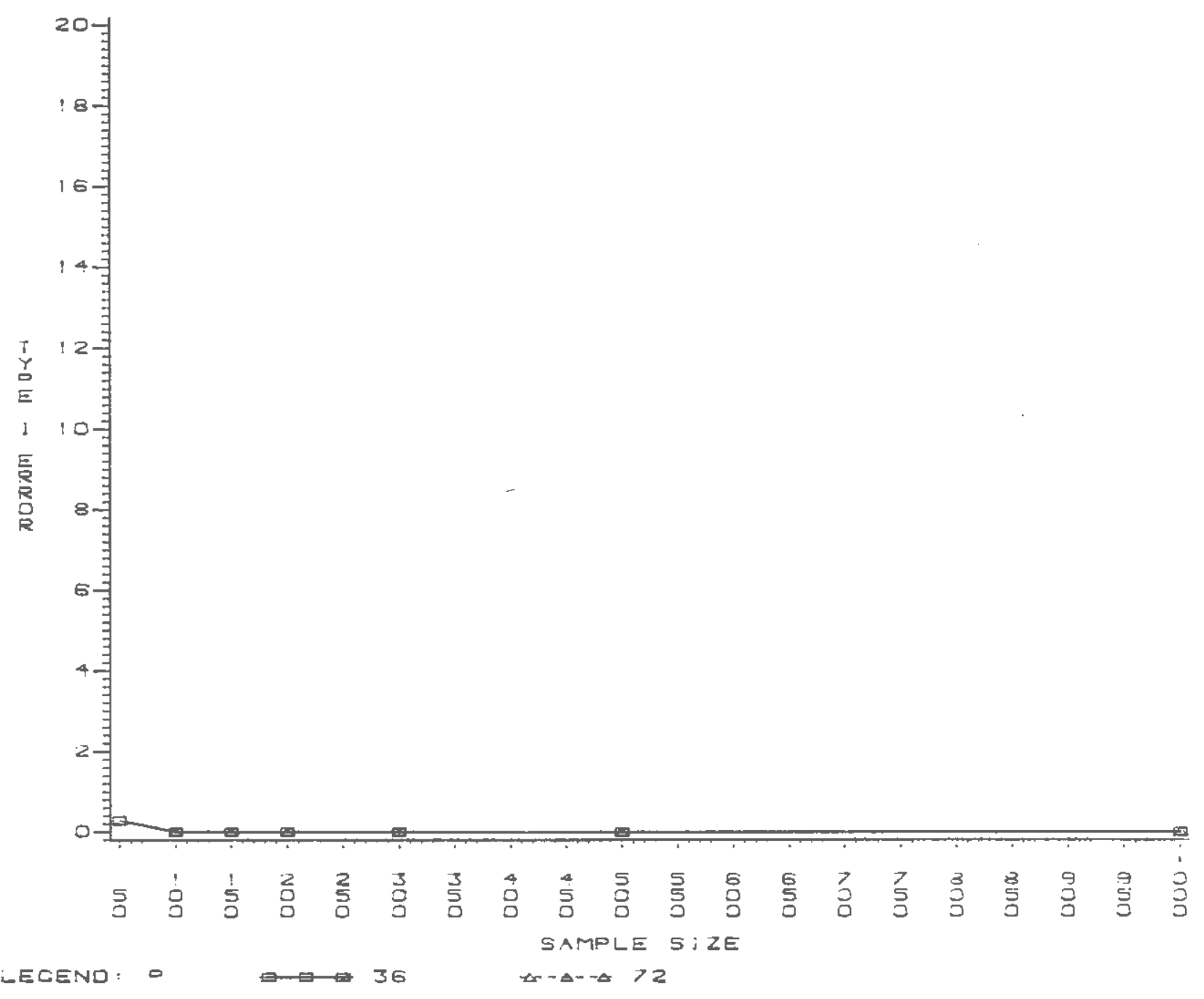




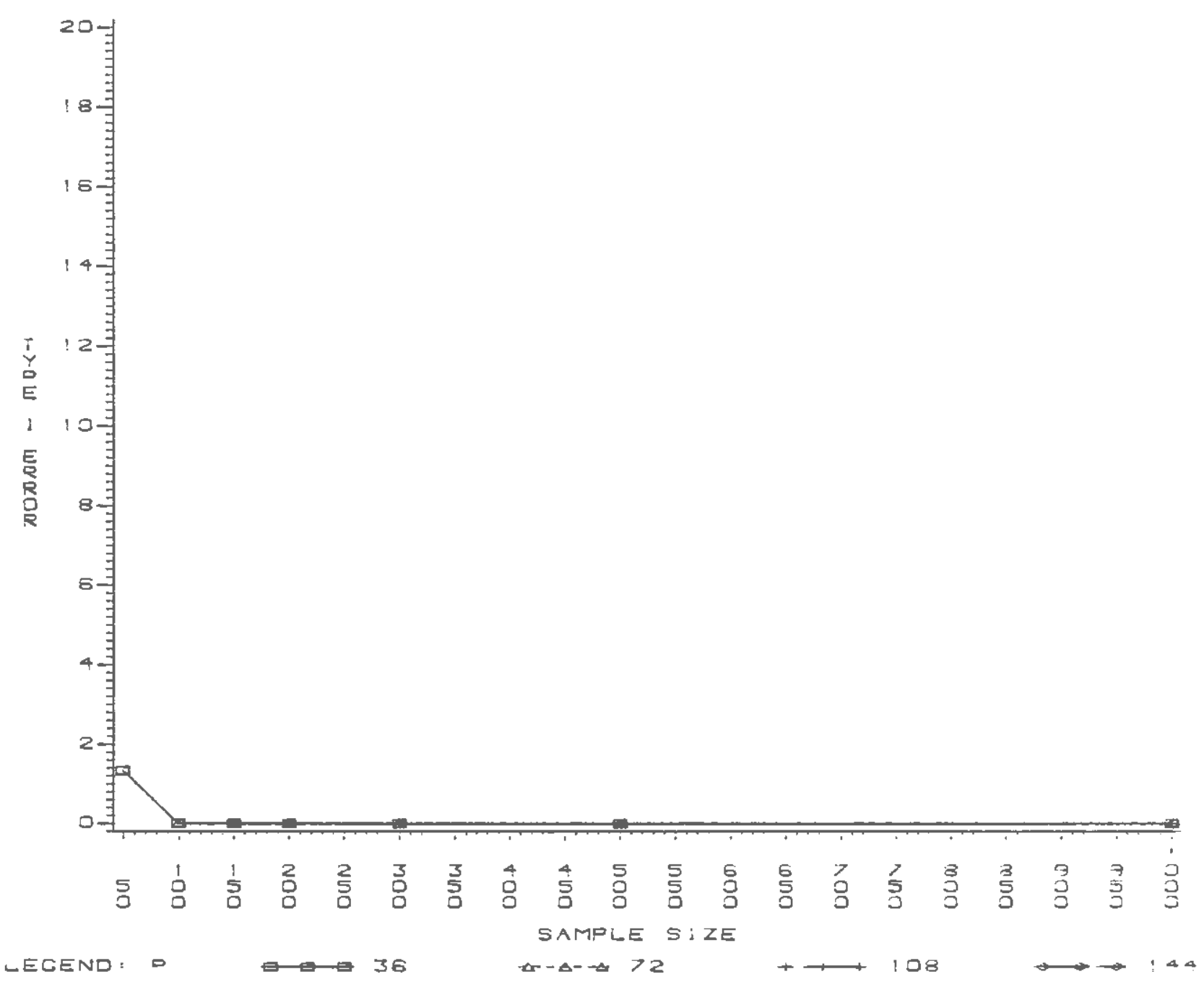




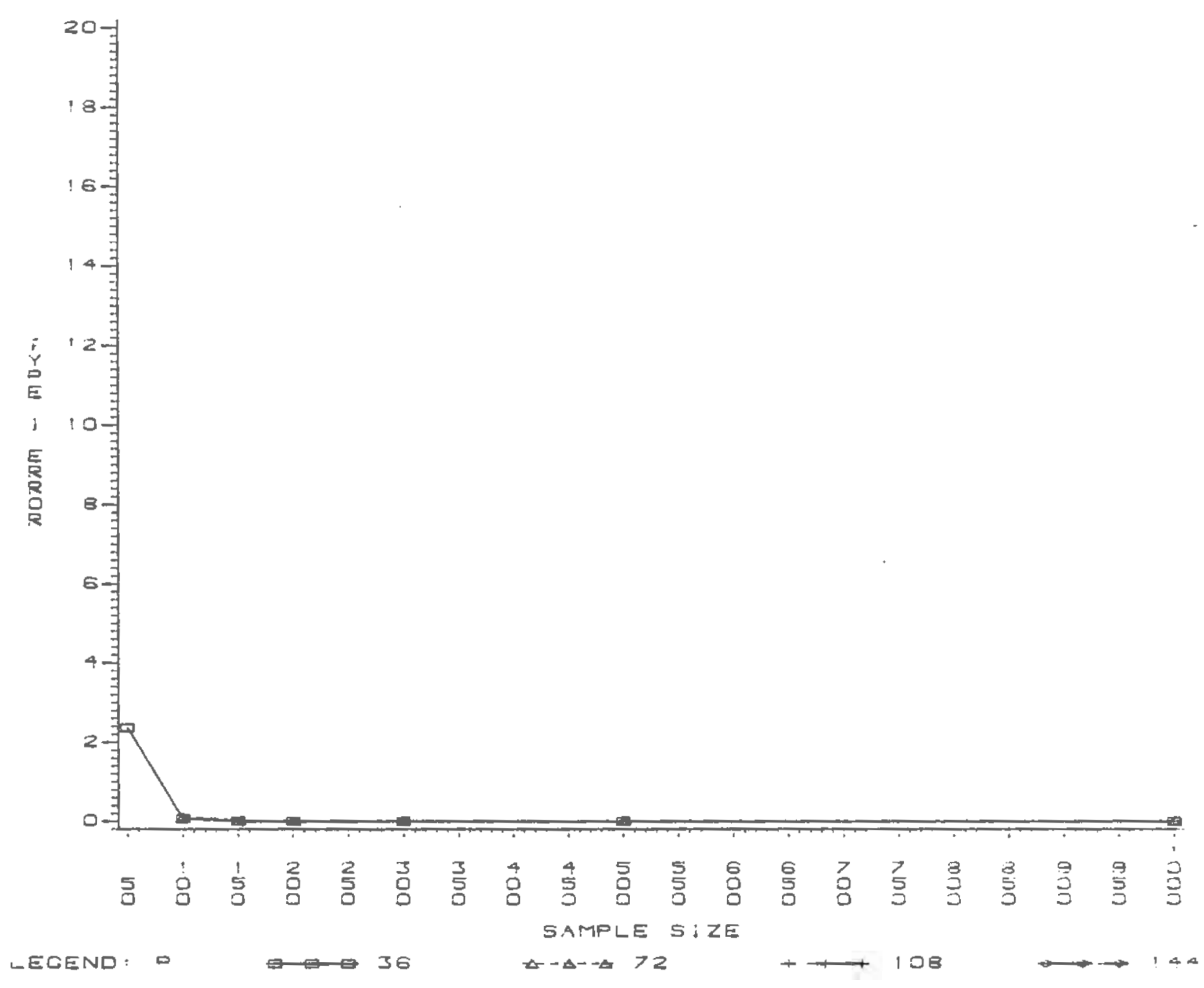




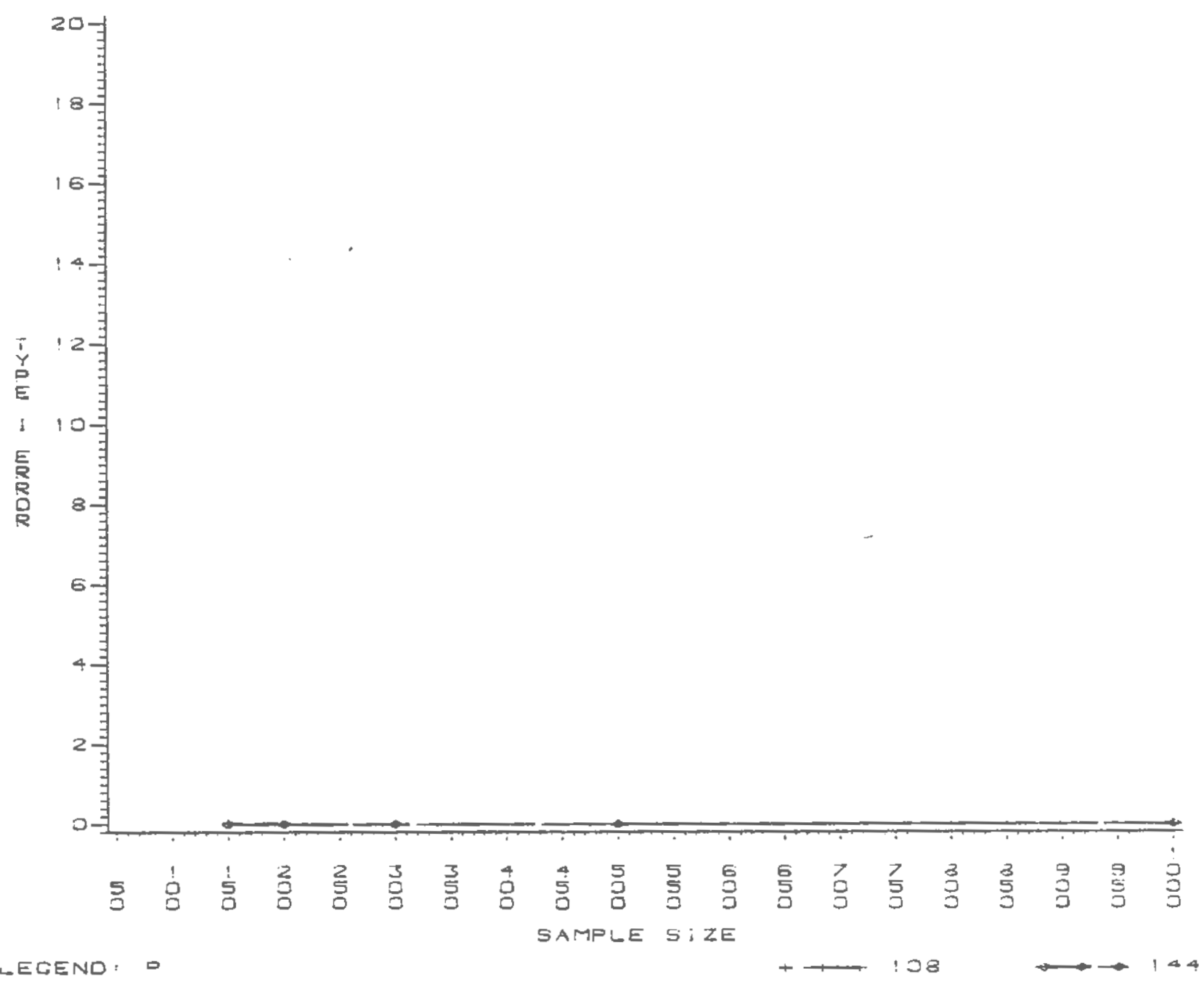


Figure D-9 Arerage Type I Error as a Function of Sample Size for -80 component Saturation and 3 components

Figure D-10 Average Type I Error as a Function of Sample Size for . 80 component Saturation and 6 components

Figure D-11 Average Type I Error as a Function of Sample size for .80 component Saturation and 9 components

Figure D-12 Average Type I Error as a Function of Sample Size for .80 component Saturation and 18 components 


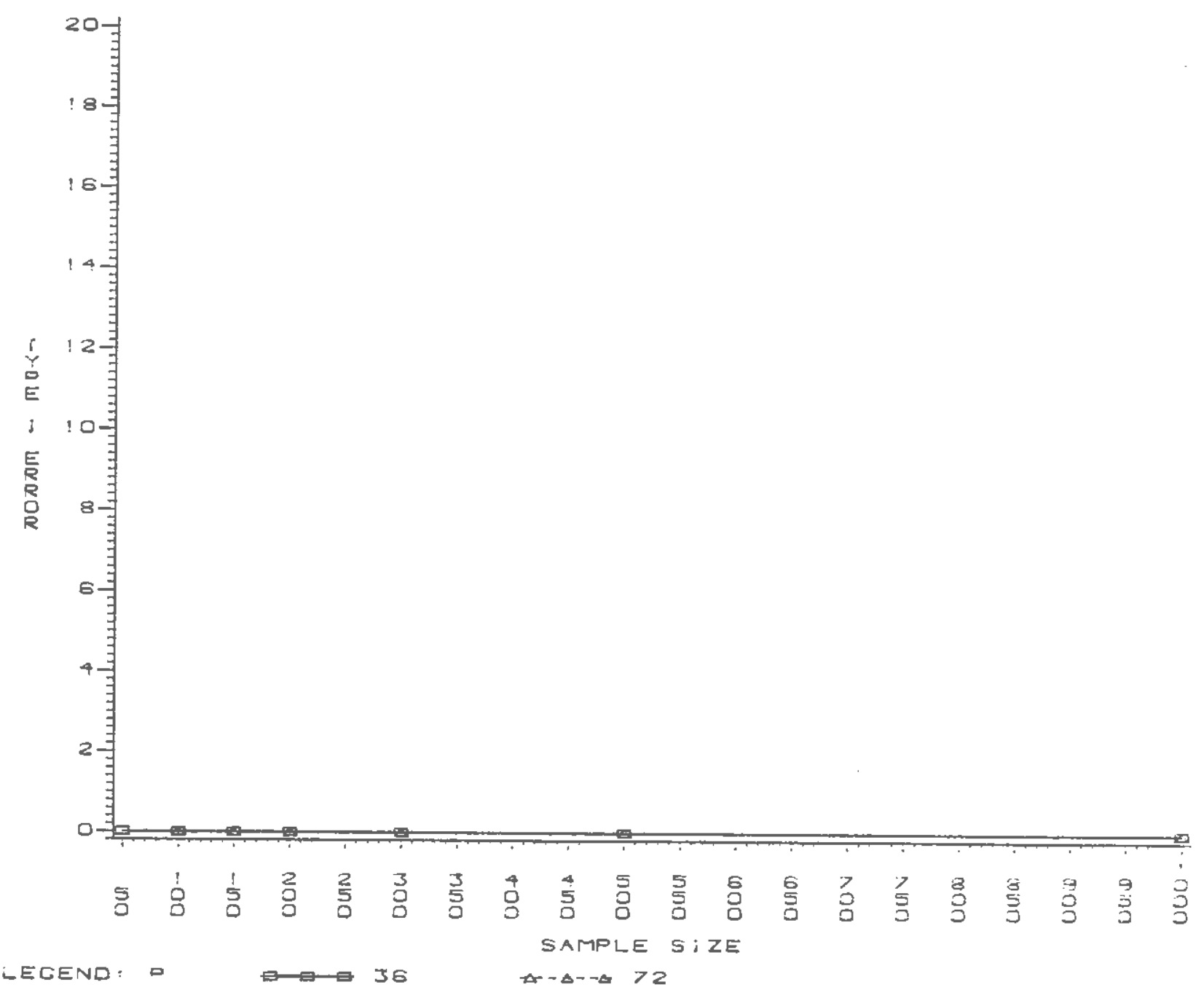




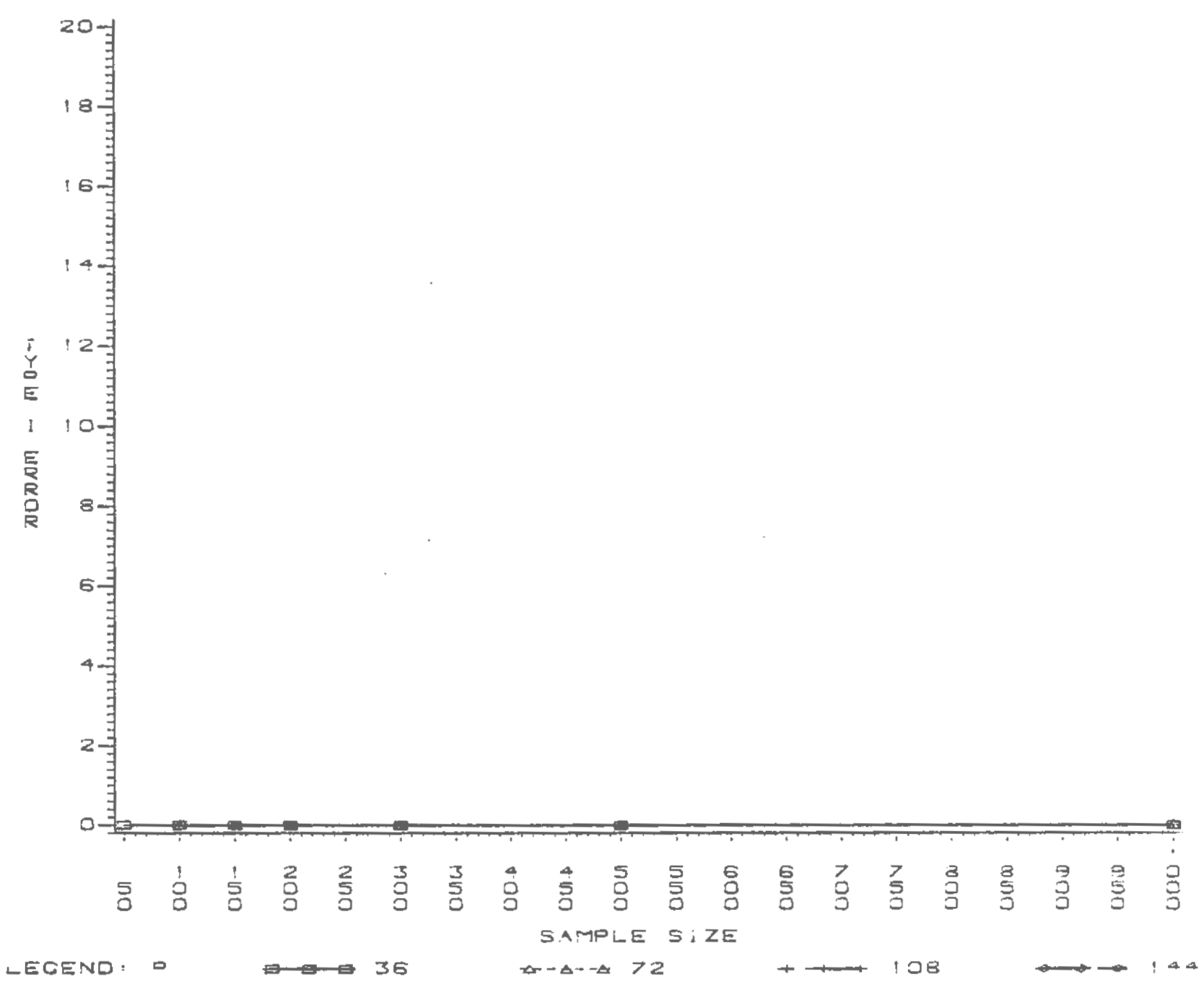




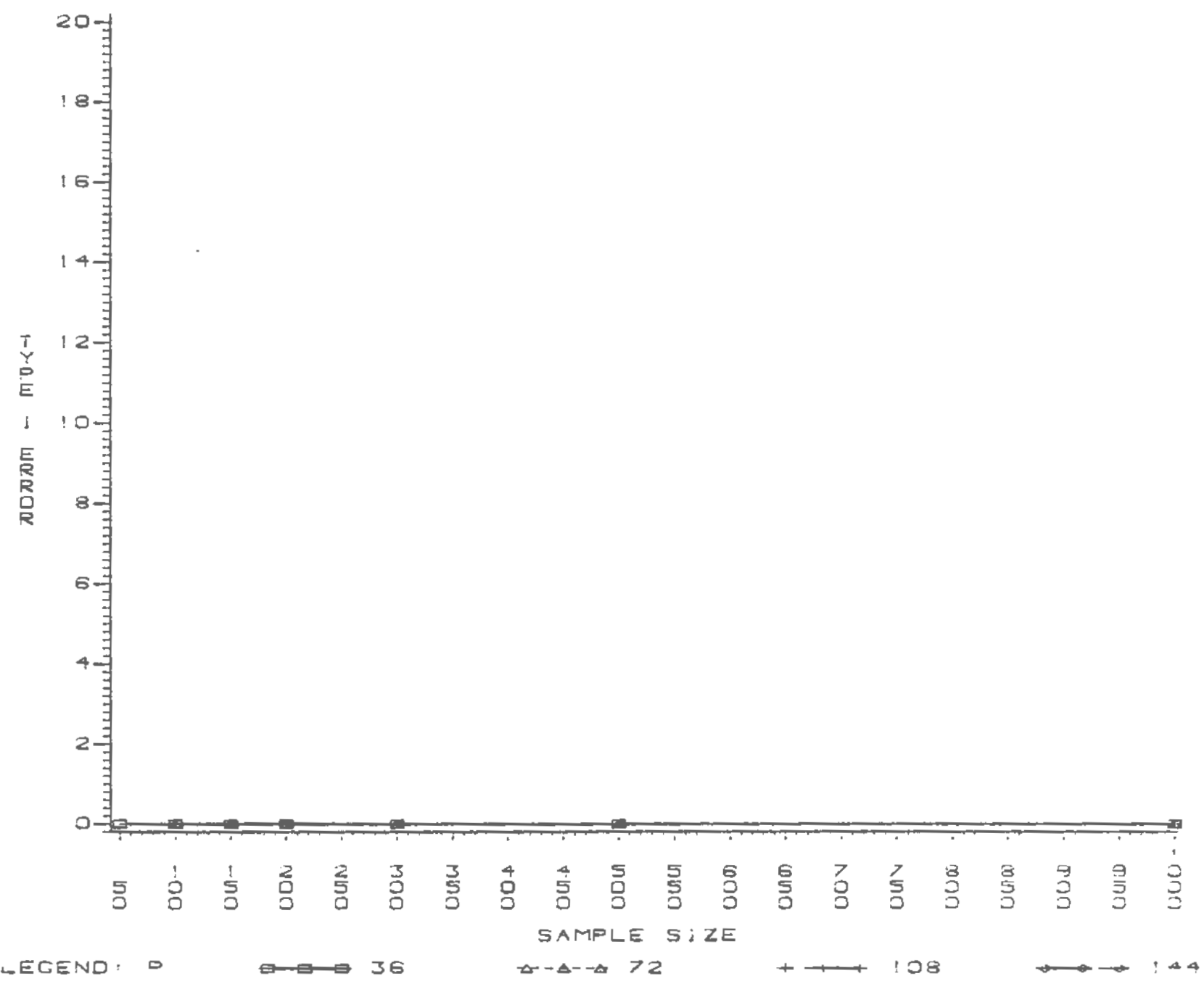




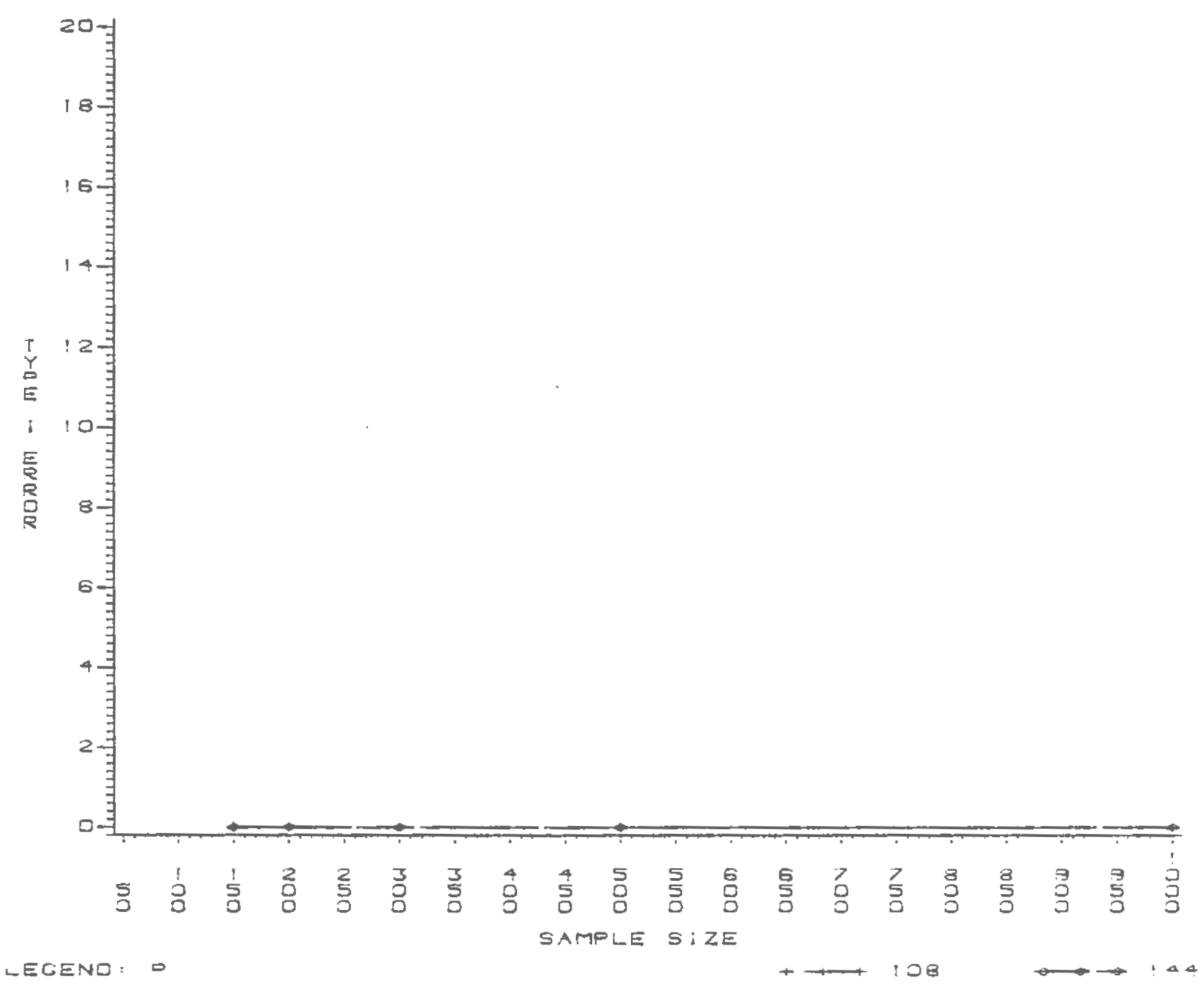


Appendix $\mathrm{E}$ 
Figure 8-1 Average Type II Error as a Punction of Sample Size for 40 Component Saturation and 3 Conponents

Figure E-2 Average Type II Error as a Function of Sample Size for 40 Component Saturation and 6 components

Figure E-3 Average Type II Error as a Function of Sample Size for - 40 Component Saturation and 9 components

Pigure E-4 Average Type II Error as a Function of Sample Size for 40 Component Saturation and 18 components 


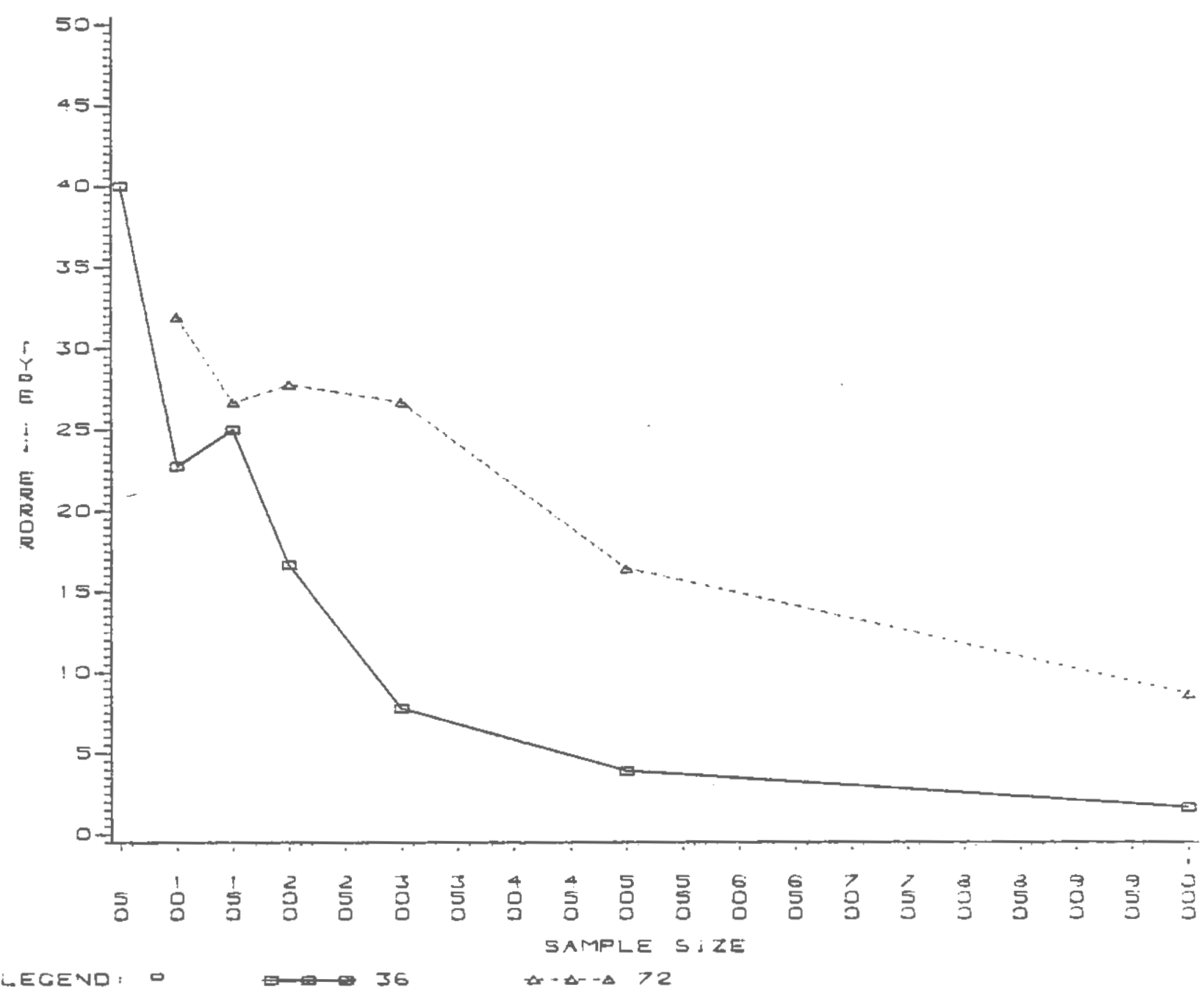




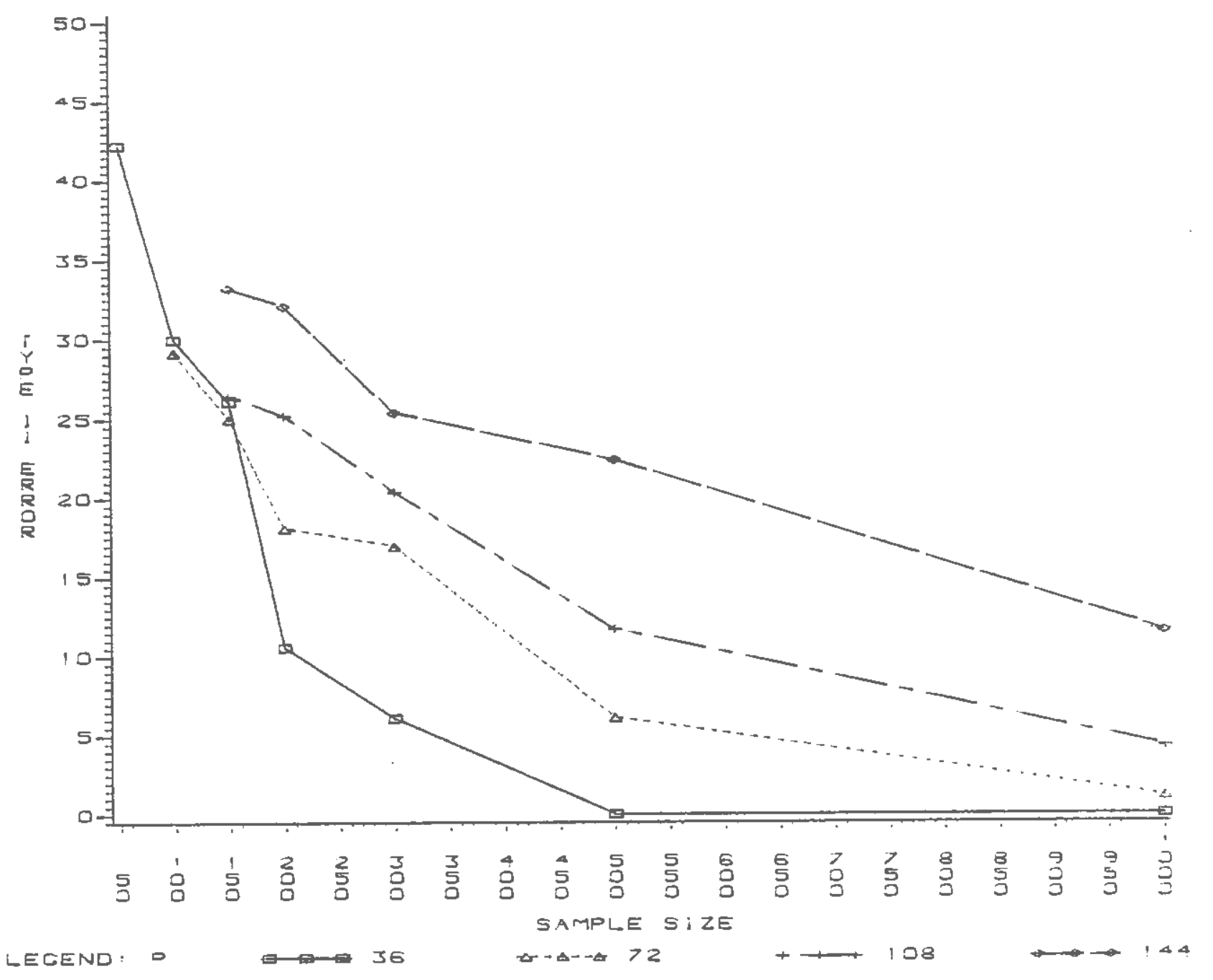




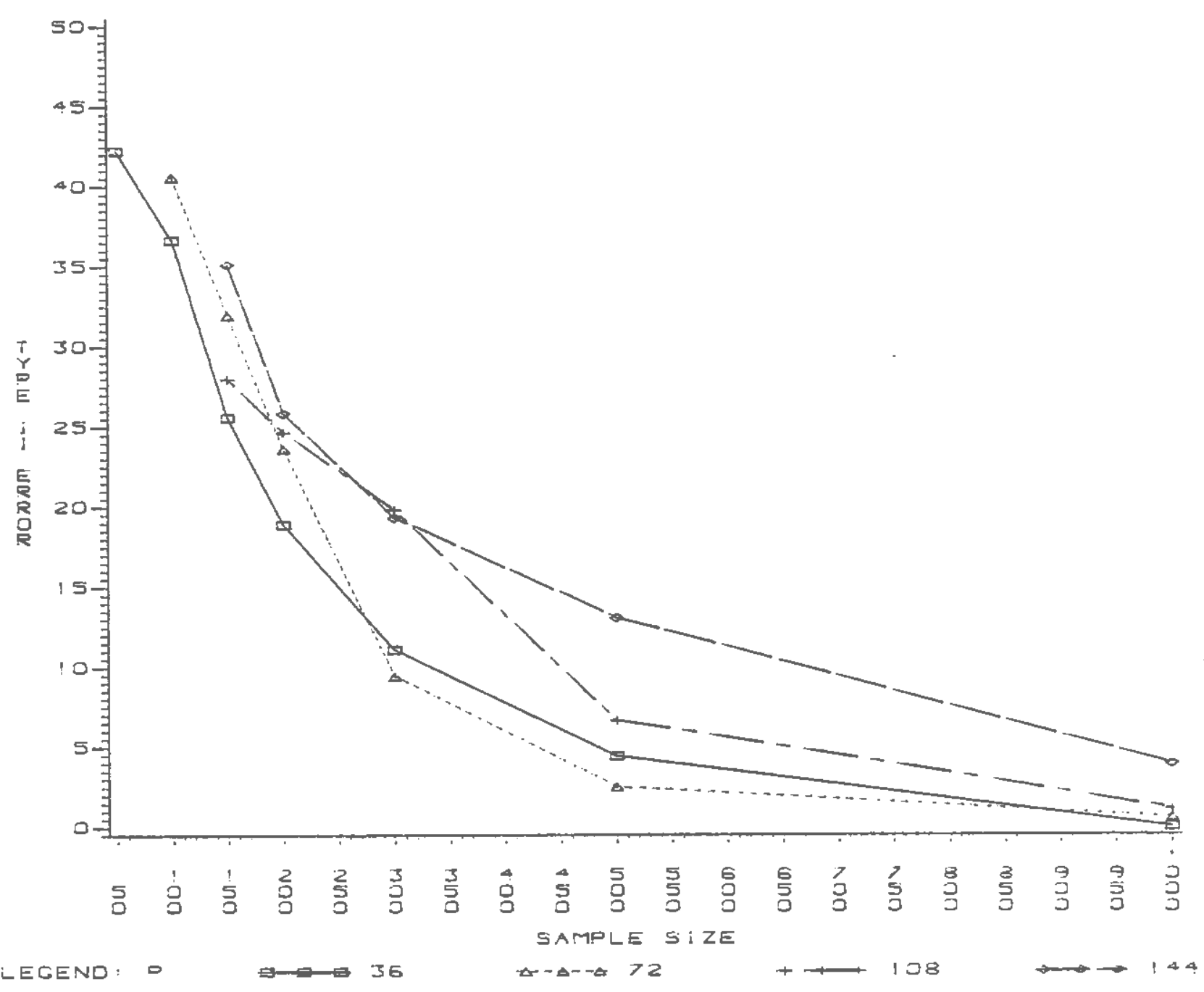




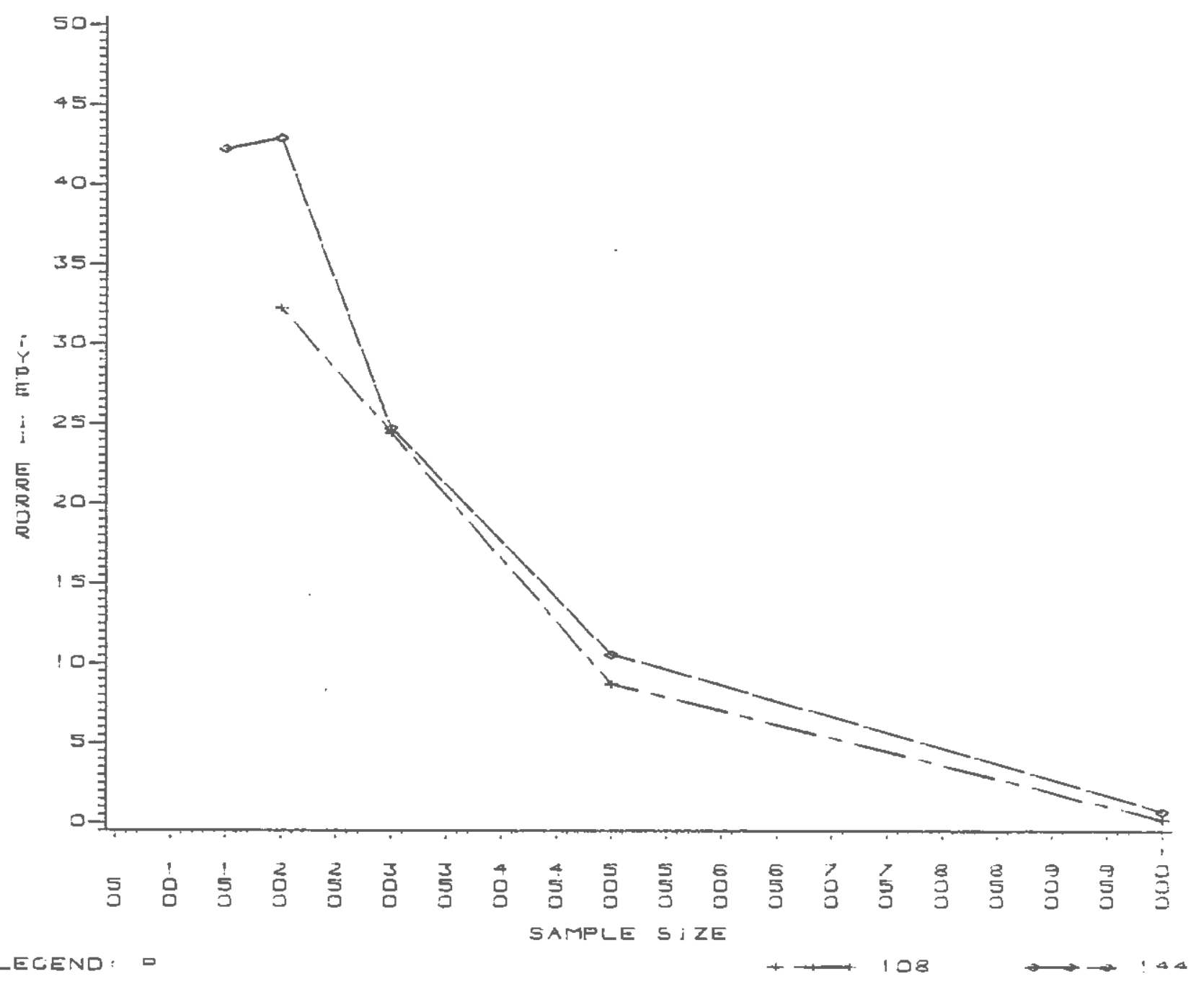


Figure E-5 Average Type II Error as a Function of Sample Size for .60 Component Saturation and 3 components

Figure E-6 Average Type II Error as a Function of Sample size for .60 Component Saturation and 6 components

Pigure $5-7$ Average Type II Error as a Function of Sample size for .60 Component Saturation and 9 Components

Figure E-8 Average Type II Error as a Function of Sample Size for -60 Component Saturation and 18 Components 


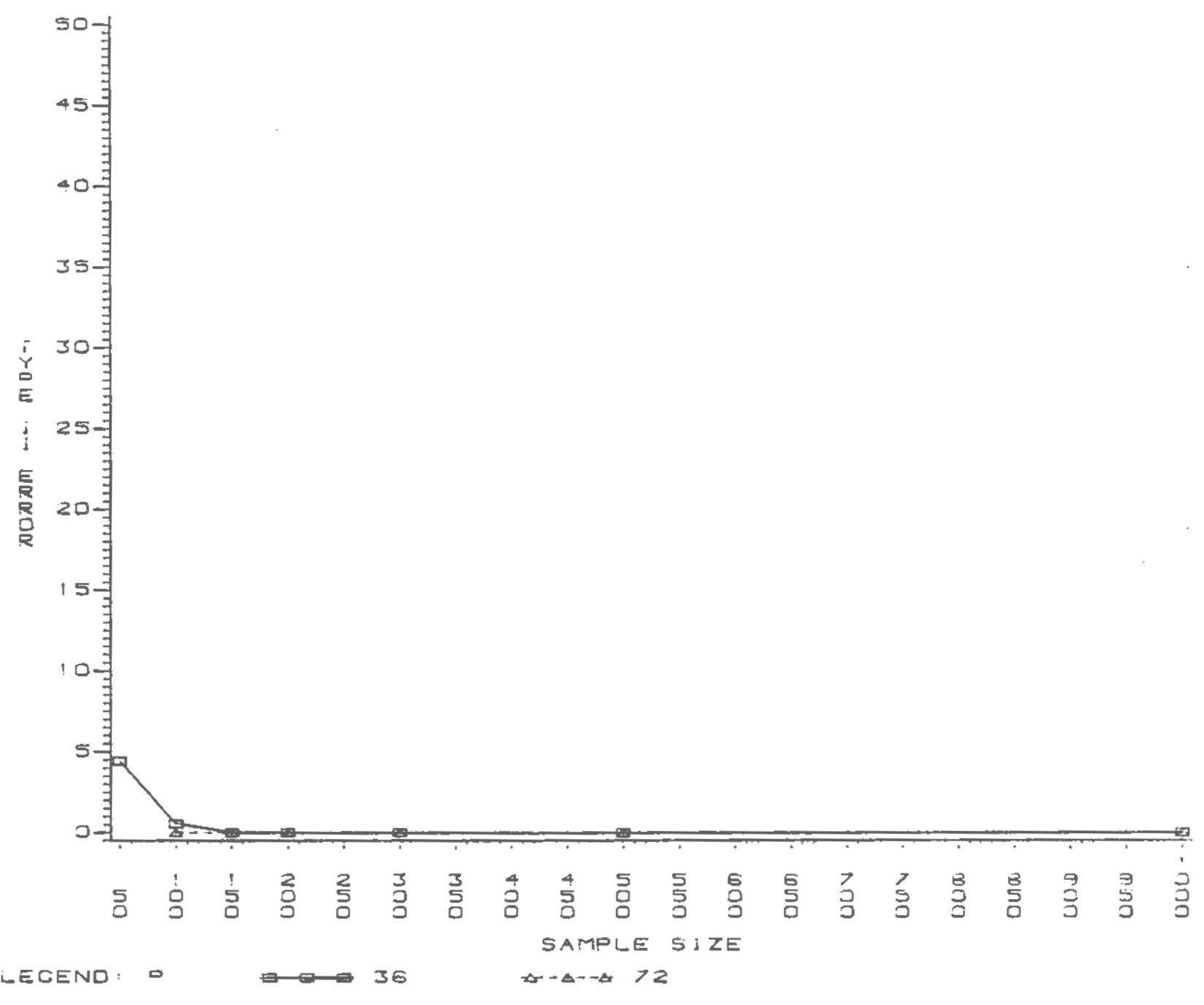




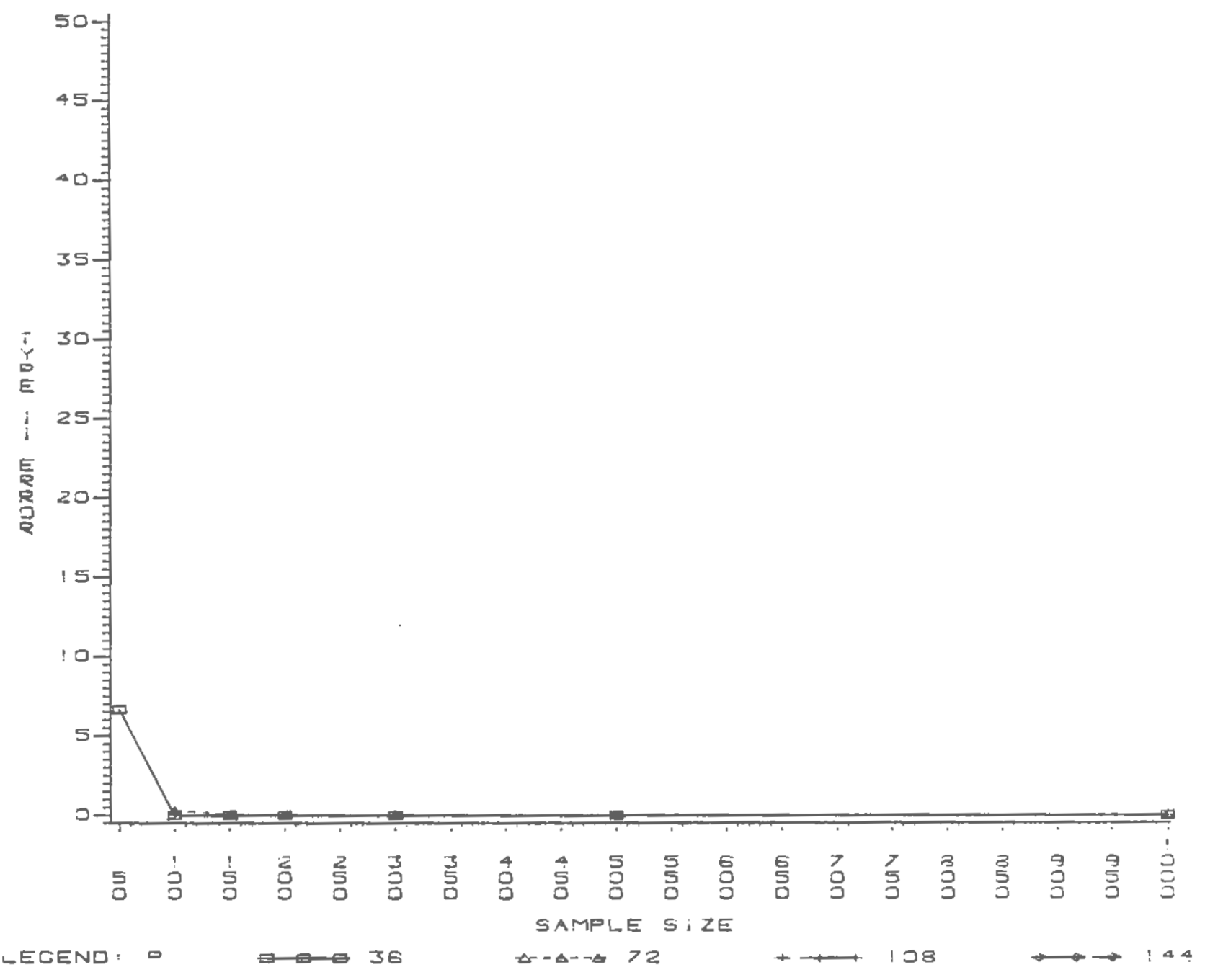




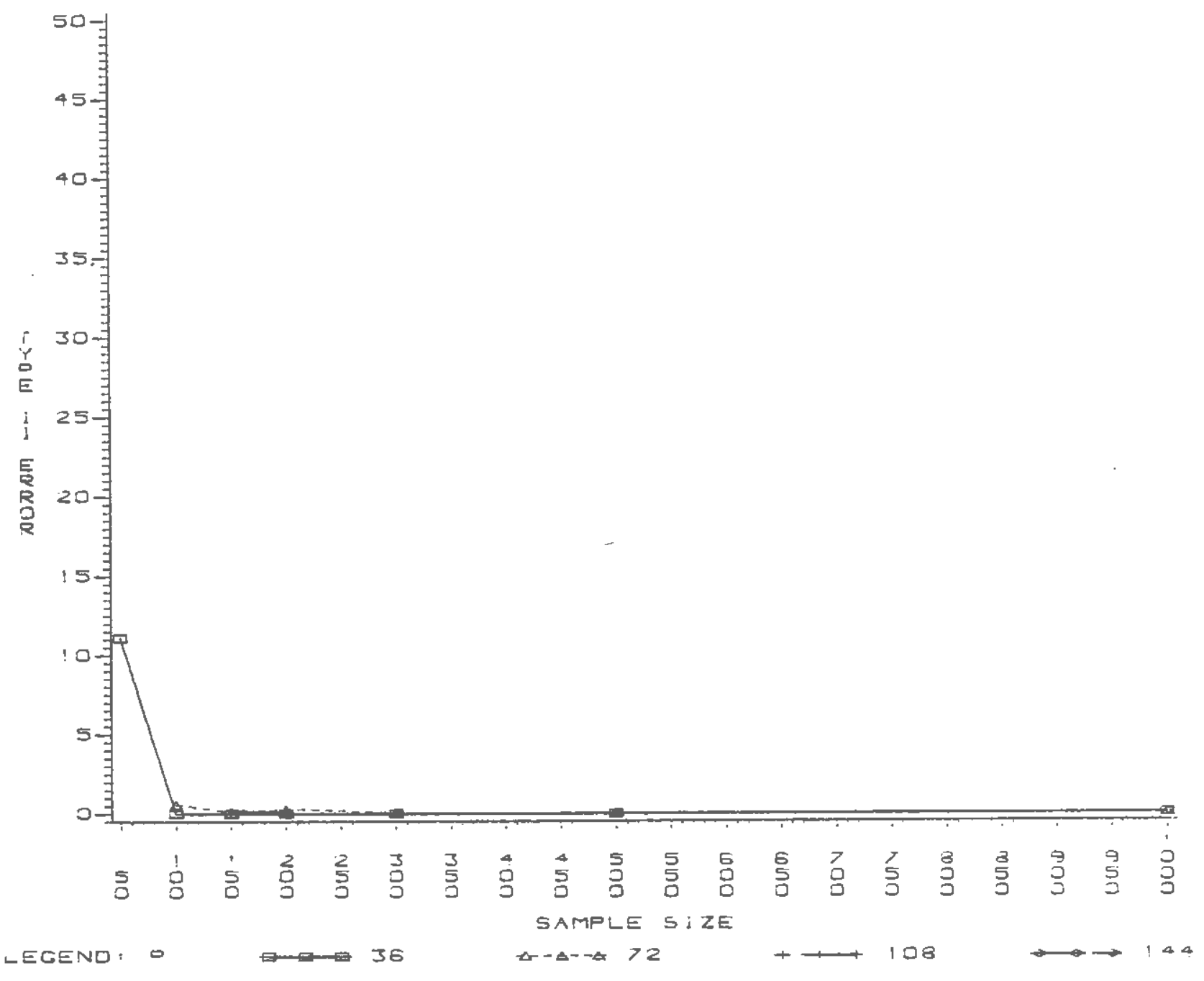




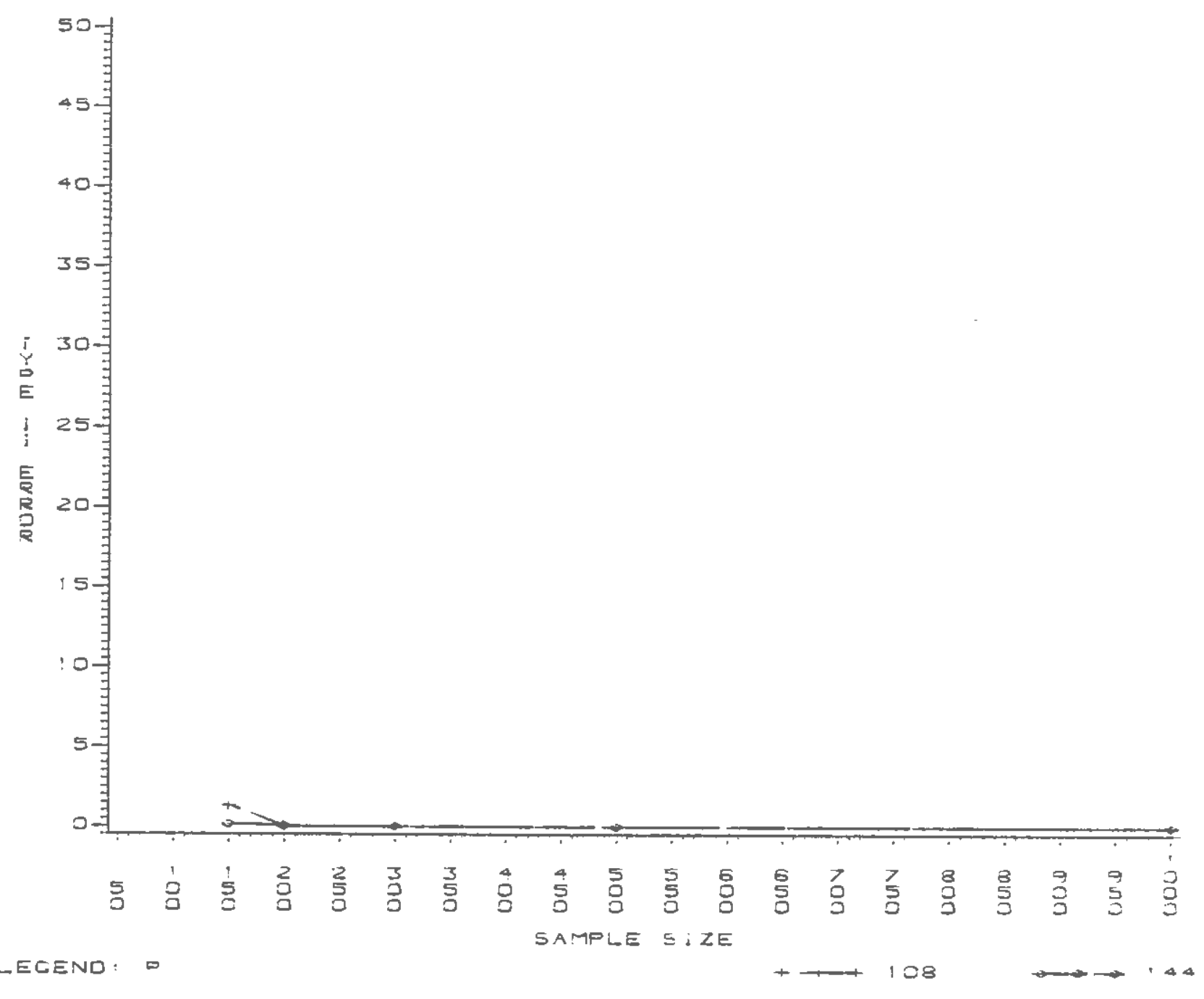


Figure E-9 Average Type II Error as a Function of Sample Size for .80 Component Saturation and 3 components

Figure E-10 Average Type II Error as a Function of Sample Size for 80 Component Saturation and 6 components

Fiqure E-tt Average Type II Error as a Function of Sample Size for .80 component Saturation and 9 components

Figure E-12 Average Type II Error as a Function of Sample size for .80 Component Saturation and 18 components 


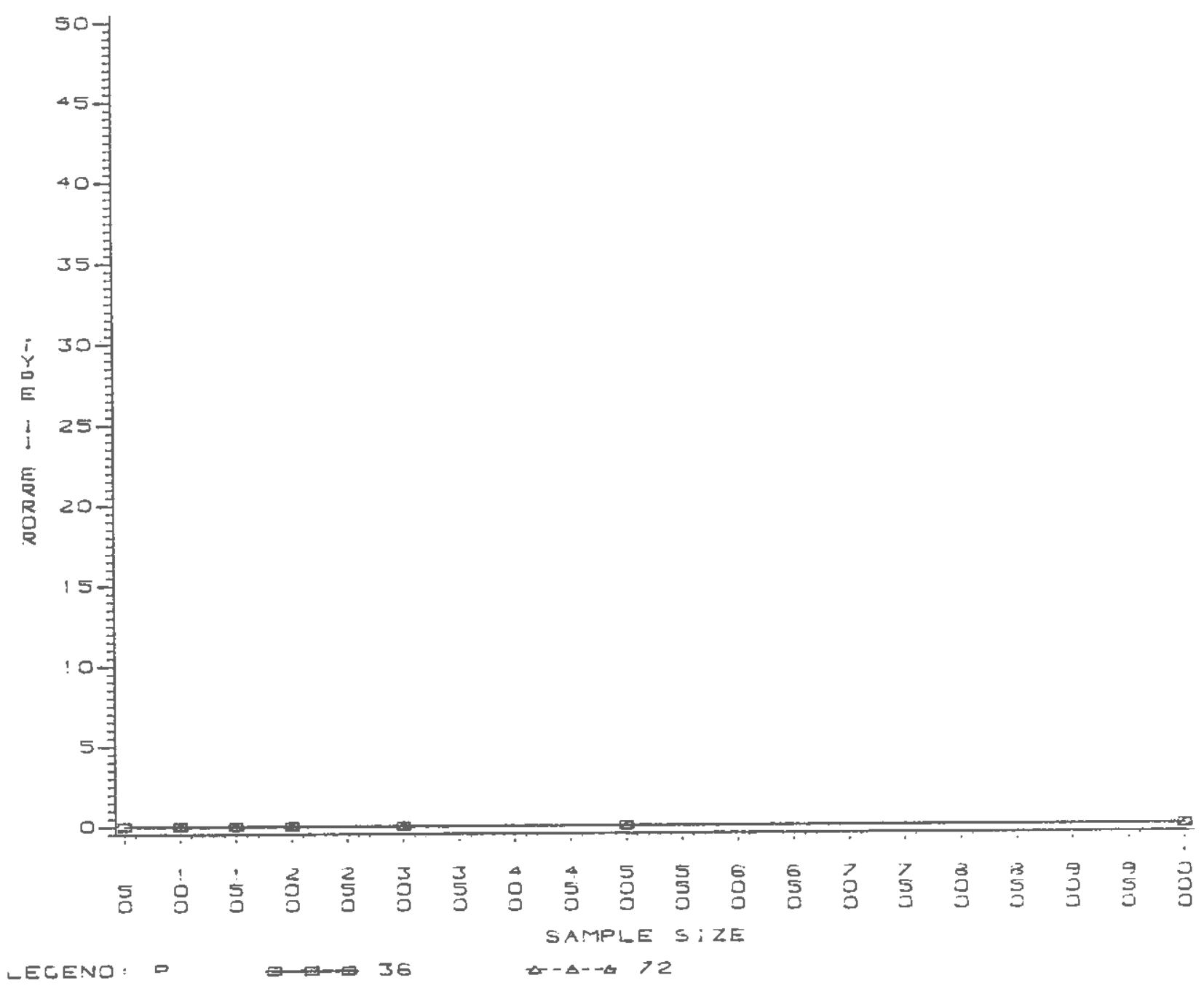




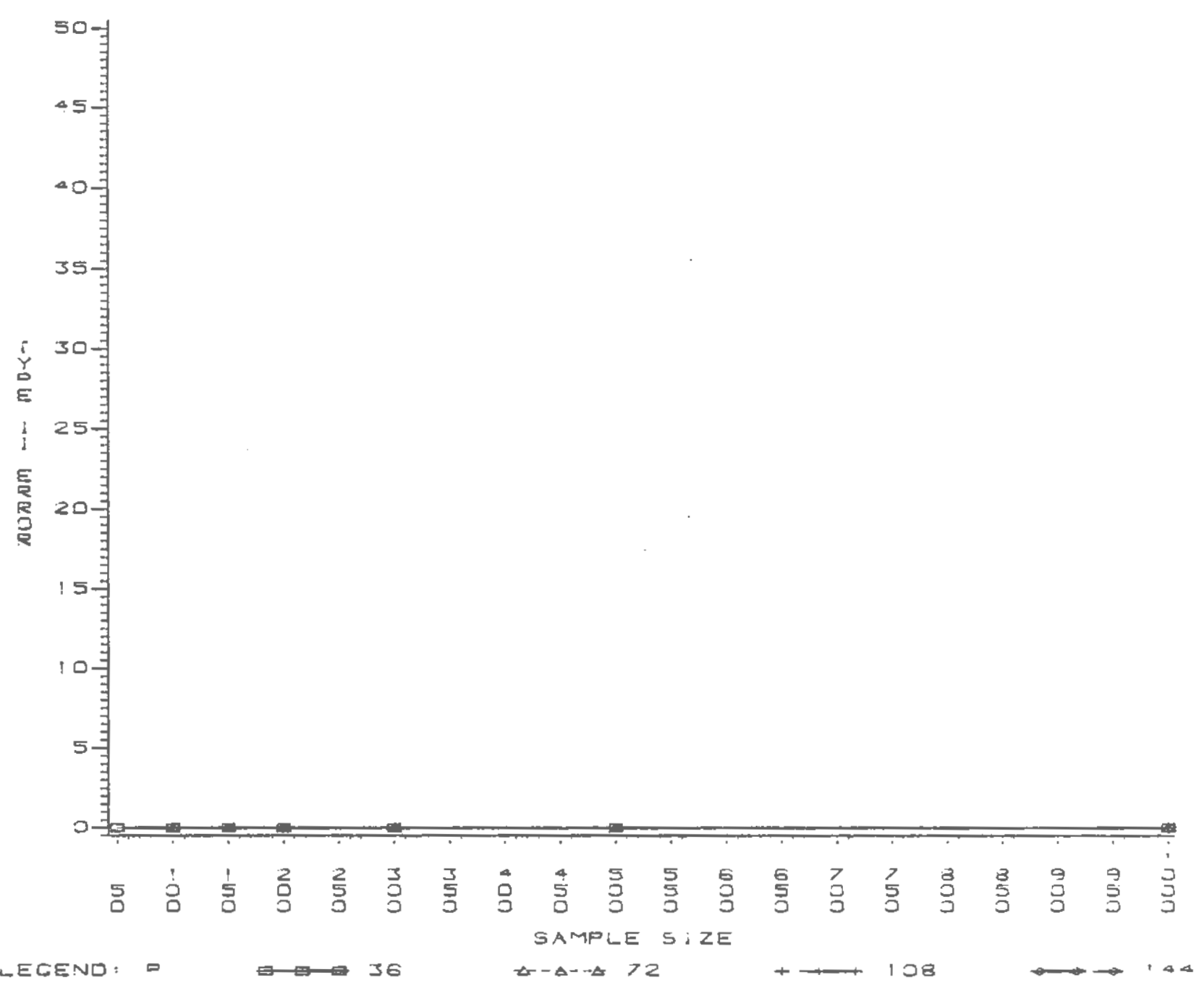




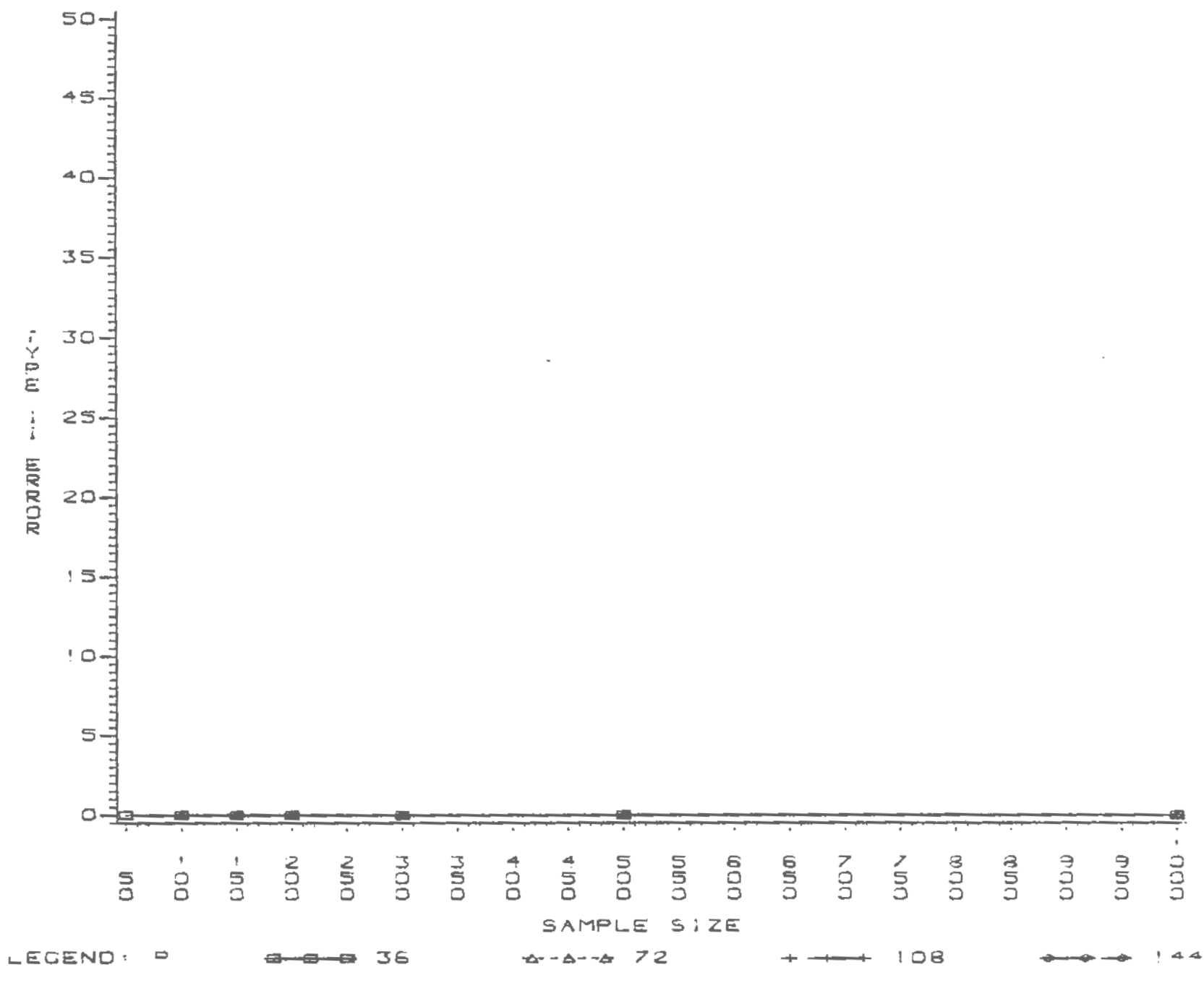




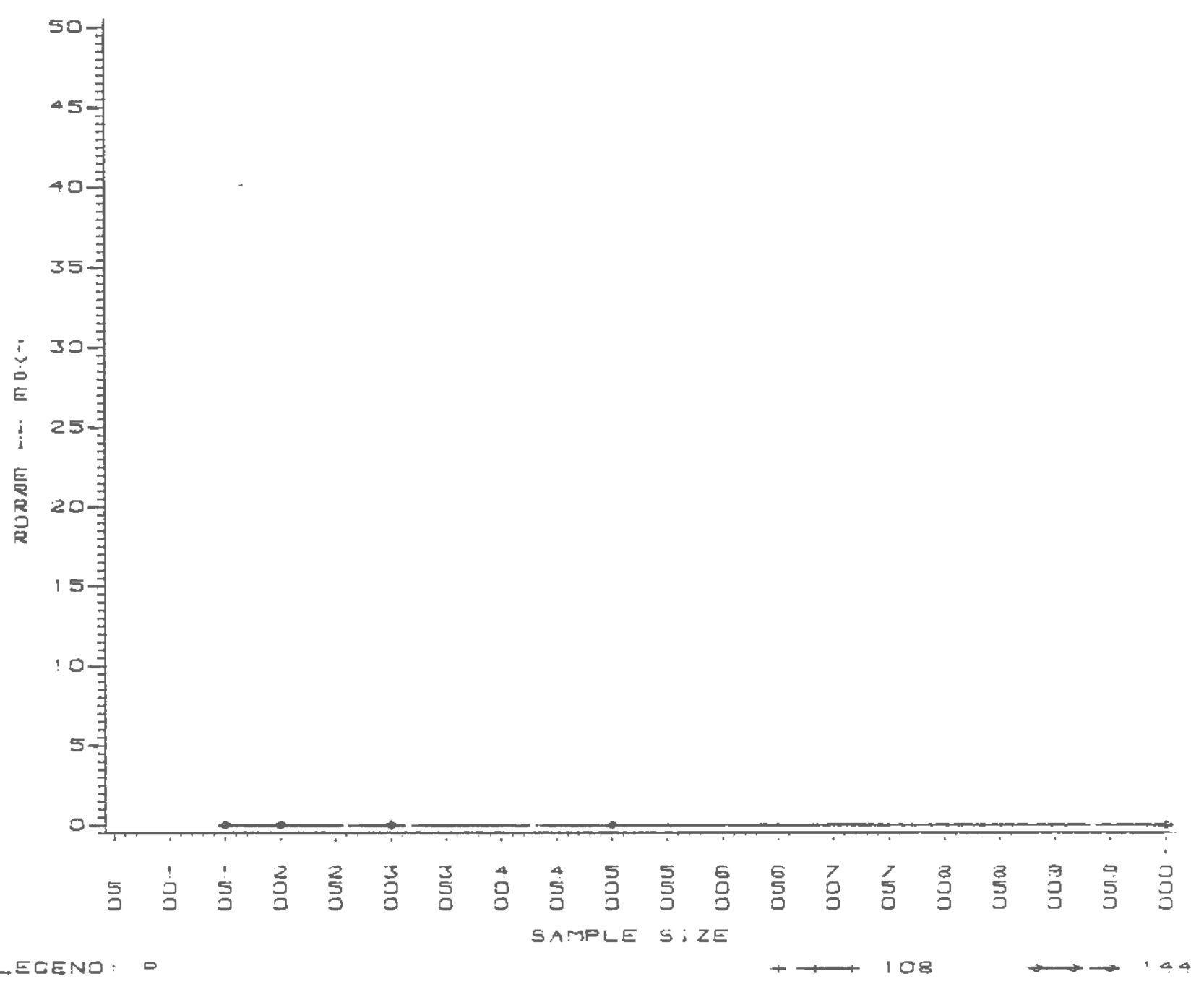

